\title{
PROJETO E DIMENSIONAMENTO DE REDES ÓPTICAS PASSIVAS (PONs)
}

\section{Paulo Takeuti}

Dissertação apresentada à Escola de Engenharia de São Carlos da Universidade de São Paulo, como parte dos requisitos para a obtenção do Título de Mestre em Engenharia Elétrica.

ORIENTADOR: Prof. Dr. Murilo Araujo Romero 
À minha esposa, Elisa, e aos meus filhos queridos, Fabiana, Tatiane, Reinaldo e Paula, porque sempre acreditaram nesta vitória. 


\section{AGRADECIMENTOS}

Ao meu orientador, Prof. Dr. Murilo Araujo Romero, pelos ensinamentos, incentivos, compreensão, e pelo voto de confiança.

Ao Prof. Dr. Amílcar Careli César, minha sincera gratidão, pela oportunidade de voltar à universidade.

Aos colegas da Telefonica e em especial, ao mestre Viltoner José Ávila, pelas sugestões e referências, pelos incentivos manifestados, o material cedido e o apoio constante.

Aos colegas da Telemar, Tyco, Furukawa e NEC, que tanto contribuíram para o aprimoramento deste trabalho.

Ao doutor Stilante Koch Manfrin, pelos valiosos e-mails de comentário e apoio regularmente enviados.

Aos colegas de mestrado pela amizade e agradáveis momentos em que vivemos, nos convívios sociais e na busca de novos conhecimentos.

À Universidade de São Paulo. 
"O meio é a mensagem porque é o meio que modela e controla a escala e forma das associações e trabalho humanos"

Herbert Marshall McLuhan 


\section{RESUMO}

Redes Ópticas Passivas são redes de acesso que utilizam fibras ópticas interligadas na topologia estrela e na configuração ponto-multiponto, sendo constituídas apenas por componentes ópticos passivos entre o Terminal de Linha Óptica (Optical Line Terminal - OLT) e a Unidade de Rede Óptica (Optical Network Unit - ONU). Como estratégia de evolução tecnológica, podem ser utilizadas para aproveitar a base instalada de cabos de cobre e cabos coaxiais na rede de acesso, servindo como cabo alimentador para uso das tecnologias Digital Subscriber Line (DSL), Cable Modem e Local Multipoint Distribution System (LMDS), e, no futuro, para disponibilizar a fibra óptica até às instalações do usuário. O principal mérito da arquitetura das Redes Ópticas Passivas está na redução dos custos de implantação e de manutenção, pela ampliação da largura de banda disponível sem a necessidade de aumento no número de componentes ópticos ativos na rede, como lasers e amplificadores ópticos. Neste contexto, este trabalho define as Redes Ópticas Passivas, apresenta o histórico de seu desenvolvimento, seu princípio de funcionamento e suas aplicações como forma de acesso a serviços de banda larga, identifica fornecedores visando à implementação de um teste de campo e discute as perspectivas para o futuro dessa tecnologia.

Palavras-chave: rede óptica passiva; acesso; terminal de rede óptica; unidade de rede óptica; PON. 


\begin{abstract}
Passive Optical Networks (PONs) are access networks which use interconnected optical fibers configured in a point to multipoint star topology having only passive optical components between the Optical Line Terminal (OLT) and the Optical Network Unit (ONU). As a strategy for technological evolution they can be used to take advantage of copper and coax base cables installed in the access network, serving as a feeder cable for the use of DSL, Cable Modem and LMDS technologies, in order to allow optical fibers to reach customers' facilities. The main merit of the Passive Optical Networks architecture consists on the cost reduction involved on its implantation and maintenance, offering bandwidth enlargement without increasing the number of active optical components, such as lasers and optical amplifiers, in the network. In this context, this text defines PONs, presents its development history, operation principle and their applications as a way to provide broadband access services, identifies suppliers for field test implementation and discusses the perspectives for the future.
\end{abstract}

Keywords: passive optical network; Access; optical line terminal; optical network unit; PON. 


\section{LISTA DE FIGURAS}

Figura 1 - Visão genérica de um sistema de comunicações ópticas $\quad 8$

Figura 2 - Aplicações típicas com respectivas taxas de transmissão 9

Figura 3 - Exemplo de uma arquitetura da planta externa 12

Figura 4 - Classificação das redes de acesso ópticas $\quad 14$

Figura 5 - Representação esquemática de uma rede óptica passiva 15

Figura 6 - Evolução de uma arquitetura básica PON no ambiente FTTx 17

$\begin{array}{ll}\text { Figura } 7 \text { - Distribuição geográfica das operadoras da estrutura FSAN } & 19\end{array}$

Figura 8 - Elementos básicos do quadro APON 23

Figura 9 - Fases de operação das células na APON 25

Figura 10 - Serviços atendidos pela GPON 27

Figura 11 - Formato do quadro downstream na tecnologia GPON 28

Figura 12 - Formato do quadro upstream na tecnologia GPON 28

Figura 13 - Exemplo de formato de quadro EPON 30

Figura 14 - Processo de ranging caracterizando troca de mensagens 31

Figura 15 - Tráfego downstream na tecnologia EPON 32

Figura 16 - Configuração de PON com uso da técnica WDM e um único tipo de ONU 33

Figura 17 - Tráfego upstream na tecnologia EPON 34

Figura 18 - Esquemático comparativo entre o quadro Ethernet e o padrão 802.1Q 35

Figura 19 - Situação comparativa dos sinais ópticos recebidos pelo OLT 36

Figura 20 - Sinais ópticos recebidos pelo OLT operando no modo rajada 37

Figura 21 - Modelo típico de criptografia 38

Figura 22 - Mercado da tecnologia Ethernet em função do número de portas 43

Figura 23 - Análise comparativa de custos das tecnologias, por conexão e por Mbps $\quad 44$

Figura 24 - Representação esquemática do projeto EPON I 50

Figura 25 - Cabo Fis-optic-DG

Figura 26 - Detalhes do conector SC em um cordão óptico 53

Figura 27 - Divisor óptico passivo 1:N 54

Figura 28 - Detalhes da caixa de emenda óptica primária 55

Figura 29 - Vista frontal da terminação óptica de assinante 55

Figura 30 - Vista frontal do equipamento edgeGear 2000 da Alloptic 59

Figura 31 - Vista traseira do equipamento mduGear da Alloptic 59 


\section{LISTA DE TABELAS}

Tabela 1 - Taxas de transmissão em função do par metálico e distância até o usuário

Tabela 2 - Taxas de transmissão em função da taxa de utilização de pares e distância 11

Tabela 3 - Identificação das operadoras que constituem o consórcio FSAN

Tabela 4 - Resumo das recomendações G.983

Tabela 5 - Comparativo das tecnologias APON, GPON e EPON 42

Tabela 6 - Características admissíveis para componentes passivos da rede EPON

Tabela 7 - Cálculo da margem de desempenho do sistema 48

Tabela 8 - Pontos de terminação de rede do projeto EPON I 50

Tabela 9 - Custos dos produtos da rede EPON I 57

Tabela 10 - Custos de mão-de-obra para rede EPON I 58

Tabela 11 - Comparativo dos custos da rede 58

Tabela 12 - Custos por usuário na rede APON 60

Tabela 13 - Custos de equipamentos na rede GPON 61

Tabela 14 - Custos de uma rede EPON 61

Tabela 15 - Comparativo de custos dos equipamentos por usuário 62

Tabela 16 - Custos totais da rede EPON na USP 


\section{LISTA DE SIGLAS}

ACTS: Advanced Communications Technologies (Tecnologias e serviços avançados de and Services comunicações)

ADSL: $\quad$ Asymmetrical Digital Subscriber Line

(Linha digital assimétrica de assinante)

ANSI: $\quad$ American National Standards Institute

(Instituto nacional americano de padronização)

APC: $\quad$ Angled Physical Contact

(Contato físico angular)

APON: $\quad$ ATM on Passive Optical Network

(Rede óptica passiva ATM)

ARD: $\quad$ Armário de Distribuição Metálico

ATM: Asynchronous Transfer Mode (Modo assíncrono de transferência)

ATM-F: $\quad$ ATM Forum

(Fórum ATM)

BER: $\quad$ Bit Error Rate

(Taxa de erro de bit)

BIBL: Biblioteca

BPON: Broadband PON (PON banda larga)

BT: $\quad$ British Telecommunications

CAASO: Centro Acadêmico Armando Salles Oliveira

CATV: Cable TV (TV a cabo)

CEP: $\quad$ Caixa de Emenda óptica Principal

CES: Circuit Emulation Service (Serviço de emulação de circuito)

CFI: Canonical Format Indicator (Indicador de formato canônico)

CISC: $\quad$ Centro de Informática de São Carlos

CRC: Cyclic Redundancy Check (Verificação de redundância cíclica)

CSMA/CD: Carrier Sense Multiple Access with (Acesso múltiplo com percepção de Collision Detection $\quad$ portadora e detecção de colisão)

DBA: Dynamic Bandwidth Allocation $\quad$ (Alocação dinâmica de banda)

DEEC: Departamento de Engenharia da Electrônica e das Comunicações

DFB: $\quad$ Distributed FeedBack $\quad$ (Realimentação distribuída)

DFQ: Departamento de Físico-Química

DMT: Discrete Multitone (Multitom discreto)

DQFM: Departamento de Química e Física Molecular

DSL: Digital Subscriber Line (Linha digital de assinante)

DSLAM: Digital Subscriber Line Access $\quad$ (Multiplexador de acesso DSL) Multiplexer

DT: $\quad$ Deutsche Telekom 
DWDM: Dense Wavelength Division Multiplexing (Multiplexagem densa por divisão de comprimento de onda)

EESC: $\quad$ Escola de Engenharia de São Carlos

EFM: Ethernet in the First Mile (Ethernet na primeira milha)

EPON: Ethernet-PON

ET: $\quad$ Estação Telefônica

ETSI: European Telecommunications (Instituto europeu de normas de Standardization Institute telecomunicações)

Facesp: $\quad$ Federação das Associações Comerciais do Estado de São Paulo

Fapesp: $\quad$ Fundação de Amparo à Pesquisa do Estado de São Paulo

FCM: Departamento de Física e Ciência dos Materiais

FEC: $\quad$ Frame Error Check $\quad$ (Verificação de erro de quadro)

FFI: Departamento de Física e Informática

FSAN: Full Service Access Network $\quad$ (Rede de acesso de serviço amplo)

FT: $\quad$ France Telecom

FTTB: Fiber-to-the-Building (Fibra até o edifício)

FTTC: Fiber-to-the-Curb (Fibra até a calçada)

FTTCab: Fiber-to-the-Cabinet (Fibra até o armário)

FTTH: Fiber-to-the-Home (Fibra até a residência)

GbE: $\quad$ Gigabit Ethernet

GEM: GPON Encapsulation Method $\quad$ (Método de encapsulação GPON)

GFP: Generic Framing Procedure (Procedimento genérico de enquadramento)

GPON: Gigabit PON

GTC: GPON Transmission Convergence (Convergência de transmissão GPON)

HFC: Hybrid-Fiber-Coaxial (Híbrida fibra-coaxial)

ICMC: Instituto de Ciências Matemáticas e de Computação

IDG: International Data Group (Grupo internacional de dados)

IEEE: Institute of Electrical and Electronics (Instituto dos engenheiros eletrônicos e Engineers eletricistas)

IFSC: $\quad$ Instituto de Física de São Carlos

IP: Internet Protocol (Protocolo de Internet)

IQSC: Instituto de Química de São Carlos

ISDN: Integrated Services Digital Network (Rede digital de serviços integrados)

ITU: International Telecommunication Union (União internacional de telecomunicações) 
ITU-T: $\quad$ ITU Telecommunication Standardization Sector

KPN: $\quad$ Dutch Telecom

KT: $\quad$ Korean Telecom

LAN: $\quad$ Local Area Network

LxAxP: Largura x Altura $x$ Profundidade

LLID: $\quad$ Logical Link Identification

LMDS: $\quad$ Local Multipoint Distribution System

MAC: $\quad$ Medium Access Control

MAN: $\quad$ Metropolitan Area Network

MPCP: $\quad$ Multi-Point Control Protocol
(Seção normativa da união internacional de telecomunicações)

(Rede local)

(Identificação de ligação lógica)

(Sistema de distribuição multiponto local)

(Controle de acesso ao meio)

(Rede metropolitana)

(Protocolo de controle multiponto)

MUXFIN: Multiplexador Flexível com Interfaces Normalizadas

NGN: $\quad$ Next-Generation Network

(Rede de nova geração)

NRZ: $\quad$ Non Return to Zero

(Não retorno a zero)

NTT: $\quad$ Nippon Telegraph and Telephone

OAM: $\quad$ Operation, Administration and

(Operação, administração e manutenção) Maintenance

OAM\&P: Operation, Administration, Maintenance

(Operação, administração, manutenção e and Provisioning aprovisionamento)

O/E/O: Óptico/Elétrico/Óptico

OLT: $\quad$ Optical Line Terminal

OMCI: $\quad$ ONT Management and Control Interface

(Terminal de linha óptica)

(Interface de controle e do gerenciamento do ONT)

ONT: Optical Network Terminal (Terminal de rede óptica)

ONU: Optical Network Unit (Unidade de rede óptica)

OPAL: Optical Passive Access Line (Linha de acesso óptica passiva)

OSI: Open Systems Interconnection (Sistema aberto de interconexão)

OTDR: $\quad$ Optical Time Domain Reflectometer Reflectômetro óptico no domínio do tempo

PCASC: Prefeitura do Campus Administrativo de São Carlos

PHY: Physics (Física)

PIN: $\quad$ Positive - Intrinsic - Negative $\quad$ (Positivo - Intrínseco - Negativo)

PKI: $\quad$ Philips Kommunikations Industrie (Indústria de comunicações Philips)

PLANET: Photonic Local Access Network $\quad$ (Rede de acesso local fotônica)

PLOAM: Physical Layer Operation, Administration (Operação, administração e manutenção and Maintenance da camada física) 


\begin{tabular}{|c|c|c|}
\hline PMD: & Physical Media Dependent & (Dependente do meio físico) \\
\hline PON: & Passive Optical Network & (Rede óptica passiva) \\
\hline POTS: & Plain Old Telephone Service & (Serviço telefônico convencional) \\
\hline PPPoE: & Point to Point Protocol over Ethernet & Protocolo ponto a ponto através da \\
\hline PTSP: & Packet Transport System Protocol & $\begin{array}{l}\text { Ethernet } \\
\text { (Protocolo do sistema de transporte de } \\
\text { pacote) }\end{array}$ \\
\hline PVC: & Permanent Virtual Channel & (Canal virtual permanente) \\
\hline QAM: & Quadrature Amplitude Modulation & (Modulação de amplitude em quadratura) \\
\hline QoS: & Quality of Service & (Qualidade de serviço) \\
\hline RDSI: & Rede Digital de Serviços Integrados & \\
\hline RFC: & Request For Comments & (Requisição para comentários) \\
\hline SC: & Subscription Channel & (Canal de assinante) \\
\hline SDH: & Synchronous Digital Hierarchy & (Hierarquia digital síncrona) \\
\hline Sebrae: & \multicolumn{2}{|c|}{ Serviço Brasileiro de Apoio às Micro e Pequenas Empresas } \\
\hline SEL: & \multicolumn{2}{|l|}{ Departamento de Engenharia Elétrica } \\
\hline SEM: & \multicolumn{2}{|l|}{ Departamento de Engenharia Mecânica } \\
\hline SLA: & Service-Level Agreement & (Acordo de nível de serviço) \\
\hline SNMP: & Simple Network Management Protocol & $\begin{array}{l}\text { (Protocolo de gerenciamento de rede } \\
\text { simples) }\end{array}$ \\
\hline SOHO: & Small Office/Home Office & (Pequena empresa/empresa em casa) \\
\hline SONET: & Synchronous Optical Network & (Rede óptica síncrona) \\
\hline SPL: & Splitter & (divisor óptico passivo) \\
\hline STB: & Set-Top-Box & (Unidade receptora externa) \\
\hline STM: & Synchronous Transfer Mode & (Modo de transferência síncrono) \\
\hline TC: & Transmission Convergence & (Convergência de transmissão) \\
\hline TCI: & Tag Control Information & (Informação de controle de etiqueta) \\
\hline TCP: & Transmission Control Protocol & (Protocolo de controle de transmissão) \\
\hline TDM: & Time Division Multiplexing & (Multiplexagem por divisão no tempo) \\
\hline TDMA: & Time Division Multiple Access & $\begin{array}{l}\text { (Acesso multiplexado por divisão no } \\
\text { tempo) }\end{array}$ \\
\hline
\end{tabular}

TIDIA: Tecnologia da Informação no Desenvolvimento da Internet Avançada

TOA: Terminal Óptico de Assinante

TPI: $\quad$ Tag Protocol Identifier (Identificador de protocolo de etiqueta)

TPON: Telephony over PON (Telefonia PON)

USP: $\quad$ Universidade de São Paulo 


$\begin{array}{lll}\text { UTP: } & \text { Unshielded Twisted Pair } & \text { (Par trançado sem blindagem) } \\ \text { VC: } & \text { Virtual Channel } & \text { (Canal virtual) } \\ \text { VCI: } & \text { Virtual Channel Identifier } & \text { (Identificador de canal virtual) } \\ \text { VDSL: } & \text { Very high rate DSL } & \text { (DSL de taxa muito alta) } \\ \text { VID: } & \text { VLAN Identifier } & \text { (Identificador de VLAN) } \\ \text { VLAN: } & \text { Virtual Local Area Network } & \text { (LAN virtual) } \\ \text { VoD: } & \text { Video-on-Demand } & \text { (Vídeo sob demanda) } \\ \text { VoIP: } & \text { Voice over IP } & \text { (Voz sobre IP) } \\ \text { VP: } & \text { Virtual Path } & \text { (Caminho virtual) } \\ \text { VPI: } & \text { Virtual Path Identifier } & \text { (Identificador de caminho virtual) } \\ \text { VPN: } & \text { Virtual Private Network } & \text { Rede privada virtual } \\ \text { WAN: } & \text { Wide Area Network } & \text { (Rede de longa distância) } \\ \text { WDM: } & \text { Wavelength Division Multiplexing } & \text { (Multiplexagem por divisão de } \\ & & \text { comprimento de onda) }\end{array}$




\section{SUMÁRIO}

RESUMO

iv

ABSTRACT

LISTA DE FIGURAS

$\mathrm{v}$

LISTA DE TABELAS

vi

LISTA DE SIGLAS

vii

1 INTRODUÇÃO 2

1.1 Histórico 2

1.2 Motivação e objetivos deste trabalho $\quad 4$

$\begin{array}{lll}1.3 & \text { Estrutura do trabalho } & 6\end{array}$

2 REDE DE ACESSO DE BANDA LARGA 7

$\begin{array}{lll}2.1 & \text { Arquitetura geral da rede óptica } & 7\end{array}$

2.2 Rede de acesso 9

$\begin{array}{lll}2.3 & \text { Rede óptica passiva } & 15\end{array}$

$\begin{array}{lll}2.4 & \text { Atuação do comitê FSAN } & 18\end{array}$

$2.5 \quad$ Conceito da ATM-PON 22

2.6 Conceito de Gigabit-PON 26

$2.7 \quad$ Atividades do grupo Ethernet in the first mile 29

$2.8 \quad$ Conceito de Ethernet-PON 29

2.9 Avaliação das tecnologias APON, GPON e EPON 39

3 PROJETO E DIMENSIONAMENTO DA REDE 45

3.1 Considerações iniciais 45

3.2 Cálculo da largura de banda $\quad 45$

3.3 Cálculo de balanço de potência 46

3.4 Representações esquemáticas $\quad 49$

3.5 Dimensionamento e custos do projeto $\quad 52$

$\begin{array}{lll}3.6 & \text { Requisitos gerais da rede } & 52\end{array}$

3.7 Quantificação e estimativa de custos para a rede 56

$\begin{array}{lll}3.8 & \text { Requisitos gerais dos equipamentos } & 59\end{array}$

$\begin{array}{lll}3.9 & \text { Estimativa de custo para os equipamentos } & 60\end{array}$

$3.10 \quad$ Custo total do projeto $\quad 62$

4 CONSIDERAÇÕES FINAIS $\quad 63$

5 REFERÊNCIAS BIBLIOGRÁFICAS 64

ANEXO - Resumo e palavras-chave - IEEE Std 802.3ah.-2004 70 


\section{INTRODUÇÃO}

\subsection{Histórico}

O desenvolvimento das Passive Optical Networks (PONs) inicia-se na Inglaterra através do trabalho pioneiro de Keith Oakley e Chris Todd em 1986 nos laboratórios da British Telecom (BT), destinando-se apenas à transmissão residencial de banda estreita, com a Telephony over PON (TPON), e banda larga para empresas, através da Broadband PON (BPON) [1]-[2].

Diversas experiências de campo foram realizadas como, por exemplo, o teste nas ilhas Bermudas em 1994, que forneceu Plain Old Telephone Service (POTS) e Video-on-Demand (VoD) para 87 assinantes residenciais e 13 assinantes comerciais, distribuídos em 59 prédios, nas localidades de Collector Hill/South Road e Melville Estate. Quatro PONs conectando 61 Optical Networks Units (ONUs) foram instaladas através da estação telefônica de Hamilton, obedecendo às arquiteturas Fiber-to-the-Home (FTTH) e Fiber-to-the-Building (FTTB). Devido ao oferecimento de serviços POTS, tráfego e gerenciamento, a BT caracterizou a experiência como narrowband PON [3].

Como exemplo de uma broadband PON, foi realizado nas cidades de Colchester e Ipswich, no Reino Unido, com início em meados de 1995 e término em junho de 1996, um teste com BPON (500 ONUs) como parte de uma ampla investigação da tecnologia Asymmetrical Digital Subscriber Line (ADSL) para 2.500 residências, oferecendo VoD e serviços multimídia: home shopping e home banking, programas de televisão sob demanda, educação, filmes sob demanda, jogos com novidades que eram atualizadas no Set-Top-Box (STB), clipes musicais, etc. Os sinais de vídeo e de áudio eram codificados e comprimidos, e os clientes escolhiam a programação, através da navegação nos menus da tela de TV, utilizando um controle remoto. Essa configuração de rede estava interconectada em um anel Synchronous Digital Hierarchy (SDH) de 2,4 Gb/s [3].

Paralelamente na Europa continental, outros testes para o desenvolvimento da PON foram realizados, destacando-se [1]:

a) Deutsche Telekom (DT) - Projeto Optical Passive Access Line (OPAL) na Alemanha, atendendo diversos clientes residenciais e empresariais no sistema PON. Dos 7 projetos OPAL, a Deutsche Telekom escolheu os projetos OPAL numerados e identificados como OPAL 4, OPAL 5 e OPAL 6, todos com topologia de PON, para uma análise completa das arquiteturas criadas por 6 fornecedores dentro do conceito de uso econômico de tecnologia de fibra óptica ao nível de usuário, visando avaliar as configurações FTTH e Fiber-to-the-Curb (FTTC). Todos esses 3 projetos OPAL tiveram um número de clientes inferior a 200 usuários: 
- OPAL 4: realizado em Leipzig, com início operacional em novembro de 1991, sendo a central telefônica o modelo S12 da Alcatel e o fornecedor do sistema a Siemens;

- OPAL 5: realizado em Stuttgart com início operacional em abril de 1992, sendo a central também a S12 da Alcatel e o fornecedor do sistema a própria Alcatel;

- OPAL 6: realizado em Nuremberg com início operacional em setembro de 1991, sendo a central do tipo eletromecânico e o sistema constituído por um pool de empresas: AEG Kabel, AG, ANT Nachrichtentechnik GmbH e Philips Kommunikations Industrie (PKI) $A G$.

b) Alcatel, ATM-PON em Antuérpia no início de 1990;

c) Dutch Telecom (KPN) - Holanda - pequeno teste comercial em meados de 1990;

d) SuperPON [3]: Foi iniciado em 1998, pela fundação européia Advanced Communication Technologies and Services (ACTS), dentro do projeto denominado AC050 PLANET, cuja sigla PLANET significa Photonic Local Access Network, na região de Bruxelas, um enfoque de tecnologia PON maximizando o compartilhamento em enlace de longo alcance 2.000 usuários em uma distância de $100 \mathrm{~km}$. Adotando o princípio de que a arquitetura PON requer o uso exclusivo de componentes passivos na planta externa e utilizando equipamentos optoeletrônicos ativos somente nas unidades OLT e ONU, amplificadores ópticos implantados nessas unidades propiciaram a necessária regeneração dos sinais.

A história do sistema PON inicia-se no Japão em 1996 pela Nippon Telegraph and Telephone (NTT) com um teste de campo de um sistema proprietário BPON. Esse sistema ofereceu Cable TV (CATV), VoD e serviços de Rede Digital de Serviços Integrados (RDSI) para usuários residenciais, e caminhos virtuais para usuários corporativos e do tipo Small Office/Home Office (SOHO). A tecnologia proprietária BPON foi combinada com o sistema ATM da NTT, o que viabilizou o primeiro desenvolvimento do sistema BPON em nível comercial, iniciado em abril de 1997. A NTT desenvolveu então, a partir de 1997, uma sucessão de sistemas BPON de acordo com a recomendação G.983. Após uma fase de testes de laboratório, foi introduzido em junho de 1999 um sistema compatível com a recomendação G.983 da International Telecommunication Union (ITU): uma BPON 155,52 Mb/s simétricos, suportando ATM em 155,52 Mb/s monomodo e multimodo óptico, 44,736 Mb/s coaxial e 25 $\mathrm{Mb} / \mathrm{s}$ Unshielded Twisted Pair (UTP). Os sistemas PON foram instalados nas regiões de Tachikawa, Yokosuka e Urayasu, e aprovados pela NTT, como uma arquitetura de melhor custo-benefício para prover os usuários empresariais de serviços ATM. Como a demanda de serviços continua aumentando a cada ano, vários sistemas PON coexistem através de cerca de 3000 centrais equipadas com OLTs [4].

$\mathrm{Na}$ América do Norte foram realizados vários testes de laboratório e de campo pelas empresas BellSouth, SBC, Verizon e Qwest na década de 90. Como exemplo destes testes, a BellSouth implantou o primeiro sistema FTTH BPON compatível com a recomendação G.983.1 
em outubro de 1999. O serviço ofereceu dados e vídeo em faixa larga cobrindo uma área de aproximadamente 400 residências, em sua maioria atendidas por rede aérea. A implantação foi à parte da planta existente de cobre, que continuou oferecendo serviços de telefonia. Foram implementados dois tipos de PON: uma BPON, com um cartão de interface cliente 10/100BaseT Ethernet para serviços de dados em faixa larga, em uma arquitetura de divisão em cascata, sendo um divisor óptico passivo 1:8 localizado em um terminal remoto e um outro divisor óptico passivo 1:4 instalado em um ambiente protegido das intempéries climáticas e posicionado sobre um pedestal construído na calçada ou em uma câmara subterrânea, ou ainda fixado no poste de telefonia, que proveu a rede de um compartilhamento total de 32 vias, e a segunda PON com um Optical Network Terminal (ONT) de vídeo analógico para fornecimento de serviços de vídeo de entretenimento. No total, este sistema disponibilizava uma largura de banda de 155,52 Mb/s simétrica compartilhada a uma quantidade máxima de 32 usuários. A interface 10/100BaseT Ethernet era alimentada por um Permanent Virtual Channel (PVC) ATM o qual estava preparado para dispor $1,5 \mathrm{Mb} / \mathrm{s}$ no sentido downstream (da rede para os usuários) e $256 \mathrm{~kb} / \mathrm{s}$ no sentido upstream (dos usuários para a rede) [5].

Dentre as especificações, as recomendações PON baseadas em tecnologia ATM são desenvolvidas pelo comitê Full Service Access Network (FSAN) e aprovadas pela ITU. As padronizações de redes de acesso baseadas em tecnologia Ethernet são realizadas pelo grupo Ethernet in the First Mile (EFM) e aprovadas pelo Institute of Electrical and Electronics Engineers (IEEE).

Reconhecidos fóruns de tecnologias PON constituídos por pesquisadores e profissionais disponibilizam informações on-line. O PON fórum apresenta em seu site, artigos e estudos de caso, focados em negócios e mercado da indústria PON. O EPON fórum propicia discussões e troca de informações dentro da comunidade IEEE.

\subsection{Motivação e Objetivos deste Trabalho}

As tecnologias de comunicação tem sido uma das mais importantes e de maior crescimento nas últimas décadas, propiciando um aumento do número mundial de usuários de banda larga de 72\% em 2002, se comparado ao ano de 2001 [6]. Mundialmente, 62 milhões de pessoas utilizaram os serviços de faixa larga, segundo a ITU. De acordo com a ITU, usuários residenciais são os principais responsáveis pelo crescimento dos serviços de banda larga, se destacando, como fatores preponderantes que impulsionam a adesão a uma maior largura de banda, a queda de preço na oferta dos serviços e a troca e compartilhamento de arquivos. Finalmente, a ITU apurou que, no final de 2002, aproximadamente 84 países em todo o mundo ofereciam serviços de acesso de faixa larga [6]. 
No Brasil esse crescimento tem se intensificado devido à privatização do setor de telecomunicações ocorrida no ano de 1998, e apresentou, no ano de 2002, segundo dados do International Data Group (IDG) (2003 apud SANTOS, 2003), 694.000 usuários de acesso de banda larga [7].

O uso de computadores cresceu $12 \%$ nas micro, pequenas e médias empresas da cidade de São Paulo, passando de $42 \%$ para $47 \%$, segundo estudo do Serviço Brasileiro de Apoio às Micro e Pequenas Empresas -SP (Sebrae-SP) (2003 apud DINIZ, 2003) divulgado durante a feira de tecnologia Comdex realizada no mês de agosto de 2003, destacando que o percentual de empresários que acessam a Internet chega a 54\%, superando os $47 \%$ de empresas informatizadas. Como estímulo ao uso da tecnologia a serviço das micro, pequenas e médias empresas e ferramenta facilitadora dos processos de gestão, a Câmara Brasileira de Comércio Eletrônico (Camara-e.net) vem promovendo no país eventos focados na inclusão digital desse público. Outras iniciativas vem surgindo na esteira da utilização da Internet, como a parceria entre o provedor iG e a Federação das Associações Comerciais do Estado de São Paulo (Facesp) com o lançamento de um portal com facilidades para as pequenas empresas, o IJ, com acesso pelo site $<$ http://www.ij.com.br>. Outro exemplo é um projeto da Secretaria de Ciência e Tecnologia do estado de São Paulo que está delineando os Ceps - ambientes virtuais de fomento à capacitação e à produção - para apoio a pólos de empreendimentos [8]. No campo acadêmico, destaca-se o programa Tecnologia da Informação no Desenvolvimento da Internet Avançada (TIDIA), lançado pela Fundação de Amparo à Pesquisa do Estado de São Paulo (Fapesp) em 2001, com o objetivo de transformar a Internet em objeto de pesquisa, através dos projetos KyaTera, projeto cooperativo visando o estabelecimento de uma rede de fibra óptica interligando laboratórios de pesquisa para o estudo, desenvolvimento e demonstração de tecnologias e aplicações da Internet Avançada; E-learning, projeto de pesquisa visando o desenvolvimento de ferramentas de suporte e apoio ao ensino e aprendizagem com interações presenciais e à distância, síncronas e assíncronas; e Incubadora Virtual, para projetos cooperativos de desenvolvimento de conteúdos digitais.

Por outro lado, a implementação de novos serviços a usuários residenciais e a pequenas e médias empresas em geral impõe a uma operadora de telecomunicações a exploração máxima da infra-estrutura de cabos de pares metálicos na rede de acesso, em oposição aos altos custos de implantação de novas redes totalmente ópticas. Isso porque as redes telefônicas, atualmente instaladas, representam um imenso capital investido.

Nessa perspectiva, é importante destacar a estratégia utilizada pelas empresas de telecomunicações, adotando um programa de retenção com seus clientes, propiciando acesso banda larga com taxas de transmissão da ordem de alguns megabits por segundo a uma parte de seus usuários, através da tecnologia ADSL numa rede legada de pares metálicos. Todavia, dados obtidos de relatório técnico da empresa Telecomunicações de São Paulo - Telesp, datado de 
1999, indicam que essa rede, não construída para esse fim, freqüentemente requer bobinas de pupinização ${ }^{1}$ e derivações de linhas ao longo dos cabos telefônicos, elementos esses que tendem a diminuir a capacidade de transmissão do canal [9].

Além dos meios de transmissão já mencionados, existem outros meios de transmissão, embora menos utilizados em redes de acesso, como a rede sem fio baseada em sistema rádio, que é uma alternativa técnica empregada em regiões onde é difícil, ou mesmo impossível, instalar cabos metálicos ou de fibra óptica.

Como alternativa, o objetivo deste trabalho é analisar a rede óptica passiva para discussão dos seus conceitos básicos e dos seus principais componentes, a estrutura e os mecanismos de operação destes componentes, bem como os principais tipos de PON. A partir da apresentação da rede óptica passiva, é desenvolvido o projeto e o dimensionamento de uma rede PON no câmpus desta Universidade, prevendo pontos de conectividade dentro das várias áreas acadêmicas, para teste de novos serviços, servindo de estrutura às tecnologias de comunicação, e no futuro, disponibilizando um centro de capacitação e qualificação tecnológica.

\subsection{Estrutura do Trabalho}

Esta dissertação está estruturada em quatro capítulos, sendo o primeiro a introdução e o último composto pelas considerações finais e perspectivas futuras do trabalho. No primeiro capítulo encontram-se a motivação e objetivos do trabalho, origem do estudo das redes ópticas passivas, acompanhados de breve histórico das iniciativas nessa área pelas operadoras de telecomunicações, bem como a estrutura de apresentação deste documento.

O Capítulo 2, "Rede de Acesso de Banda Larga", compõe a base conceitual do trabalho, abordando conceitos relativos ao estudo da PON, obtidas através da pesquisa bibliográfica. Este capítulo compreende ainda a descrição das arquiteturas ATM on Passive Optical Network (APON), Gigabit PON (GPON) e Ethernet-PON (EPON) e discute comparativamente suas principais funcionalidades.

O Capítulo 3, "Projeto e Dimensionamento da Rede", apresenta uma proposta de projeto de uma rede PON, para atendimento a 240 usuários. Baseado no estudo da rede óptica existente e na localização dos prédios no câmpus, também se define os pontos de instalação dos componentes ópticos passivos nos diversos departamentos e órgãos da universidade.

No Capítulo 4 são apresentadas as considerações finais do trabalho e as recomendações para uma eventual implantação futura da rede PON.

\footnotetext{
${ }^{1}$ Bobinas de carga intercaladas nos condutores, para melhorar a transmissão de sinais telefônicos. O termo pupinização tem origem no nome do pesquisador que patenteou o sistema, Michael I.Pupin.
} 


\section{REDE DE ACESSO DE BANDA LARGA}

\subsection{Arquitetura Geral da Rede Óptica}

As redes ópticas podem ser classificadas em três categorias principais: $\operatorname{core}^{2}$, metropolitana e acesso. Não existem limites geográficos definidos para a identificação dessas três redes, porém elas podem ser distinguidas através da escala de suas operações e da taxa de tráfego.

A rede core opera em escala nacional, continental e até mesmo mundial. Sua taxa de tráfego varia desde centenas de gigabits por segundo até alguns terabits por segundo.

A rede metropolitana opera em escala regional, analogamente às áreas metropolitanas das grandes cidades. A taxa de tráfego varia de centenas de megabits por segundo até dezenas de gigabits por segundo.

A rede de acesso proporciona ao usuário o acesso às redes ópticas mundiais através das redes metropolitanas. Essa rede opera em escala local e sua taxa varia desde dezenas e centenas de quilobits por segundo até dezenas de megabits por segundo.

Uma arquitetura geral de rede óptica pode ser vista como uma rede core circundada por redes metropolitanas que, por sua vez, são circundadas por redes de acesso, conforme se observa na Figura 1, permitindo aos clientes comunicação através da rede mundial de telecomunicações. Partindo de uma visão empresarial, a rede core tem um valor muito mais significativo em relação à rede de acesso pois, enquanto a rede core suporta centenas de milhões de clientes, a rede de acesso por sua vez suporta comparativamente um número reduzido de clientes. Considerando que cada cliente produz em média o mesmo volume de informação a ser transmitida, e, uma vez que o investimento em redes é realizado de forma proporcional ao número de clientes que essas redes suportam, muito mais dinheiro é investido no desenvolvimento de redes core e metropolitanas.

\footnotetext{
${ }^{2}$ Redes core são as redes de longa distância, ópticas e/ou via satélite.
} 


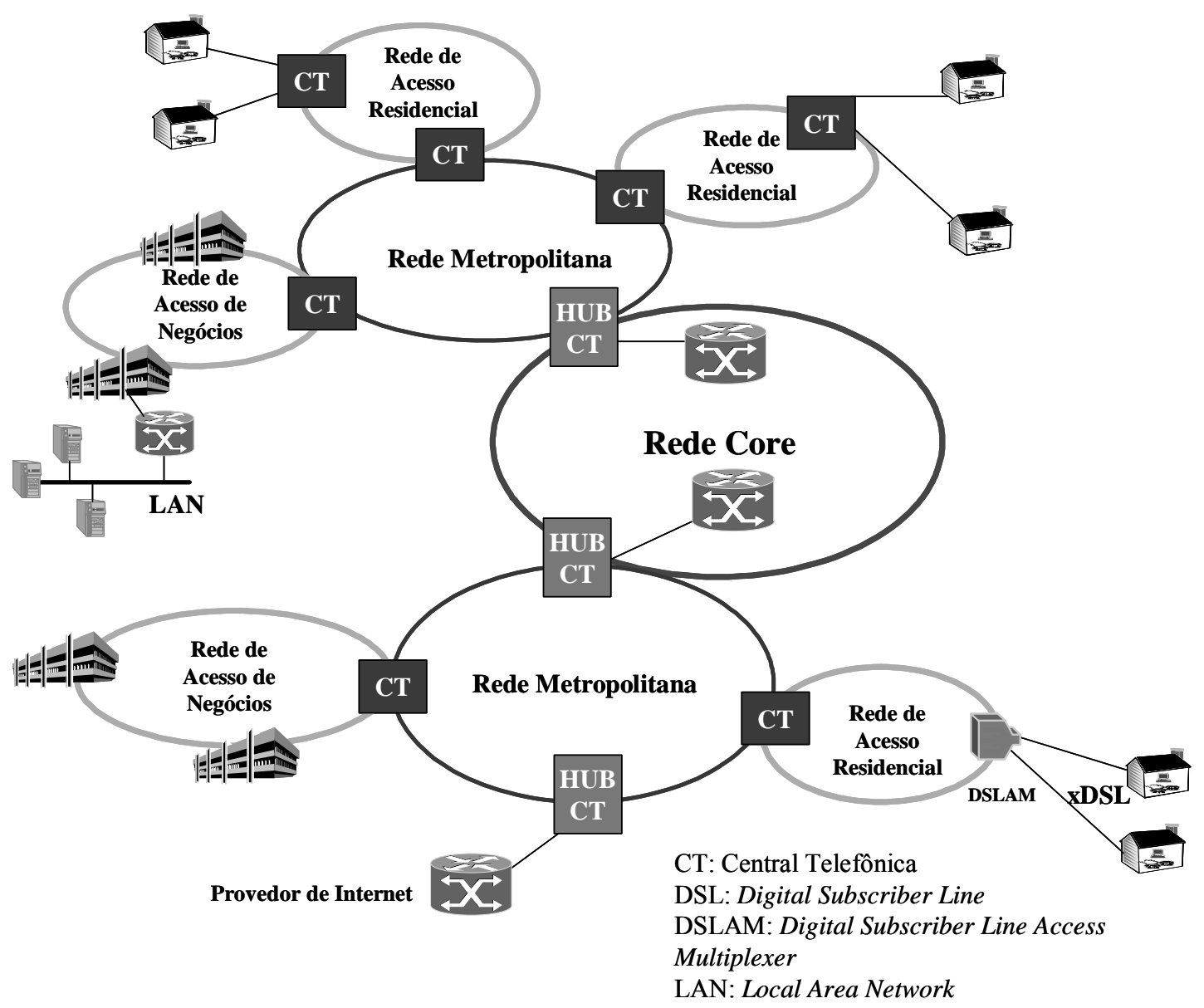

Figura 1 - Visão genérica de um sistema de comunicações ópticas

O desenvolvimento dos sistemas de comunicações ópticas nasceu da necessidade de atendimento ao crescimento exponencial do volume de tráfego. Desta forma, no final do século $\mathrm{XX}$, novas redes core foram maciçamente dispostas, e o uso da tecnologia de multiplexação por divisão de comprimento de onda (Wavelength Division Multiplexing - WDM) aumentou a capacidade dessas redes. Com relação às redes metropolitanas, anéis interconectados por sistemas SDH permitiram um aumento em sua capacidade de tráfego. O resultado que se observa é que a rede de acesso pode se tornar um ponto de estrangulamento de tráfego nas comunicações mundiais [10]. 


\section{$2.2 \quad$ Rede de Acesso}

A idéia de rede de banda larga está associada ao fornecimento simultâneo de voz, dados e vídeo, o que demanda uma alta taxa de transmissão, conforme pode ser observado em algumas aplicações destacadas na Figura 2, considerando que serviços como vídeo sob demanda e TV digital necessitam de taxas a partir de 1 megabits por segundo (Mbps).

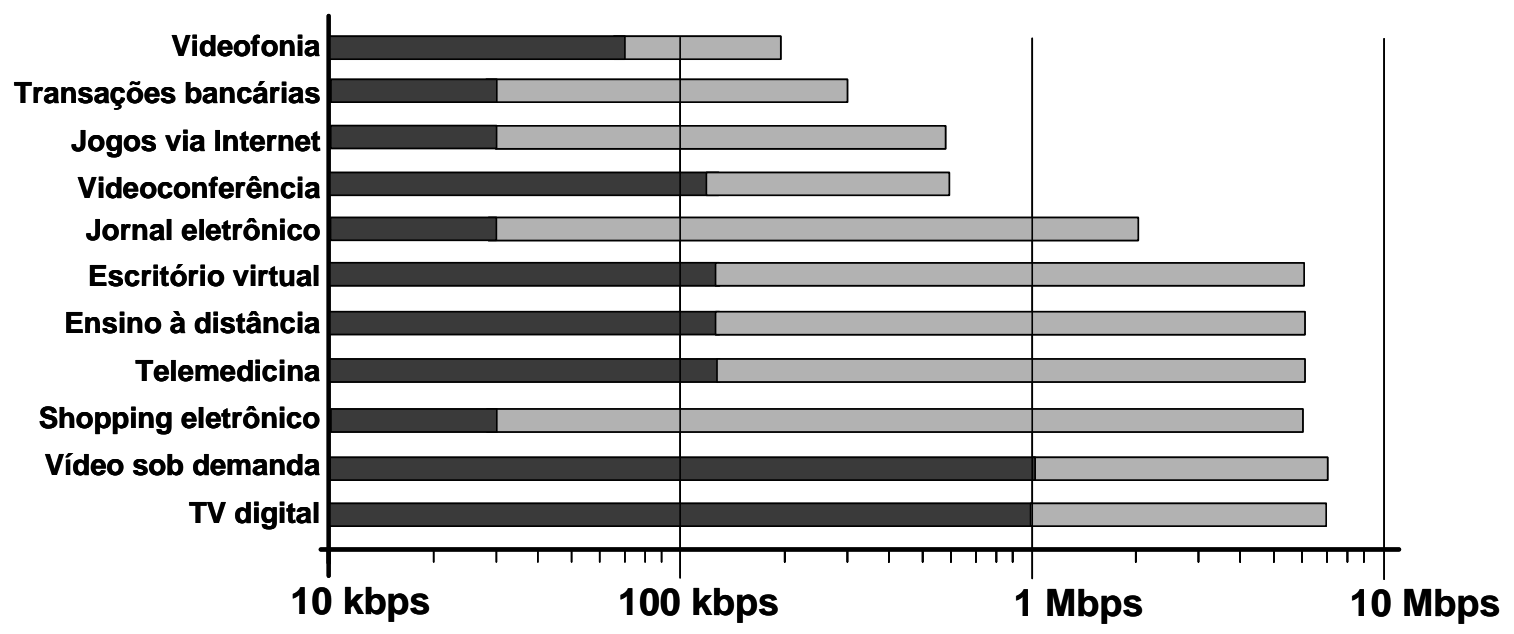

Mínima

Fonte: Plannedapproachlnc.com

<http://broadband.ic.gc.ca/binder/Rural\%20Health.pdf> kbps: quilobits por segundo

Figura 2 - Aplicações típicas com respectivas taxas de transmissão

A necessidade de altas taxas de transmissão é justificada também pelo rápido desenvolvimento das Local Area Networks (LANs), aumentando a pressão sobre a rede de acesso.

O cenário atual se configura da seguinte forma: pequenos e médios empresários necessitando de mais banda para suas atividades, famílias procurando para suas residências um acesso à Internet com maior largura de banda, e as tecnologias como DSL e cable modem se constituindo como uma resposta imediata das empresas operadoras de telecomunicações e de TV a cabo frente às crescentes necessidades de banda dos clientes.

Partindo-se da visão de uma empresa operadora de telecomunicações, há duas classes de clientes: uma categoria é a grande empresa que pode construir uma rede dedicada própria ou utilizar, por exemplo, um anel SDH dessa operadora; a outra categoria se constitui do pequeno e 
médio empresário e dos clientes residenciais que utilizam somente as facilidades padrão da operadora.

Como as linhas telefônicas conectam praticamente todas as residências e áreas empresariais com uma central telefônica, as companhias telefônicas oferecem acesso banda larga sobre essas linhas usando tecnologias tais como RDSI e DSL. Todavia, a tecnologia RDSI permite taxa de transmissão de, no máximo, 128 quilobits por segundo (kbps), o que não se configura como banda larga, e o atraso da sua implantação no Brasil motivou clientes empresariais e residenciais a adotarem de forma mais efetiva o seu concorrente DSL.

Dentro da família DSL predomina a tecnologia ADSL, que utiliza o mesmo par metálico da rede de voz, sendo a tecnologia mais empregada por usuários comerciais e residenciais. Utilizando um modem ADSL no lado do cliente e um concentrador ADSL conhecido como Digital Subscriber Line Access Multiplexer (DSLAM) na empresa de telefonia, essa tecnologia provê taxas de transmissão de até $2 \mathrm{Mb} / \mathrm{s}$ downstream para uma distancia de até $5,5 \mathrm{~km}$, conforme pode ser constatado nos dados indicados na Tabela 1 [11].

\begin{tabular}{|c||c||c|}
\hline $\begin{array}{c}\text { Taxa de transmissão } \\
(\mathrm{Mbps})\end{array}$ & $\begin{array}{c}\text { Diâmetro do par metálico } \\
(\mathrm{mm})\end{array}$ & $\begin{array}{c}\text { Distância até o usuário } \\
(\mathrm{km})\end{array}$ \\
\hline \hline \multirow{2}{*}{$1,5-2,0$} & 0,4 & 4,6 \\
\cline { 2 - 3 } & 0,5 & 5,5 \\
\hline \multirow{2}{*}{6,1} & 0,4 & 2,7 \\
\cline { 2 - 3 } & 0,5 & 3,7 \\
\hline
\end{tabular}

Tabela 1 - Taxas de transmissão em função do par metálico e distância até o usuário

A análise de dados obtidos em campo pela empresa operadora de telecomunicações Telefonica indica que para instalar um serviço ADSL no estado de São Paulo é necessária uma pré-qualificação da linha e, muitas vezes, esse serviço não é disponibilizado aos clientes devido à má qualidade da rede metálica existente. A tecnologia ADSL é um grande avanço em relação às conexões de banda estreita oferecidas pelos modems analógicos, mas, em relação ao uso da fibra óptica no acesso, tal tecnologia é caracterizada como "ponte" de transição para atender os usuários imediatamente $\mathrm{e}$, assim, retê-los. Diversos fatores provocam a diminuição da capacidade de transmissão do canal formado por pares de cobre nos quais trafegam sinais modulados em $\mathrm{DMT}^{3} / \mathrm{QAM}^{4}$ : perda de inserção, relação sinal/ruído, variação na geometria dos

\footnotetext{
${ }^{3}$ DMT: Discrete Multitone

${ }^{4}$ QAM: Quadrature Amplitude Modulation
} 
condutores metálicos com diâmetros nominais $0,4 \mathrm{~mm}$ e $0,5 \mathrm{~mm}$, com uma ou mais derivações (paralelismo da rede) ao longo do cabo e comprimentos diversos bem como a existência de bobinas de pupinização. A partir da Tabela 2 é possível observar que, em até $2 \mathrm{~km}$ de raio a partir da central telefônica, praticamente todos os usuários podem ser atendidos para a capacidade de 2 Mbps. Acima deste limite, todas as linhas devem ser testadas para garantir a qualidade de transmissão. A taxa de utilização da rede indicada na Tabela 2 caracteriza a capacidade de transmissão da central telefônica.

Finalmente, o estudo realizado apresenta um fator comum $(\approx 1,56)$ que relaciona os valores do comprimento de linha da Tabela 1 com as distâncias do raio especificado na Tabela 2 [9].

\begin{tabular}{|c||c||c|}
\hline $\begin{array}{c}\text { Taxa de transmissão } \\
(\mathrm{Mbps})\end{array}$ & $\begin{array}{c}\text { Taxa de utilização } \\
(\%)\end{array}$ & $\begin{array}{c}\text { Distância da central até o } \\
\text { usuário }(\mathrm{km})\end{array}$ \\
\hline \hline \multirow{3}{*}{2} & 1 & 3,86 \\
\cline { 2 - 3 } & 10 & 3,07 \\
\hline \multirow{3}{*}{4} & 100 & 3,86 \\
\hline \multirow{3}{*}{6} & 1 & 2,71 \\
\cline { 2 - 3 } & 10 & 1,71 \\
\hline \multirow{3}{*}{8} & 100 & 3,07 \\
\cline { 2 - 3 } & 1 & 2,50 \\
\cline { 2 - 3 } & 100 & 1,43 \\
\hline & 100 & 2,71 \\
\hline
\end{tabular}

Tabela 2 - Taxas de transmissão em função da taxa de utilização de pares e distância

A Figura 3 apresenta uma arquitetura típica de planta externa projetada por uma operadora de serviços de telecomunicação. Objetivando oferecer serviços de voz, cabos de pares metálicos são distribuídos pela rede de acesso, a partir de uma central telefônica, para atendimento aos usuários residenciais e às pequenas e médias empresas, tendo o cabo principal uma capacidade inicial de 3.600 pares. A partir de emendas principais, cabos secundários ou de derivação, com capacidade de 2.400 a 1.200 pares, são direcionados às regiões com grande 
densidade populacional. Esses cabos secundários são multiplexados em equipamentos denominados Armários de Distribuição Metálicos (ARDs), para atendimento a diversas áreas, constituídas cada uma de 400 a 600 usuários. Para atendimento de serviços de voz e dados a grandes empresas, a operadora de serviços utiliza cabos de fibras ópticas distribuídos na rede de acesso, também a partir de uma central telefônica. O esquemático da Figura 3 demonstra que usuários localizados a uma distância superior a $4 \mathrm{~km}$ de uma estação, que não poderiam ser atendidos pela central telefônica através de cabos metálicos devido às perdas por atenuação, têm condições de atendimento com a utilização de concentradores nomeados Multiplexadores Flexíveis com Interfaces Normalizadas (MUXFINs) que realizam a interface entre sinais no domínio óptico e sinais elétricos, permitindo que cabos de fibras ópticas sejam utilizados como cabos principais e cabos de pares metálicos sejam designados como cabos secundários ou de distribuição, a partir desses equipamentos. Em quaisquer dos casos apresentados, destaca-se que a rede é projetada para atendimento de serviços de voz e dados [12].

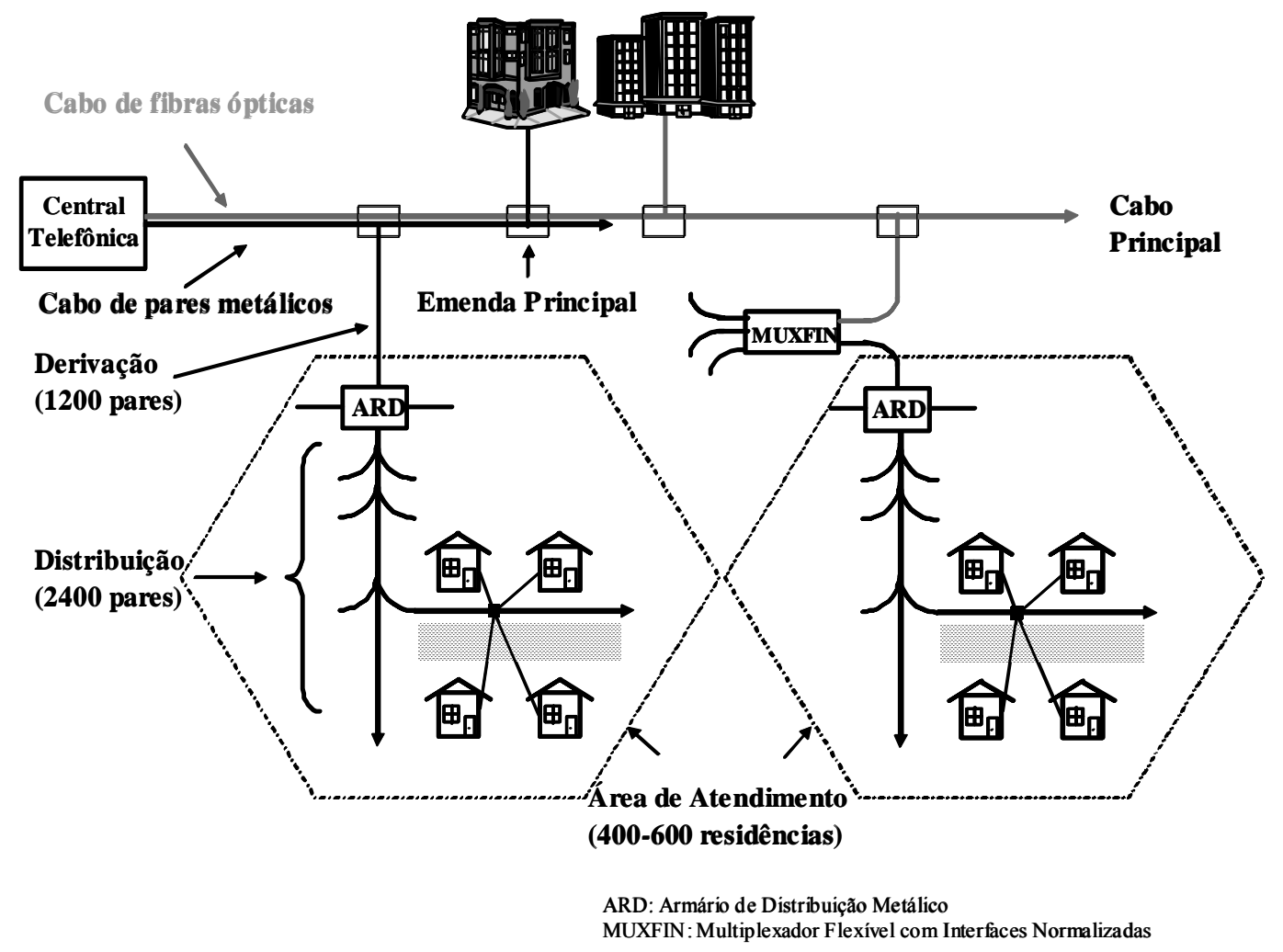

Figura 3 - Exemplo de uma arquitetura da planta externa

Por outro lado, as empresas de TV a cabo oferecem a tecnologia de Cable Modem, um serviço de acesso à Internet em banda larga, baseado na infra-estrutura de transmissão de TV por assinatura. As redes de TV a cabo utilizam uma arquitetura denominada Hybrid-Fiber-Coaxial (HFC). Essa arquitetura, partindo das imediações dos clientes, se configura de forma que uma série de residências, normalmente com um número máximo de 2000, compartilhem o mesmo cabo coaxial, sendo este cabo conectado a uma fibra óptica alimentadora, a qual segue para um 
centro de distribuição (Head-end). O cabo coaxial funciona de forma semelhante à tecnologia Ethernet, sendo que uma banda típica de $36 \mathrm{Mbps}$ é compartilhada por todas as residências.

A partir deste ponto, o mais importante problema a ser resolvido na área de redes de acesso óptico é o custo de sua instalação e operação. De fato, a instalação de um novo cabo de fibra óptica com equipamento terminal em cada empresa ou residência se torna um empreendimento de monta.

A Figura 4.a exemplifica a forma mais simples e, também, a mais cara de instalação, através do projeto e da implantação de uma fibra óptica independente para cada usuário. A quantidade de fibra óptica necessária e o número de transmissores de dados (transceptores) no concentrador da empresa prestadora de serviços tornam esta arquitetura extremamente onerosa.

A Figura 4.b apresenta uma forma de redução da quantidade de fibra óptica necessária, através da instalação de uma única fibra óptica a partir da empresa prestadora de serviços até um concentrador próximo aos clientes, a partir do qual a arquitetura permanece a mesma que a anterior. $\mathrm{O}$ aspecto negativo deste tipo de arquitetura é o posicionamento do concentrador, situado na planta externa. Por ser um elemento ativo na rede de acesso, isto é, elemento necessitando de alimentação de energia elétrica com redundância, existe a obrigatoriedade dos serviços de manutenção e supervisão, o que implica em um aumento nos custos de operação de uma rede. O custo estimado de implantação para esse tipo de arquitetura está situado entre US\$ 22.000 e US\$ 28.000 por quilômetro [10]. Em contrapartida, o custo anual de operação para uma linha telefônica normal é de aproximadamente US\$ 315 [10]. Como exemplo, citamos que, nos Estados Unidos, grandes empresas pagam por mês o equivalente a US\$ 3.200 a US\$ 4.300 pelo uso de uma conexão Synchronous Optical Network (SONET), e US\$ 375 por mês por um canal $\mathrm{T}^{5}$. Portanto, esse tipo de arquitetura não é passível de ser implementado visando pequenos e médios empresários e clientes residenciais. A única alternativa possível é o compartilhamento dos custos entre os clientes; esta é a fundamentação da PON [13].

\footnotetext{
${ }^{5}$ T1: padrão norte-americano que define linha digital, com taxa de transmissão de 1,544 Mbps.
} 
a) Fibra óptica dedicada

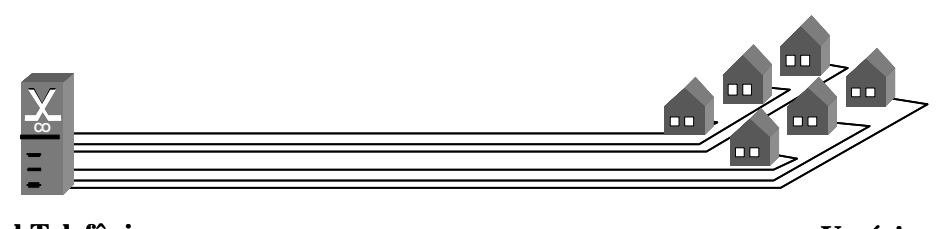

Central Telefônica

Usuários

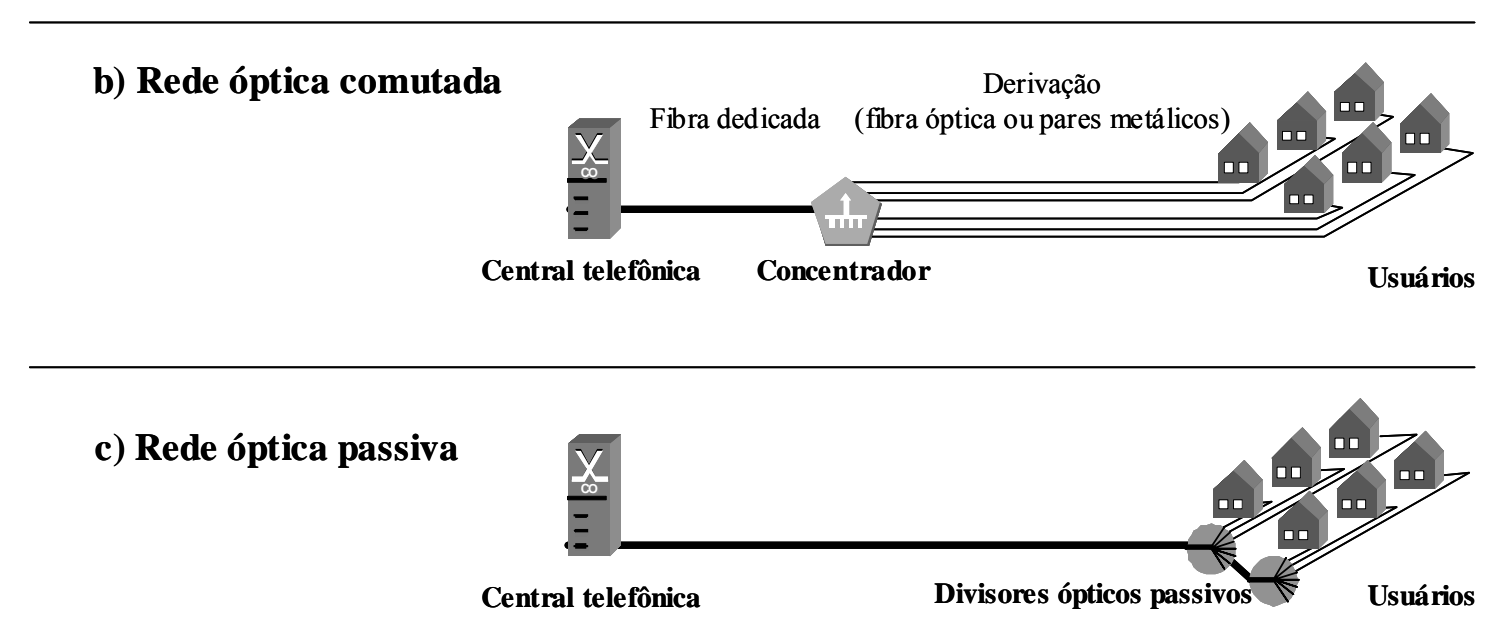

Figura 4 - Classificação das redes de acesso ópticas

A substituição do concentrador por um elemento óptico passivo é a base da PON. Conforme pode ser visto na Figura 4.c, é projetada uma rede ponto-multiponto sem elementos ativos na rede de acesso, isto é, uma rede que não necessita de energia elétrica, utilizando somente fibras ópticas e divisores ópticos passivos. Um OLT transmite um sinal no domínio óptico, que é distribuído para os diversos usuários através dos divisores ópticos passivos e é convertido em um formato eletrônico nas ONUs. A saída desses dispositivos disponibiliza sinais elétricos para os telefones, máquinas de fax, computadores, aparelhos de TV e outros equipamentos nas instalações dos clientes [10]. 


\section{$2.3 \quad$ Rede Óptica Passiva}

Uma PON é uma rede de acesso em fibra óptica interligada, em topologia estrela e na configuração ponto-multiponto, que possui somente componentes ópticos passivos entre o OLT e a ONU. O termo passivo se origina da principal característica dessa rede, uma vez que não existem elementos ativos, isto é, elementos que necessitem de energia elétrica para seu funcionamento, entre os equipamentos do cliente e do prestador de serviço, conforme pode ser observado na Figura 5.

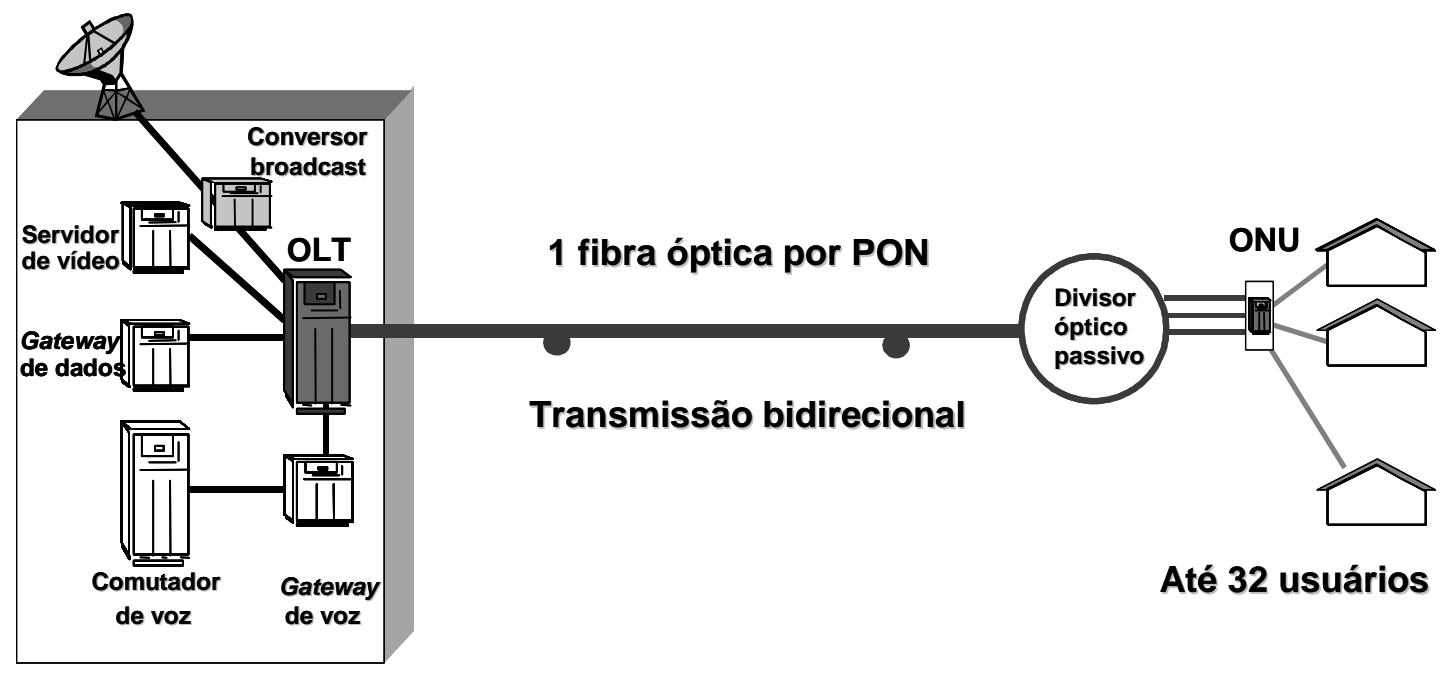

OLT: Optical Line Terminal ONU: Optical Network Unit

Figura 5 - Representação esquemática de uma rede óptica passiva

Um sinal óptico é compartilhado entre todos os usuários interligados por essa rede, permitindo baixo custo operacional e um número reduzido de eventuais intervenções de manutenção. O elemento que propicia esse compartilhamento da fibra óptica é o divisor óptico passivo que, dependendo da direção da luz incidente, ou divide o sinal óptico em uma dada taxa de fracionamento e distribui os sinais do OLT às ONUs ou encaminha os sinais ópticos provenientes das ONUs ao OLT, através das fibras interligadas aos equipamentos dos usuários. O divisor óptico passivo pode ser localizado em 3 posições distintas: dentro do ambiente da central telefônica, na planta externa, devidamente protegido contra as intempéries climáticas, ou no interior de um prédio. 
A arquitetura PON requer equipamento optoeletrônico ativo somente nos terminais de envio (OLT) e recepção (ONU), para a conversão óptico/elétrica/óptico $(\mathrm{O} / \mathrm{E} / \mathrm{O})$ dos sinais recebidos em diferentes formatos de transmissão, enquanto que os equipamentos de interconexão, a planta externa de fibras ópticas e os divisores ópticos são componentes passivos. Dessa forma, OLTs e ONUs possuem ambos um transmissor e um receptor, pois ambos apresentam os 2 modos de operação. Um típico transmissor consiste de um diodo laser operando em $1.500 \mathrm{~nm}$ no sentido downstream e/ou $1.300 \mathrm{~nm}$ no sentido upstream e demais componentes eletrônicos de suporte. Um típico receptor é constituído de um fotodetector e de dispositivos eletrônicos de processamento.

A fibra óptica tipo monomodo tem como função interligar OLT e ONUs, enquanto os divisores ópticos passivos se caracterizam pela divisão dos sinais ópticos em uma dada taxa de fracionamento. Dividir um sinal óptico 1:4, por exemplo, implica que cada sinal de saída transporta um quarto da potência de entrada. Isto se traduz como uma limitação de distância para a arquitetura PON. Considerando uma fonte óptica laser distributed feedback (DFB) 1310 $\mathrm{nm}$, admite-se que para um fracionamento de 16 vias se tenha um comprimento típico de $24 \mathrm{~km}$. Para um fracionamento de 32 vias, esse comprimento se reduz para $14 \mathrm{~km}$ [14].

A arquitetura PON compartilha os equipamentos de rede com um dado número de clientes, possibilitando à empresa operadora de rede dividir os custos de instalação e de operação. Como não há elemento ativo localizado na planta externa de fibra óptica, a manutenção no campo é simplificada e, portanto, o custo operacional é minimizado. A Figura 6 apresenta a arquitetura básica da rede PON e uma estratégia de aproximação da ONU ao usuário, ou seja, trazer a fibra óptica mais próxima do usuário e conseqüentemente diminuir o volume e extensão da rede metálica no acesso, iniciando pelo primeiro estágio Fiber-to-theCabinet (FTTCab), onde temos o equipamento ONU localizado em um armário de distribuição situado em um pedestal na calçada ou fixado no poste de telefonia ou de energia elétrica. $O$ segundo estágio, caracterizado pela sigla FTTC, significa que a ONU está situada no quarteirão do usuário, ou seja, nas suas imediações. O terceiro e, também, último estágio está identificado pelas siglas FTTB e FTTH, quando a ONU está instalada dentro do ambiente do usuário, condição em que a rede de acesso está constituída totalmente por cabo de fibra óptica. Identificamos o componente ONT que se traduz como o equipamento ONU dentro do ambiente do usuário [15]-[17]. 


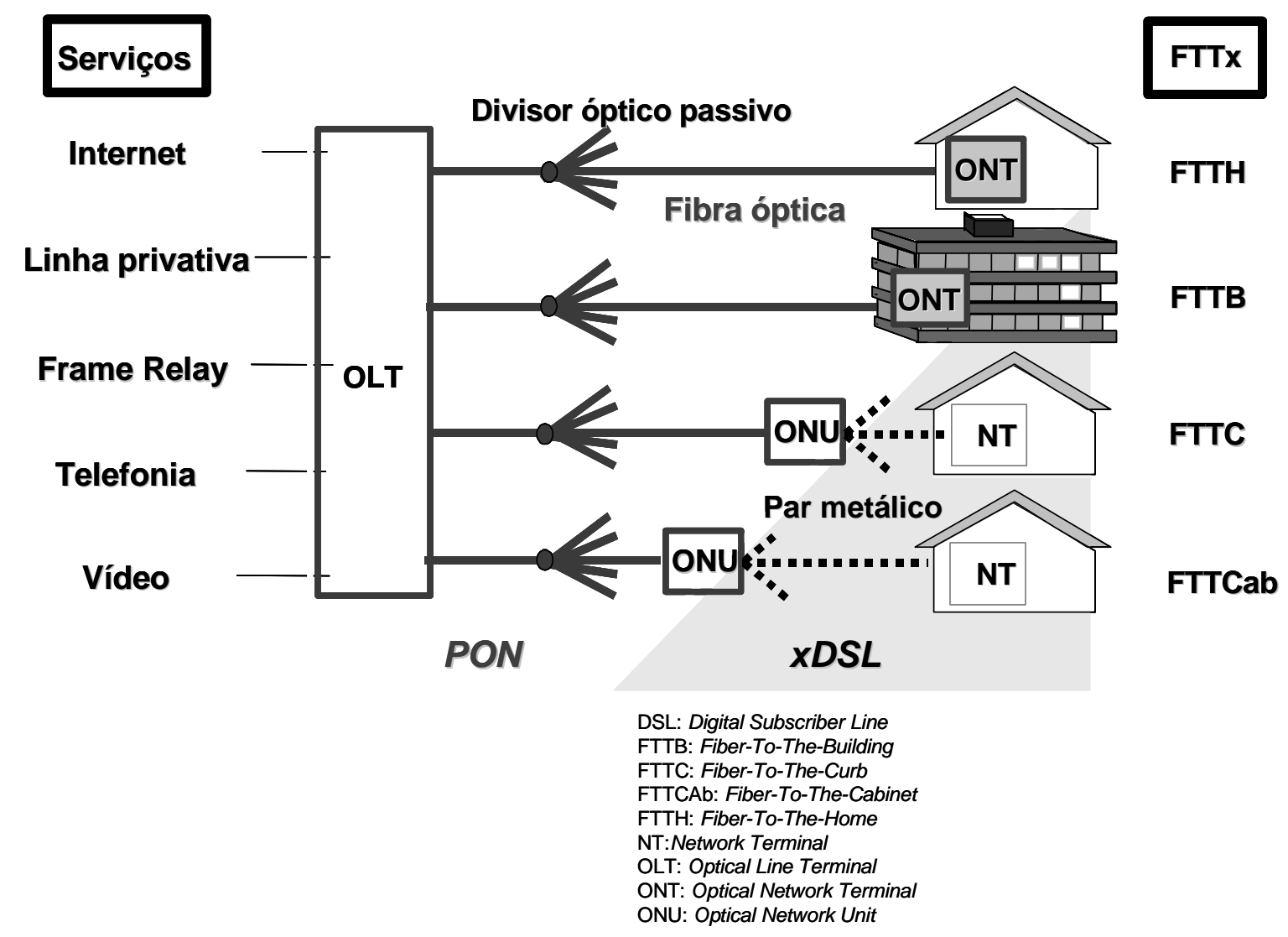

Figura 6 - Evolução de uma arquitetura básica PON no ambiente FTTx 


\subsection{Atuação do Comitê FSAN}

Em 1995 foi constituído o Full Service Access Network (FSAN), um Comitê Internacional criado pelas operadoras BT, DT, NTT e France Telecom (FT), com o intuito de desenvolver padrões voltados aos serviços de faixa larga, como Internet Protocol (IP), vídeo e Base T Ethernet, utilizando fibras ópticas, que hoje conta com a participação de 21 operadoras em todo o mundo, conforme pode ser visto na Tabela 3 e Figura 7 [3], [12]-[13]. O comitê FSAN interage com organismos de regulamentação e normativos internacionais, tais como o ATM Forum (ATM-F), a ITU Telecommunication Standardization Sector (ITU-T), a European Telecommunications Standardization Institute (ETSI) e a American National Standards Institute (ANSI).

\begin{tabular}{|c|}
\hline BT -British Telecommunications \\
\hline Bell Canada \\
\hline BellSouth \\
\hline Bezeq Israel \\
\hline Chunghwa Taiwan \\
\hline DTAG - Deutsche Telekom \\
\hline Eire Telecom \\
\hline FT - France Telecom \\
\hline Verizon \\
\hline KPN - Dutch Telecom \\
\hline KT - Korean Telecom \\
\hline Malta Telecom \\
\hline NTT - Nippon Telegraph and Telephone \\
\hline SBC \\
\hline SingTel \\
\hline Swisscom \\
\hline Telefonica Itália \\
\hline Telefonica Espana Sweden \\
\hline Telstra \\
\hline Test \\
\hline
\end{tabular}

Tabela 3 - Identificação das operadoras que constituem o consórcio FSAN 

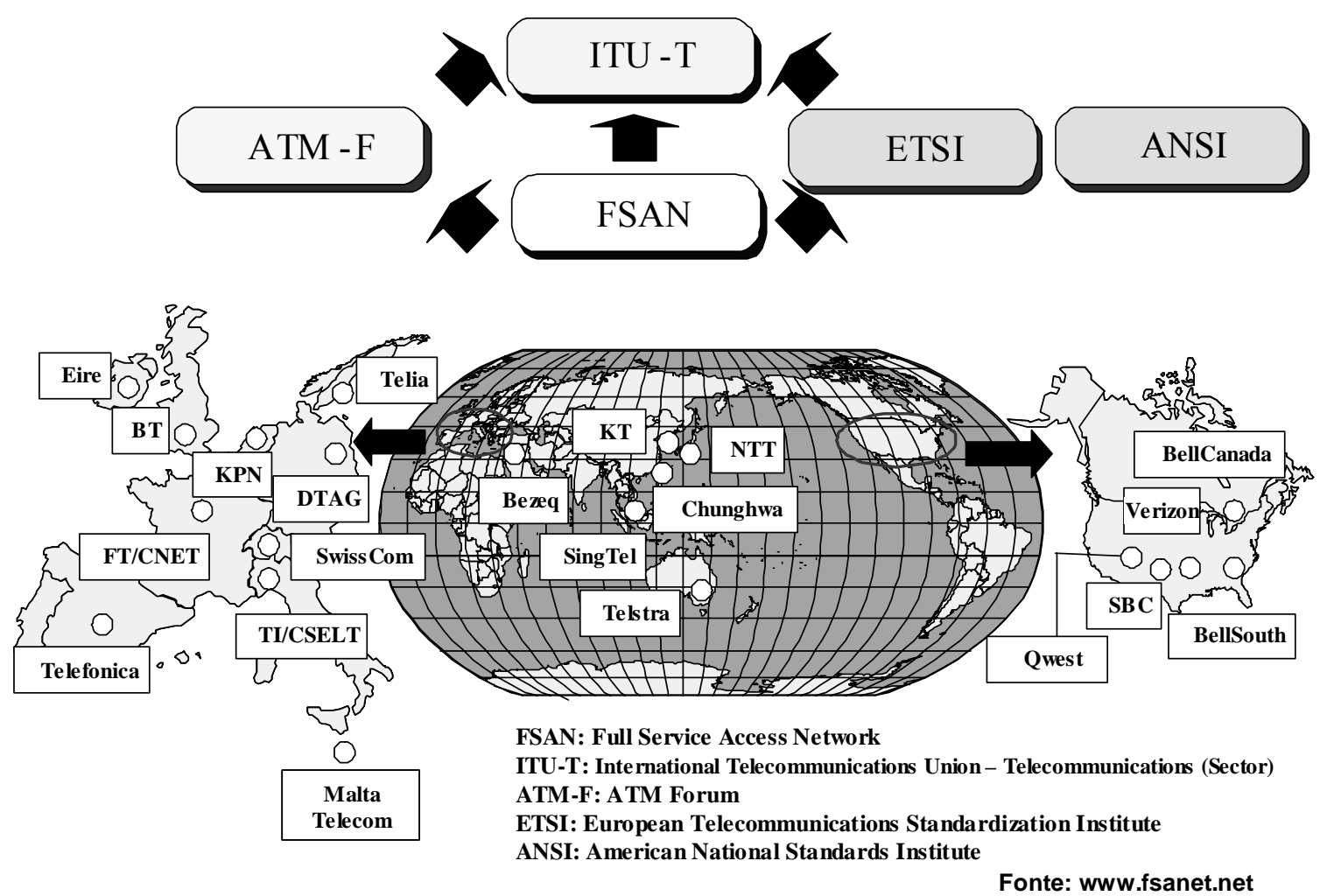

Figura 7 - Distribuição geográfica das operadoras da estrutura FSAN

O início da padronização PON ocorreu no mês de junho de 1996 em Londres, quando o FSAN definiu que o foco inicial seria a tecnologia ATM, sendo o objeto de estudo inicial a interface ATM-PON. O organismo ITU-T especificou a recomendação G.982 em novembro de 1996 como o primeiro padrão de Redes Ópticas Passivas, com foco em equipamentos RDSI. O grupo FSAN definiu na cidade de Atlanta, USA, em março de 1997, a recomendação G.983.1 como padrão da interface de linha, e no mês seguinte - abril de 1997 - propôs essa recomendação ao ITU-T como uma extensão do G.982, com a camada física adequadamente descrita e o ATM adotado como serviço de transporte. Assim, o padrão G.983.1 foi reconhecido pelo ITU-T como uma especificação de interface de linha em fevereiro de 1998; aceito como recomendação internacional em março de 1998 em Veneza, Itália, e publicado em outubro de 1998 com o título Broadband Optical Access Systems based on Passive Optical Networks (PON).

A padronização dos requisitos da APON prosseguiu em junho de 1999, com a definição da especificação básica da interface de controle e com a descrição das funcionalidades de gerenciamento do ONT, aprovada pelo ITU-T em abril de 2000 por meio da recomendação G.983.2. 
A continuidade do processo se dá em abril de 2001 com a aprovação da recomendação G.983.3, que estabeleceu comprimentos de onda específicos para serviços adicionados, tendo sido alocados, no sentido upstream, os comprimentos de onda 1250 a $1360 \mathrm{~nm}$, para downstream a faixa de 1480 a $1500 \mathrm{~nm}$, e, para serviços agregados, de 1539 a $1565 \mathrm{~nm}$.

Para prover de eficiência a transmissão dos sinais no sentido upstream, é definido o protocolo de alocação dinâmica de banda (Dynamic Bandwidth Allocation - DBA) e a recomendação G.983.4, que descreve o referido protocolo, é aprovada pelo ITU-T em dezembro de 2001.

Os mecanismos de proteção da rede PON, quer seja efetuada através da duplicação do equipamento OLT ou da duplicação da própria PON, foram especificados na recomendação G.983.5 - A Broadband Optical Access System with Enhanced Survivability, aprovada em janeiro de 2002, que teve como continuidade a G.983.6, definida em junho de 2002, que trata da interface de controle e do gerenciamento do ONT (ONT Management and Control Interface OMCI) para sistemas BPON, enfocando a proteção da linha de acesso.

A OMCI para o sistema BPON com DBA foi padronizada pelo ITU-T na recomendação G.983.7 em novembro de 2001. Destaque-se que, nesse mesmo mês, o ITU-T também aprovou o adendo da Recomendação G.983.1 definindo a taxa de 622 Mbps para a transmissão de sinais no sentido upstream.

A recomendação G.983.8 aprovada em março de 2003 estabelece suporte da interface de controle e gerenciamento do ONT ao sistema BPON, complementando as funções contidas na G.983.2. O suporte OMCI está especificado para funcionalidades de roteador IP nos cartões LAN, interfaces RDSI, monitoramento do desempenho Ethernet, interfaces de vídeo, Virtual Local Area Network (VLAN), conexões Virtual Channel (VC), ONUs, dentre outras funções. 
A Tabela 4 apresenta, em ordem seqüencial do número de recomendação, os títulos e as respectivas datas de publicação dos documentos que tratam da rede PON, elaborados pelo grupo FSAN e aprovados pelo ITU-T.

\begin{tabular}{|l|l|c|}
\hline \multicolumn{1}{|c|}{ Recomendação } & \multicolumn{1}{|c|}{ Título } & $\begin{array}{c}\text { Data } \\
\text { Publicação }\end{array}$ \\
\hline \hline G.983.1 & $\begin{array}{l}\text { Broadband Optical Access Systems based on } \\
\text { Passive Optical Network (PON) }\end{array}$ & $10 / 1998$ \\
\hline G.983.1 (Adendo 1) & $\begin{array}{l}\text { High Speed Optical Access Systems based on } \\
\text { Passive Optical Network (PON) Techniques }\end{array}$ & $11 / 2001$ \\
\hline G.983.2 & $\begin{array}{l}\text { ONT Management and Control Interface } \\
\text { Specification for ATM PON }\end{array}$ & $04 / 2000$ \\
\hline G.983.3 & $\begin{array}{l}\text { A Broadband Optical Access System with Increased } \\
\text { Service Capability by Wavelength Allocation }\end{array}$ & $04 / 2001$ \\
\hline G.983.4 & $\begin{array}{l}\text { A Broadband Optical Access System with Increased } \\
\text { Service Capability using Dynamic Bandwidth } \\
\text { Assignment }\end{array}$ & $12 / 2001$ \\
\hline G.983.5 & $\begin{array}{l}\text { A Broadband Optical Access System with } \\
\text { Enhanced Survivability }\end{array}$ & $01 / 2002$ \\
\hline G.983.6 & $\begin{array}{l}\text { ONT Management and Control Interface } \\
\text { Specification for B-PON System with Protection } \\
\text { Features }\end{array}$ & $06 / 2002$ \\
\hline G.983.7 & $\begin{array}{l}\text { ONT Management and Control Interface } \\
\text { Specification for Dynamic Bandwidth Assignment } \\
\text { (DBA) B-PON System }\end{array}$ & $11 / 2001$ \\
\hline G.983.8 & $\begin{array}{l}\text { B-PON OMCI support for IP, ISDN } \\
\text { VLAN Tagging, VC Cross-Connections and other } \\
\text { select functions }\end{array}$ & $03 / 2003$ \\
\hline
\end{tabular}

Tabela 4 - Resumo das recomendações G.983

O Sistema GPON, especificado para transmitir sinais em gigabits por segundo, é padronizado a partir das recomendações G.984, aprovadas pelo ITU-T em março de 2003:

- G.984.1, que trata das características gerais de um sistema GPON, ou seja, arquitetura, taxas de transmissão, alcance, retardo de transferência do sinal e proteção;

- G.984.2, que especifica a camada Physical Media Dependent (PMD) para o padrão GPON, descrevendo uma rede de acesso em fibra óptica capaz de suportar os

\footnotetext{
${ }^{6}$ ISDN: Integrated Services Digital Network, é o mesmo que RDSI.
} 
requisitos de banda larga dos serviços aos usuários residenciais e corporativos. Essa recomendação abrange sistemas com taxas de transmissão nominais de 1,25 gigabits por segundo (Gbps) e 2,5 Gbps no sentido downstream e 155 Mbps, $622 \mathrm{Mbps}, 1,5$ Gbps e 2,5 Gbps no sentido upstream. [13], [18-19].

\subsection{Conceito da ATM-PON}

Quando o grupo FSAN foi organizado, em 1995, o Asynchronous Transfer Mode (ATM) era considerado o melhor sistema de transporte (e, até mesmo, o único) que suportava simultaneamente a transmissão de voz, dados e vídeo.

O formato APON usado pelo FSAN e aceito pelo ITU-T, conforme recomendação G.983, focaliza aplicações residenciais utilizando fibra óptica tipo monomodo com distância entre OLT e ONT limitada a $20 \mathrm{~km}$, num número máximo de 32 ONTs, e valores de taxas de transmissão, provenientes da especificação ATM, de 155,52 Mb/s ou 622,08 Mb/s no sentido downstream com tráfego contínuo de dados, e $155,52 \mathrm{Mb} / \mathrm{s}$ no sentido upstream com característica de tráfego em forma de rajadas (bursts).

A estrutura do quadro no sentido downstream é constituída de células com 53 bytes cada, células do tipo ATM ou, ainda, células adicionais denominadas Physical Layer Operation, Administration and Maintenance (PLOAM) inseridas nessa estrutura a cada 28 time slots e responsáveis pela alocação de banda, sincronização, controle de erro, segurança, alcance (ranging) e manutenção, totalizando, para a taxa de 155,52 Mbps, o quadro com 54 células ATM e 2 células PLOAM e, para 622,08 Mbps, o quadro com 216 células ATM e 8 células PLOAM. No sentido upstream o formato se caracteriza por 53 células ATM de 56 bytes, cada uma com um cabeçalho (overhead) de 3 bytes que contêm um mínimo de 4 bits de tempo de guarda, para garantir um intervalo de tempo suficiente para prevenir colisões com células de outros ONTs.

O formato básico do quadro para a taxa de 155,52 Mbps está apresentado na Figura 8, onde se observa uma redução na capacidade de carga útil (payload) no sentido downstream de 155,52 Mbps para 149,97 Mbps, correspondendo a 54 células ATM e 2 células PLOAM localizadas uma no início e outra no meio do quadro. Cada célula PLOAM possui permissões (grants) relacionadas às células específicas dentro do quadro upstream, assim como ao código de detecção de erros polinomial, também conhecido como Cyclic Redundancy Check (CRC), e às mensagens de operação, administração, manutenção e aprovisionamento (Operation, Administration, Maintenance and Provisioning - OAM\&P). 
No sentido upstream a capacidade é reduzida para 149,19 Mbps porque há 3 bytes de overhead por célula ATM que, na Figura 8, estão identificadas como PLOAM 2, destacando que o envio de células ATM depende da autorização concedida pelo OLT, via células PLOAM no sentido downstream, enquanto o encaminhamento das células PLOAM obedece a uma taxa programada. Os 3 bytes de cada célula PLOAM 2 constituem os 4 bits de tempo de guarda e 20 bits dos campos preâmbulo e delimitação. O campo preâmbulo é usado para permitir sincronização de bit. O campo delimitação é empregado para indicar o início da célula.

O OLT e os ONTs utilizam Virtual Path (VP)/VC para a comunicação na camada ATM. Dessa forma, o cabeçalho de 5 bytes de uma célula ATM tem um campo de endereçamento de 28 bits associado com determinado Virtual Path Identifier (VPI) de 12 bits e Virtual Channel Identifier (VCI) de 16 bits, sendo que, inicialmente, no sentido downstream, o OLT envia uma mensagem para o ONT notificando-a a aceitar células contendo determinado VPI/VCI [15-16], [19].

\section{Formato Downstream}

Tamanho do quadro $=155,52 \mathrm{Mbps}=56$ células de 53 bytes $=152,67 \mu \mathrm{s}$

\begin{tabular}{|c|c|c|c|c|c|}
\hline $\begin{array}{c}\text { PLOAM } \\
1\end{array}$ & $\begin{array}{c}\text { ATM } \\
\text { Célula } 1\end{array}$ & $\begin{array}{c}\text { ATM } \\
\text { Célula 27 }\end{array}$ & $\begin{array}{c}\text { PLOAM } \\
2\end{array}$ & $\begin{array}{c}\text { ATM } \\
\text { Célula 28 }\end{array}$ & $\begin{array}{c}\text { ATM } \\
\text { Célula } 54\end{array}$ \\
\hline
\end{tabular}

Capacidade Downstream $=155,52 \mathrm{Mbps} \times 54 / 56=149,97 \mathrm{Mbps}$

\section{Formato Upstream}

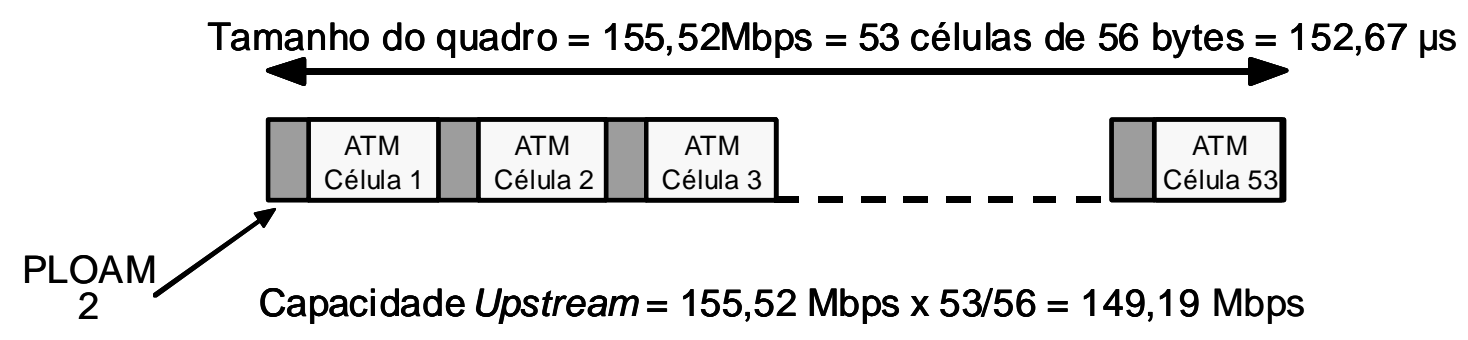

Figura 8 - Elementos básicos do quadro APON

A função de otimização de transporte para o sentido upstream, denominada DBA, é capaz de alocar os diferentes tipos de tráfego existente numa rede APON, de forma a reduzir o tráfego total. Podem ser observados três tipos diferentes de tráfego originados de três ONTs: 
modo rajada (burst), típico de aplicações de vídeo digital; rajada para uma largura de banda disponível, típico de uma LAN; e Circuit Emulation Service (CES), típico de um tráfego com taxa de bit constante gerada por um circuito Time Division Multiplexing (TDM). Na alocação estática de largura de banda, cada serviço mencionado é tipicamente transportado sobre um canal pré-determinado. A função DBA converge todo o tráfego do usuário para um único canal, possibilitando que a largura de banda não usada por um usuário seja disponibilizada para qualquer outro usuário. Essa alocação compartilhada reserva um número maior de usuários em cada canal, com ocupação automática da largura de banda disponível no caso do término da transmissão de um usuário bem como realocação de largura de banda no caso de retorno desse mesmo usuário, configurando um acesso dinâmico à camada de conexão com serviço de tráfego sob demanda. Através da implementação da função DBA, o OLT informa ao ONT qual volume de tráfego poderá ser transmitido na direção upstream a partir do Service-Level Agreement (SLA) de cada conexão individual, bem como qual a prioridade dessa conexão e largura de banda disponível na APON.

A codificação dos dados, tanto no sentido downstream como upstream, obedece a codificação NRZ, com a seguinte convenção:

- nível alto do sinal no domínio óptico para o binário UM;

- nível baixo do sinal no domínio óptico para o binário ZERO.

A Figura 9 apresenta o modo de operação das células na APON. Como uma única fibra óptica pode ser utilizada na APON, tanto para o sentido upstream como para o sentido downstream, dois comprimentos de onda são usados - $1.550 \mathrm{~nm}$ para o downstream empregando a técnica TDM, e $1.310 \mathrm{~nm}$ para o upstream associado ao acesso multiplexado por divisão no tempo (Time Division Multiple Access - TDMA), estabelecendo o protocolo para suportar a transmissão multiponto-ponto. Embora um mesmo comprimento de onda também possa ser usado, em geral, dois comprimentos de onda proporcionam um melhor isolamento óptico entre os transmissores e os receptores. Basicamente, o OLT deve determinar a distância e a localização de todos os ONTs, para que possam ser alocados os time slots, através de um processo de medição denominado ranging, permitindo a transmissão entre um ONT específico e o OLT sem a interferência nos outros ONTs [15-16], [19-20]. 


\section{Downstream}

OLT envia células ATM para o splitter

Divisor óptico envia as células para cada ONT

ONT filtra as células específicas

para o usuário e descarta as demais
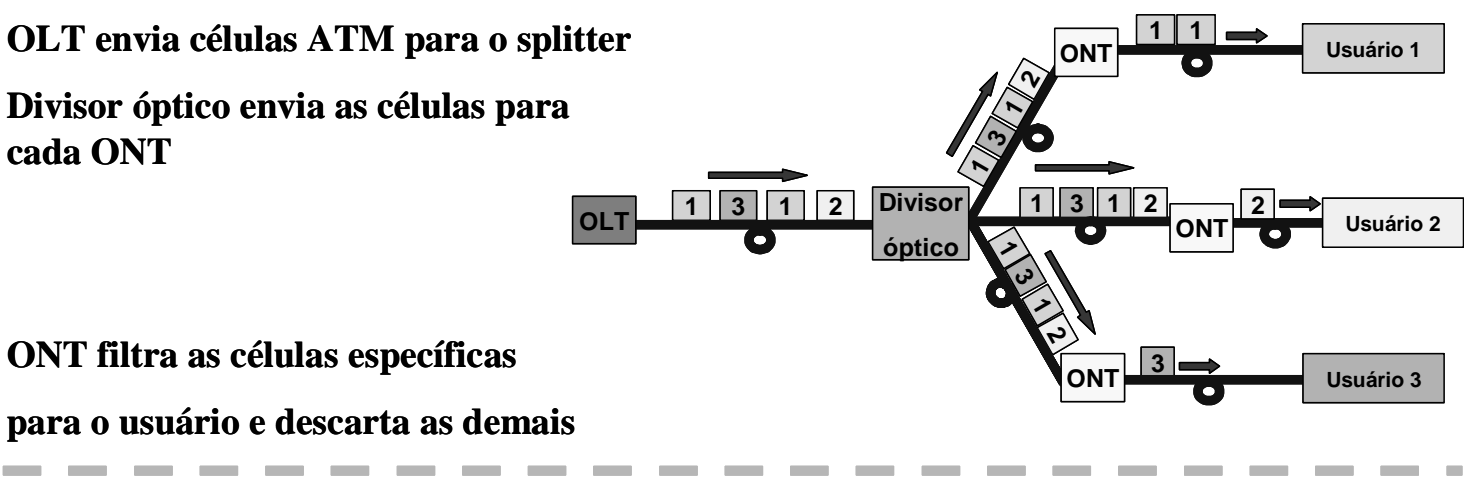

Upstream

Para cada usuário é alocado um time slot no qual o dado é transmitido

\section{Usuários estão sincronizados por um processo denominado ranging}

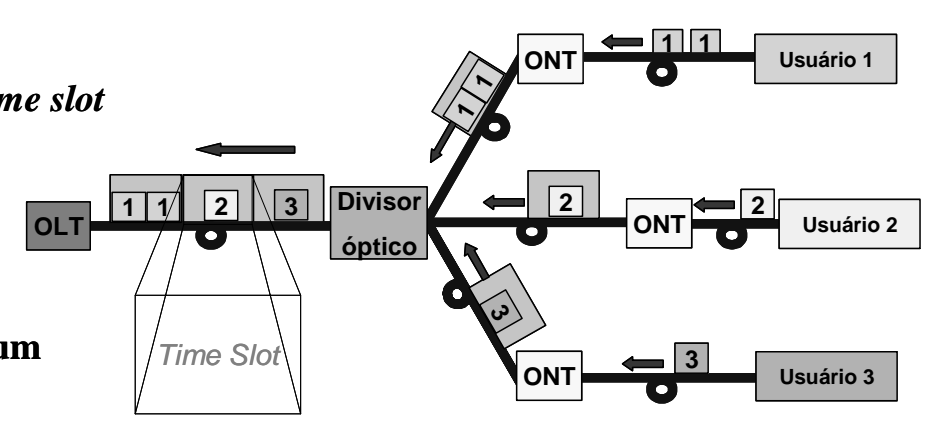

Figura 9 - Fases de operação das células na APON

Em virtude da natural configuração broadcast da PON, técnicas de criptografia são obrigatoriamente requeridas através, por exemplo, da implementação da função churning, definida na recomendação ITU-T G.983. Essencialmente, o ONT gera uma chave criptográfica enviada no sentido upstream para o OLT, que por sua vez usará a chave churning para embaralhar todo o tráfego downstream destinado àquele ONT. Isto garante que, mesmo que todos ONTs recebam em broadcast o tráfego downstream, somente o ONT destinado a receber determinada mensagem será capaz de decodificar o tráfego. Em intervalos periódicos, o OLT pedirá ao ONT que este gere uma nova chave churning, a fim de garantir a continuidade da privacidade do tráfego.

Portanto, do ponto de vista técnico, a APON provê características de operação, administração e manutenção, incluindo monitoramento de bit error rate (BER), alarmes e defeitos, alcance automático (ranging) e churning, como um mecanismo de segurança para a criptografia de tráfego downstream [15-16], [20-21].

No aspecto econômico, a arquitetura PON tem como principal mérito uma redução dos custos na construção de redes de acesso, aumentando a banda óptica disponível sem a necessidade do aumento do número de componentes ópticos na rede, como lasers e amplificadores. Em termos de custos de instalação, em uma APON, considerando a infra- 
estrutura de dutos já existente, contabiliza-se $50 \%$ do custo como correspondente ao equipamento ativo (OLT e ONTs) e 50\% referente aos componentes passivos (fibras ópticas e divisores ópticos passivos), sendo que as fibras ópticas correspondem a 70\% deste total [22].

$\mathrm{O}$ uso do termo APON pressupunha que somente serviços ATM poderiam ser atendidos. Em conseqüência, o grupo FSAN decidiu lançar então o nome BPON. A proposta do sistema BPON é oferecer serviços de banda larga incluindo, acesso Ethernet e distribuição de vídeo. As redes BPON são definidas pela FSAN e pelos comitês do ITU-T, compreendendo tanto fornecedores de equipamentos quanto provedores de serviços [13].

\subsection{Conceito de GIGABIT-PON}

O grupo FSAN decidiu, em 2001, iniciar estudos para padronizar as redes PON operando em taxas acima de $1 \mathrm{Gbps}$, objetivando suportar múltiplos serviços e funcionalidades OAM\&P. Como resultado, em março de 2003 foi padronizada pela ITU-T a tecnologia GPON, aperfeiçoando o formato APON anteriormente especificado, com ênfase em serviços de dados e TDM nos formatos nativos. Os padrões de GPON são conhecidos como recomendações ITU-T da série G.984. As recomendações G.984.1 e G.984.2, tratam do meio físico e dos requisitos dos serviços. A recomendação G.984.3, quando aprovada, compreenderá a camada para processamento dos quadros denominados GPON Transmission Convergence (GTC), mensagem, método de alcance automático, funcionalidade OAM e segurança. [13], [19], [23].

O diagrama da Figura 10 mostra como os serviços são canalizados na tecnologia GPON, onde se destaca a unidade GPON Encapsulation Method (GEM), que encapsula pacotes ${ }^{7}$ Ethernet e TDM na direção downstream e realiza a extração dos referidos pacotes na direção upstream [24].

A camada física (PHY) é responsável pela transmissão dos bits no meio físico e também pelas características físicas, funcionais e procedurais necessárias para acesso ao meio de transmissão [25-26]. A Figura 10 ilustra a base G.7041 / T1X1.5 ${ }^{8}$, cujo mecanismo de encapsulação denominado Generic Framing Procedure (GFP) está especificado para transporte de pacotes IP sobre SONET/SDH, podendo ser aplicado diretamente em Dense Wavelength Division Multiplexing (DWDM) [27]. O padrão GFP permite o transporte de qualquer tipo de pacotes de dados, tornando o SONET/SDH mais flexível em termos de alocação de largura de

\footnotetext{
${ }^{7}$ Pacote é a unidade de informação de tamanho variável, trocada entre a camada de rede e a camada de enlace de dados da mesma máquina, ou entre pares de camada de rede.
}

${ }^{8}$ O grupo de trabalho T1X1.5 pode ser acessado no site: <http://www.t1.org/t1x1/_x15-hm.htm> 
banda, eliminando um inconveniente do SDH que era a alocação de um canal STM ${ }^{9} 1$ a 155 Mbps para transporte de um pacote em 100 BaseT [28].

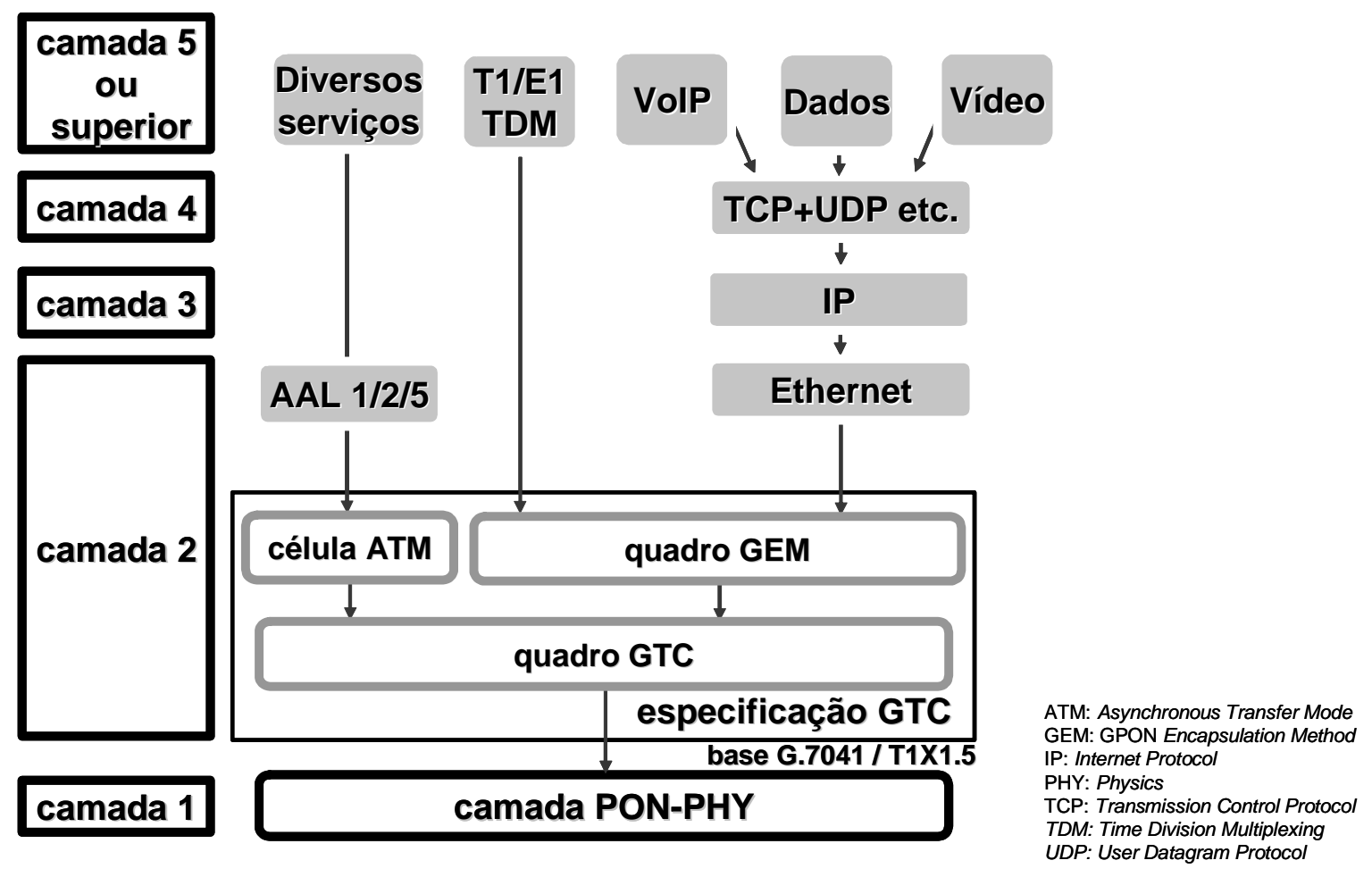

Figura 10 - Serviços atendidos pela GPON

Convém salientar que, em termos de gerenciamento, a GPON estabelece, acima da camada PHY, uma camada equivalente à camada 2 do modelo de referência $\operatorname{OSI}^{10}$, denominada Transmission Convergence (TC), onde são processados os quadros GTC, que se prestam a encaminhar informações entre a estação de gerenciamento da rede, o OLT e as ONUs. Dessa forma, o quadro GTC é montado com pacotes GEM, na direção downstream. Na direção contrária - upstream - os pacotes GEM são extraídos do quadro GTC.

Existem três mecanismos previstos para o controle e o gerenciamento do sistema GTC: mensagens de operação, administração e manutenção (OAM), PLOAM, e OMCI [21], [24], [29].

Em termos de taxas de transmissão, o padrão GPON opera com valores de $622 \mathrm{Mbps}$ simétrico, 1,25 Gbps simétrico, e assimétrico com 2,5 Gbps no sentido downstream e 1,25 Gbps no sentido upstream, estabelecidas na Recomendação G.982 - Optical access networks to support services up to the ISDN primary rate or equivalent bit rates.

\footnotetext{
${ }^{9}$ STM: Synchronous Transfer Mode

${ }^{10}$ OSI: Open Systems Interconnection
} 
A Figura 11 apresenta o formato do quadro característico da tecnologia GPON no sentido downstream, ilustrando, de modo simplificado, o conjunto formado pelo cabeçalho e carga útil com comprimento variável, para cada quadro associado ao intervalo de tempo de 125 $\mu$ s. Nesse exemplo, é mostrada a constituição da carga útil de um dos quadros através de células ATM e de fragmentos TDM e pacotes de dados.

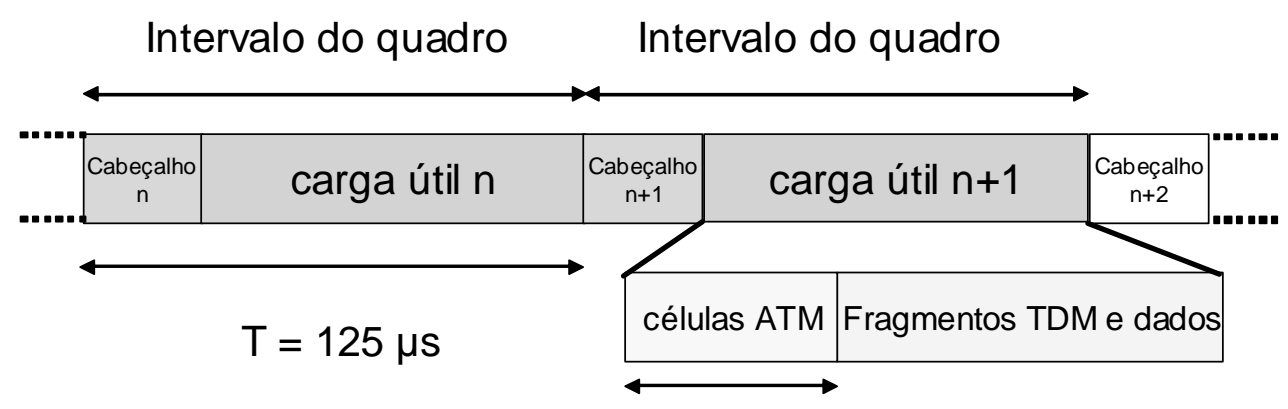

53 bytes

Figura 11 - Formato do quadro downstream na tecnologia GPON

O formato do quadro no sentido upstream está ilustrado na Figura 12, onde cada ONT tem seu respectivo time slot para encaminhamento das informações ao OLT, e cuja carga útil abrange conteúdos diversificados, como por exemplo, fragmentos TDM e Ethernet, resultantes do mecanismo de encapsulação GFP anteriormente mencionado.

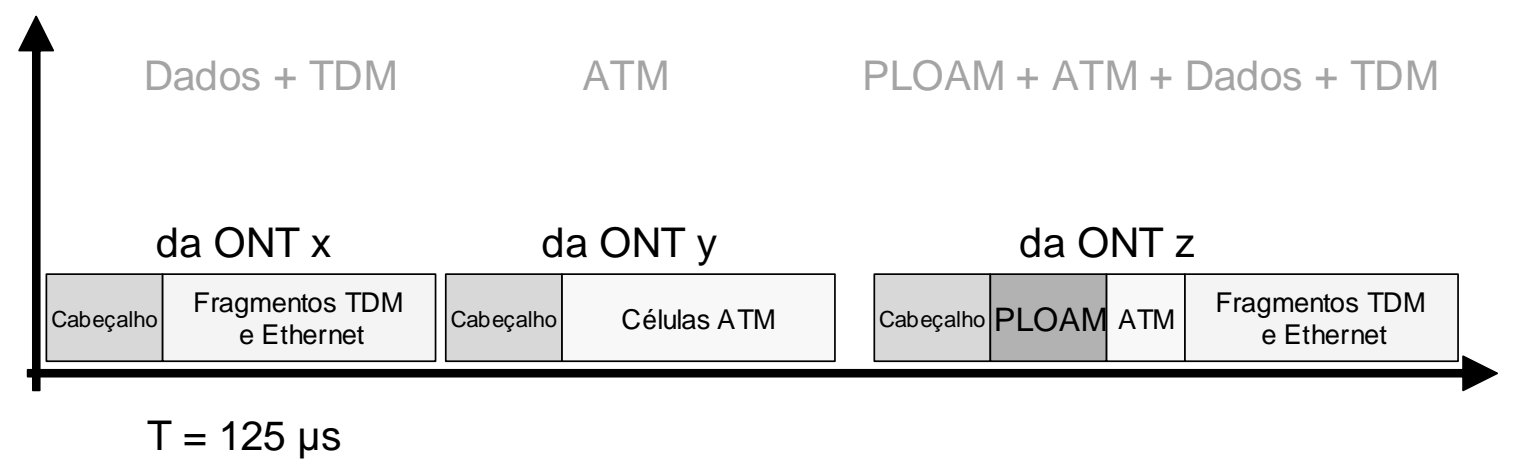

Figura 12 - Formato do quadro upstream na tecnologia GPON

Finalizando, a rede GPON está baseada no protocolo GFP que permite levar quadros ou células com comprimentos variáveis como os quadros Ethernet. Muitas desvantagens da 
tecnologia ATM são superadas com a padronização da GPON, que, todavia, como não está baseado na tecnologia Ethernet ainda requer encapsulação adicional.

\subsection{Atividades do Grupo Ethernet in the First Mile}

O Ethernet é um protocolo desenvolvido para redes LAN que está conquistando as MANs e WANs. Por causa da grande quantidade de fornecedores de componentes Ethernet, a criação de redes baseados em Ethernet pode reduzir custos. Além disso, as aplicações se voltam para IP: VoIP, crescimento de tráfego Internet, aumento na popularidade de jogos on-line e assim por diante. Dessa forma, a conversão de formato de dados IP no ambiente Ethernet aumenta o desempenho da transmissão, além de reduzir custos.

Sob esse enfoque o Institute of Electrical and Electronics Engineers (IEEE), dentro do grupo de trabalho IEEE 802.3 CSMA/CD ${ }^{11}$, realizou uma reunião em novembro de 2000 que objetivou a padronização de arquiteturas em rede metálica e fibra óptica nas topologias ponto-aponto e ponto-multiponto, para a convergência em uma estrutura de serviço Ethernet. Em julho de 2001 o IEEE aprovou oficialmente o pedido de autorização de instalação do grupo de estudo, sendo então criada a IEEE 802.3ah EFM $^{12}$ Task Force.

Os trabalhos do grupo EFM para a arquitetura fibra óptica na topologia pontomultiponto foram direcionados para a padronização de uma rede óptica baseada na tecnologia Ethernet, focados na otimização do protocolo; nos mecanismos OAM para monitoração da rede, localização de possíveis falhas e na determinação das suas condições; e em sua interoperabilidade, cujo documento foi aprovado em junho de 2004 [30-35].

\subsection{Conceito de Ethernet-PON}

O grupo FSAN definiu em 1995, através da recomendação ITU G.983, uma rede óptica de acesso utilizando o ATM como seu protocolo de nível 2. Como a tecnologia ATM é uma tecnologia de rede multisserviço, esperava-se que esta tecnologia prevaleceria nas redes LAN, Metropolitan Area Network (MAN) e no backbone. O que se observou, na realidade, foi a consolidação do domínio da tecnologia Ethernet, se tornando um padrão de fato ${ }^{13}$ e se

\footnotetext{
${ }^{11}$ CSMA-CD: Carrier Sense Multiple Access with Collision Detection.

${ }^{12}$ EFM: Ethernet in the First Mile.

13 Devido a interesses econômicos e a demora na aprovação de padrões, são elaboradas especificações que, sem ser gerados pelos órgãos oficiais, se impõem no mercado porque os usuários passam a usá-los em grande escala. Essas especificações são chamadas padrões de fato, e têm como exemplo maior a Request For Comments (RFC), dentre as quais estão todos os padrões da Internet.
} 
constituindo numa alternativa para uma rede de acesso otimizada de dados IP [17], [36]. Portanto, com a predominância do binômio IP / Ethernet, o uso da tecnologia Ethernet com a rede PON oferece a combinação que realiza um tratamento das informações de modo nativo com as redes Ethernet, sem a necessidade de camadas adicionais de protocolo para a extensão dessas redes até o usuário final, seja ele residencial ou corporativo.

Um exemplo de formato do quadro EPON é apresentado na Figura 13, com base na estrutura dos quadros 802.3 (Ethernet), ressaltando que o grupo IEEE 802.3ah desenvolveu trabalhos possibilitando, no futuro, a coexistência de múltiplos valores de cabeçalho dos quadros EPON, em função das diferentes possibilidades de configuração de parâmetros [37]. O quadro EPON se inicia com um preâmbulo de 7 bytes - propriedade comum a todas as redes Ethernet, constituído de um campo Logical Link Identification (LLID) de 2 bytes, contendo a identificação de uma ONU e do $\mathrm{CRC}$, conhecido como código polinomial com 1 byte para detecção de erros [37-38]. Em seguida, o quadro contém dois endereços, um para o destino e um para a origem, cada um com 6 bytes, um campo para informação do número de bytes existentes no campo de dados, um campo Opcode para inserção de códigos específicos de mensagens que são trocados entre OLT e ONUs: GATE, REPORT, REGISTER REQ, REGISTER e REGISTER $\mathrm{ACK}^{14}$, e os campos de sincronização, de dados e finalmente a verificação de erro de quadro (Frame Error Check - FEC) [21], [38].

\section{\begin{tabular}{|l|l|l|l|l|l|l|l|l|}
\hline LLID(2) & CRC(1) & MAC DA(6) & MAC SA(6) & Type 88-09 & Opcode(2) & Timestamp(4) & Message(40) & FEC(4) \\
\hline
\end{tabular}
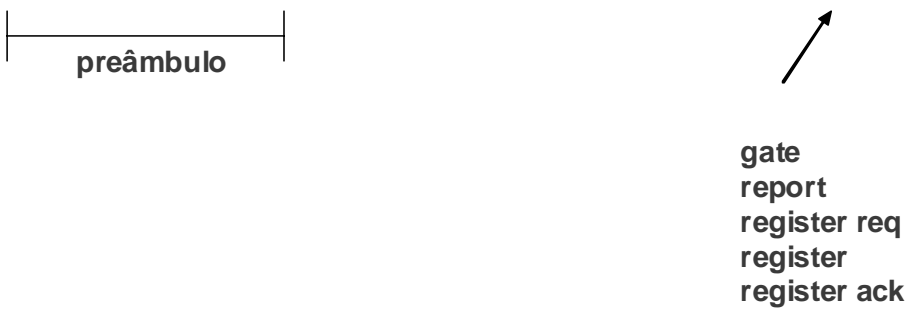

Figura 13 - Exemplo de formato de quadro EPON

As mensagens codificadas no campo Opcode têm os seguintes objetivos: GATE contêm informações que representam os períodos no qual a ONU pode transmitir; REPORT relata a informação local de cada ONU; enquanto REGISTER REQUEST, REGISTER e REGISTER ACK são utilizadas para reconhecer a presença ou a ausência de uma ONU, registrar e negociar parâmetros [32].

\footnotetext{
${ }^{14}$ ACK: Acknowledge.
} 
Convém acrescentar que a tecnologia EPON utiliza um mecanismo baseado em TDMA, chamado Multi-Point Control Protocol (MPCP), definido como uma função residente na subcamada de controle Medium Access Control (MAC). De fato, os protocolos que determinam aqueles que tem direito ao uso de um canal de difusão ou de multiacesso, pertencem à subcamada do nível de enlace de dados, assim denominada subcamada MAC [21], [38]. Desta forma, por intermédio do protocolo MPCP, o OLT se comunica individualmente com cada ONU, na topologia ponto-multiponto, através da emulação de um caminho ponto a ponto único, modificando os dois bytes no campo LLID, inserido no preâmbulo de cada quadro EPON [21]. $\mathrm{Na}$ verdade, cada ONU recebe todos os pacotes, lê os bytes do campo LLID para extrair os quadros Ethernet direcionados para seu respectivo usuário e descarta o restante do quadro EPON. O MPCP usa mensagens como GATE e REPORT, análise das ONUs e medidas de tempo para controlar o acesso numa topologia ponto-multiponto, propiciando auto-análise das ONUs, estabelecimento de ranging e pedidos de largura de banda. A Figura 14 ilustra o processo de ranging onde cada ONU recebe uma mensagem GATE do OLT, no formato de quadros de 64 bytes no sentido downstream, e envia uma mensagem REPORT, responsável pela informação local de cada ONU, na direção upstream ao OLT no seu específico time slot. Observa-se que apenas uma mensagem GATE e uma mensagem REPORT são intercambiados entre cada ONU e OLT em um ciclo temporal [30], [32], [37].

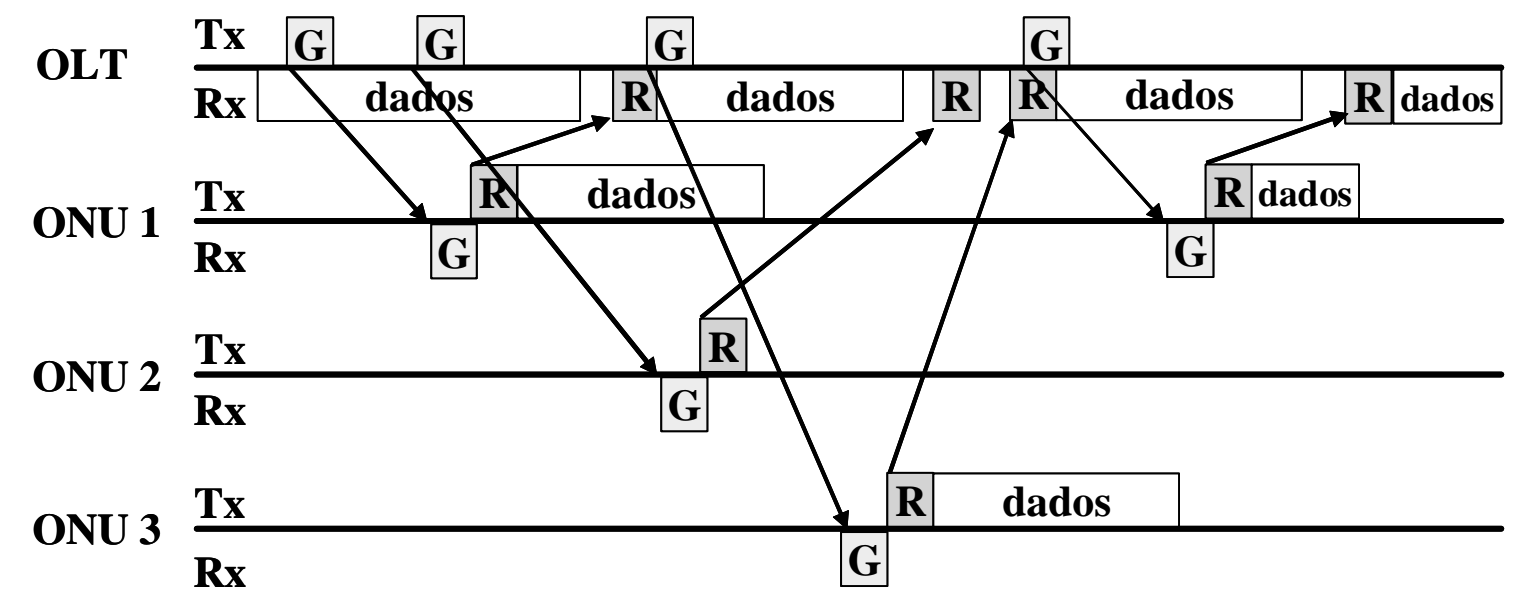

Figura 14 - Processo de ranging caracterizando troca de mensagens

No sentido downstream, os quadros Ethernet transmitidos pelo OLT passam por um elemento divisor passivo 1:N e alcançam cada uma das ONUs, sendo que as taxas de divisão estão situadas em uma faixa de valores limitados de 4 a 64 . Devido à rede Ethernet possuir característica do tipo difusão dos sinais (broadcasting), os pacotes são enviados pelo OLT e extraídos na respectiva ONU, com base no endereçamento do controle do acesso ao meio MAC (vide Figura 15). O modo de operação dos quadros é similar ao das tecnologias PON citadas 
anteriormente nesta dissertação, com exceção do tamanho variável dos quadros, em contraposição às células ATM de comprimento fixo.

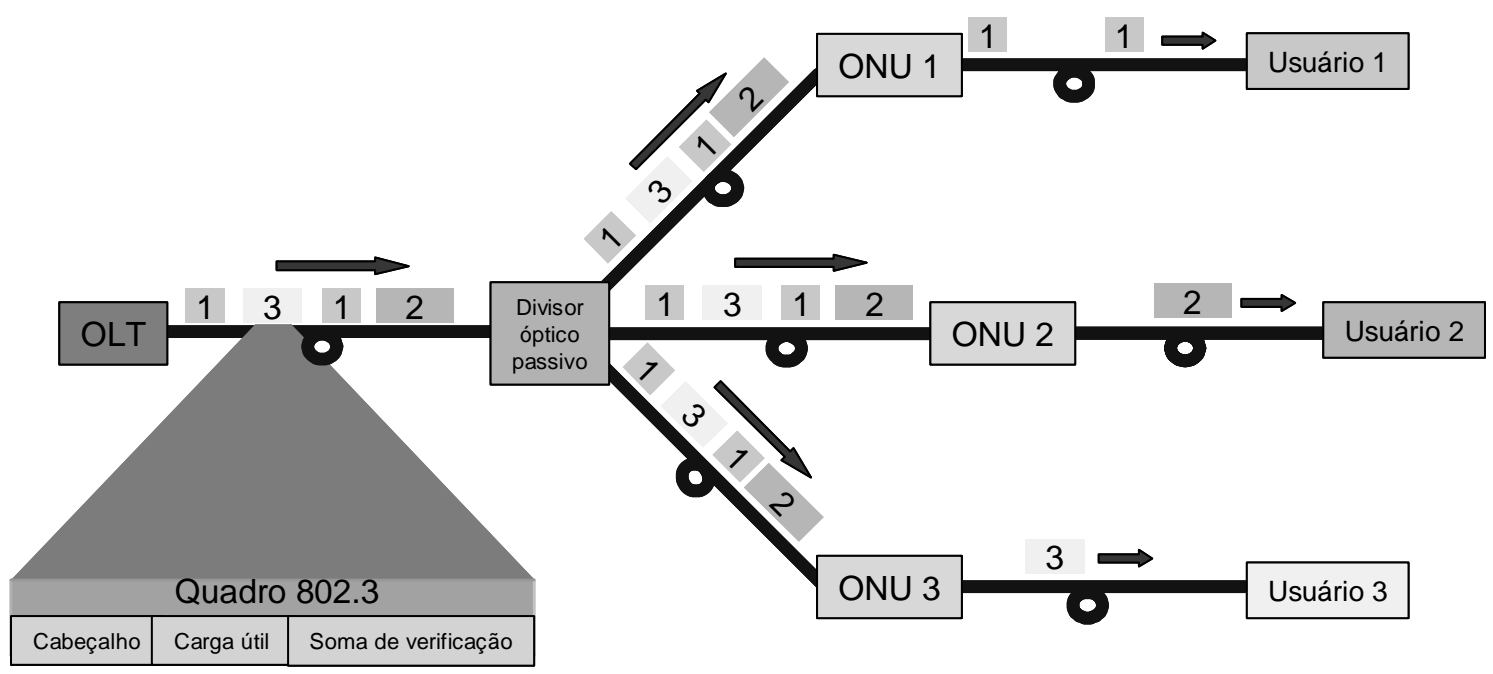

Figura 15 - Tráfego downstream na tecnologia EPON

No sentido upstream, os dados encapsulados nos quadros provenientes de qualquer das ONUs interligadas pela EPON alcançarão o OLT e não serão encaminhados às outras ONUs, uma vez que as propriedades direcionais do divisor óptico passivo propiciam um comportamento da rede com uma arquitetura ponto a ponto.

Devido à característica inerente ao sistema, as ONUs compartilham a capacidade e os recursos do canal da fibra óptica, facilitando a ocorrência de colisões dos quadros em uma rede EPON e a conseqüente perda da informação, caso diferentes ONUs transmitam quadros simultaneamente. Os estudos do grupo IEEE 802.3ah indicaram que uma dos possíveis soluções desse problema seria a separação de canais com uso da técnica WDM, por exemplo, através de um OLT equipado com receptor sintonizável ou um conjunto de receptores para os múltiplos canais, e de ONUs diferenciadas para cada comprimento de onda do transmissor [17], [21].

Neste caso, estudos sobre receptores ópticos para redes PON, realizados no Departamento de Engenharia Elétrica da Universidade de São Paulo, baseadas na técnica WDM, indicam que o OLT pode ter multiplexação/demultiplexação fixa, mas as ONUs devem ter demultiplexação sintonizável, seja através de filtros ópticos ou por meio do esquema da Figura 16, ou seja, demultiplexação fixa dos comprimentos de onda e seleção eletrônica do comprimento de onda desejado. Uma vez adotada esta última alternativa, não será necessária a utilização de diferentes tipos de ONUs na rede PON [39]. 


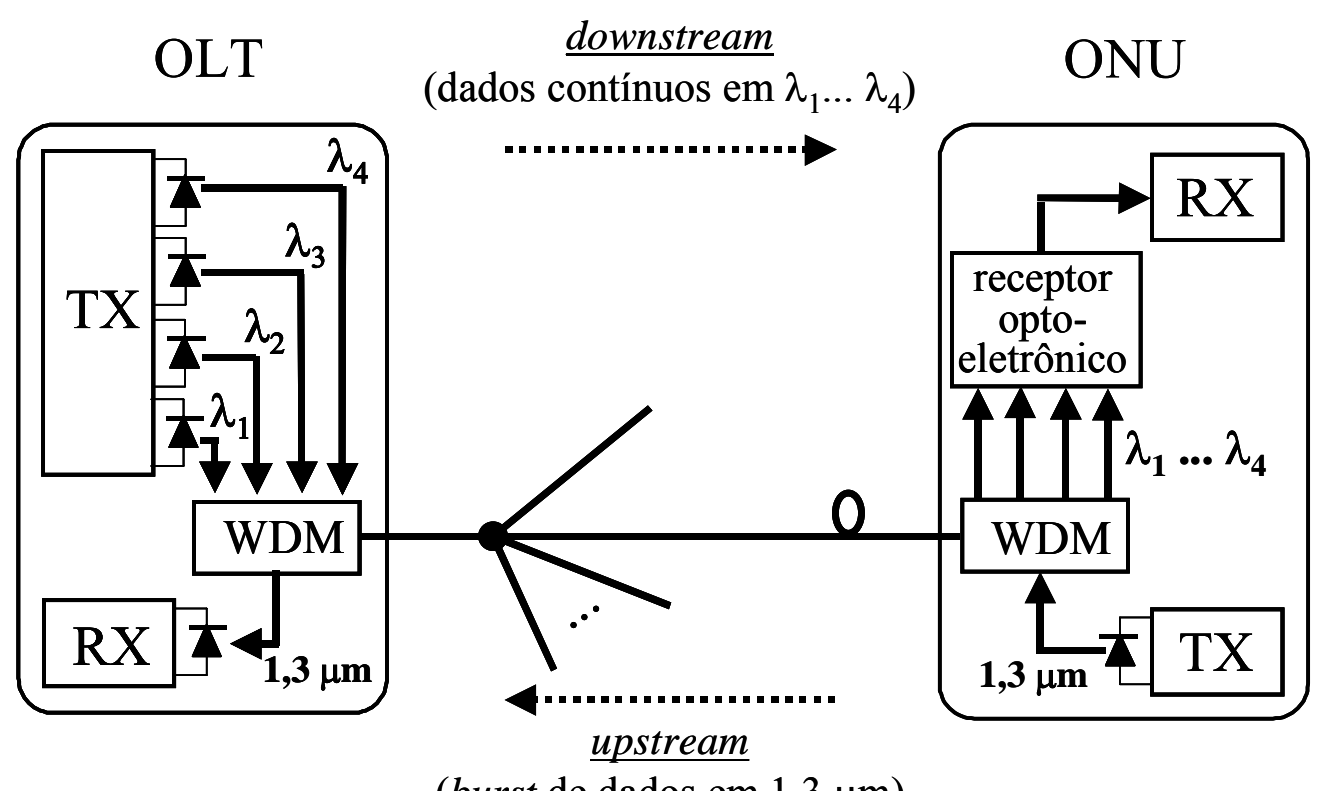

Figura 16 - Configuração de PON com uso da técnica WDM e um único tipo de ONU

Uma outra possibilidade seria o acesso ao meio com base na técnica de contenção ${ }^{15}$, uma técnica similar ao CSMA/CD, mas de difícil implementação porque as ONUs não conseguem detectar colisão no OLT, devido às propriedades direcionais do divisor óptico passivo. Um OLT poderia detectar uma colisão e informar as ONUs. Porém, devido ao comprimento da rede, que pode exceder $20 \mathrm{~km}$, a eficiência dessa técnica seria reduzida. Além disso, métodos baseados em contenção têm a desvantagem de fornecer serviços não determinísticos, o que seria inadequado aos serviços em tempo real, isto é, resulta uma rede de acesso incapaz de oferecer, além de dados, serviços de voz e de vídeo.

Finalmente, os estudos realizados pelo grupo IEEE apresentam o método indicado na Figura 17, onde todas as ONUs são sincronizadas com uma mesma base de tempo, e a cada ONU é designado um time slot específico, para transportar diversos quadros Ethernet. Nesse sentido, uma ONU retem os quadros recebidos de um usuário até o momento do seu respectivo time slot. No seu intervalo de tempo específico essa ONU encaminha para o OLT todos os quadros até então retidos, na taxa do padrão Ethernet estabelecida para o canal. Ressalta-se que, na ausência de dados a serem enviados dentro da determinada janela de tempo, são transmitidos quadros vazios.

\footnotetext{
${ }^{15}$ Numa rede baseada em contenção não existe uma ordem de acesso e nada impede que dois ou mais nós transmitam simultaneamente provocando uma colisão e, conseqüentemente, a perda de todas as mensagens.
} 


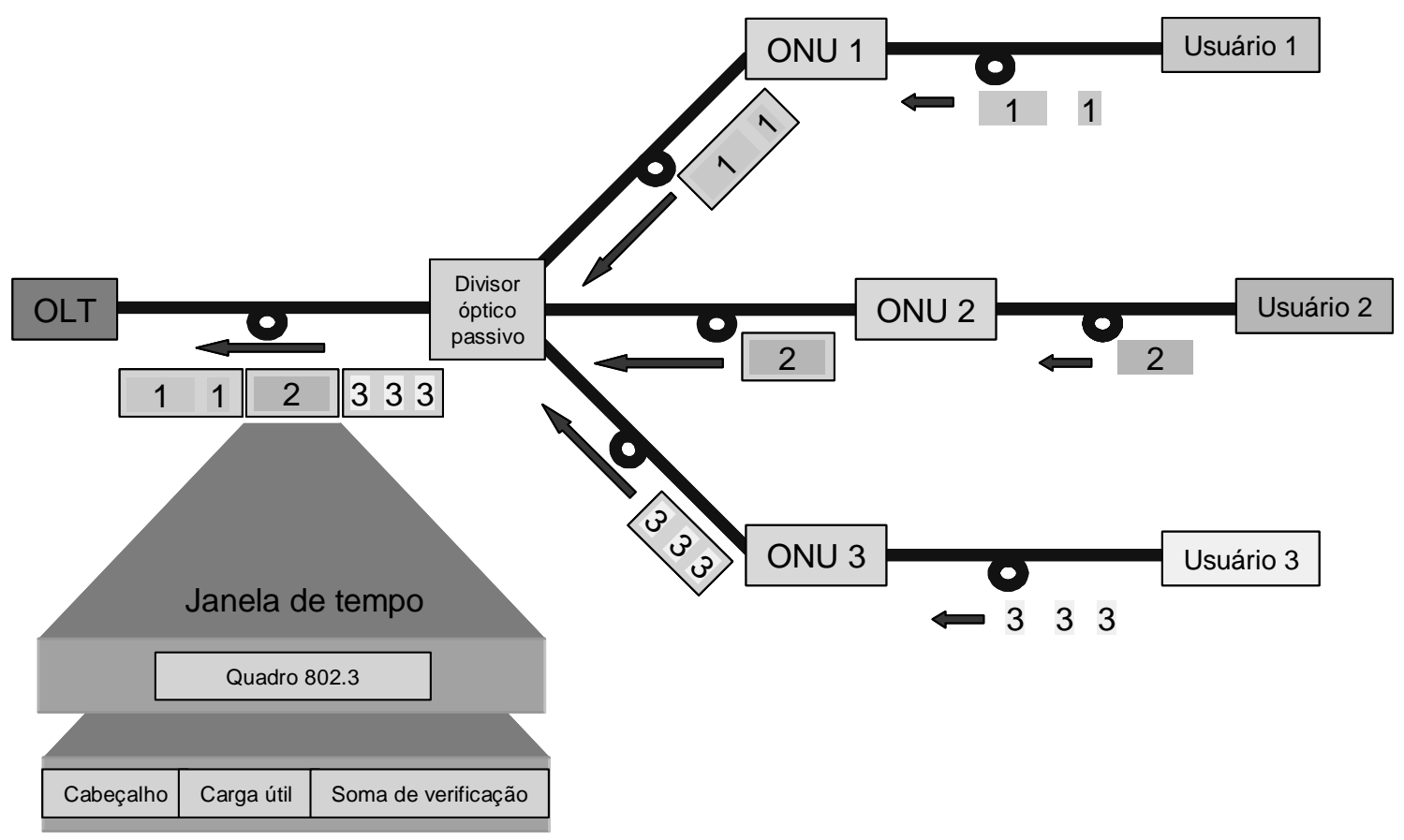

Figura 17 - Tráfego upstream na tecnologia EPON

Os estudos realizados pelo grupo do IEEE para o sistema de alocação da janela de tempo, abrangem desde alocação estática como o TDMA, até métodos de adaptação dinâmica baseado em ajustes instantâneos do tamanho da fila para cada ONU, empregando multiplexação estatística. Os estudos do IEEE analisam diversos esquemas possíveis de alocação, utilizando prioridade de tráfego, qualidade de serviço, Quality of Service (QoS), e acordos de nível de serviço, conhecidos como Service Level Agreement (SLA) [17], [21].

Uma alternativa debatida no grupo IEEE 802.3ah para aplicação na EPON é o padrão 802.1Q que, entre outras características, estabelece mecanismos de prioridade em um ambiente corporativo de LAN, que pode associar QoS às aplicações de voz e vídeo. O conceito de emulação de VLAN neste padrão é apresentado a seguir [40-41]: quatro bytes são adicionados a cada quadro Ethernet para fins de identificação de cada usuário VLAN, sendo 2 bytes para o campo Tag Protocol Identifier (TPI) e 2 bytes para o campo Tag Control Information (TCI). A estrutura do campo TCI está detalhada na Figura 18, com os campos Prioridade do Usuário, Canonical Format Indicator (CFI) e VLAN Identifier (VID). Os switches Ethernet analisam esses bytes e determinam onde os quadros devem ser entregues. Três bits dentre estes quatro bytes são utilizados para definir diferentes prioridades para os quadros Ethernet. A Figura 18 mostra os quadros Ethernet normal e o padrão 802.1Q. O cabeçalho 802.1Q contém um campo de prioridade de 3 bits, mostrando, dessa forma, que o 802.1Q permite oferecer prioridade do usuário [40-41]. 


\title{
Quadro Ethernet
}

\begin{tabular}{|c|c|c|c|c|c|c|}
\hline Preâmbulo:7 & $\begin{array}{c}\text { Início de } \\
\text { quadro:1 }\end{array}$ & $\begin{array}{c}\text { Endereço } \\
\text { destino:6 }\end{array}$ & $\begin{array}{c}\text { Endereço } \\
\text { origem:6 }\end{array}$ & $\begin{array}{c}\text { camponho } \\
\text { dados:2 }\end{array}$ & Dados 48-1500 & CRC:4 \\
\hline
\end{tabular}

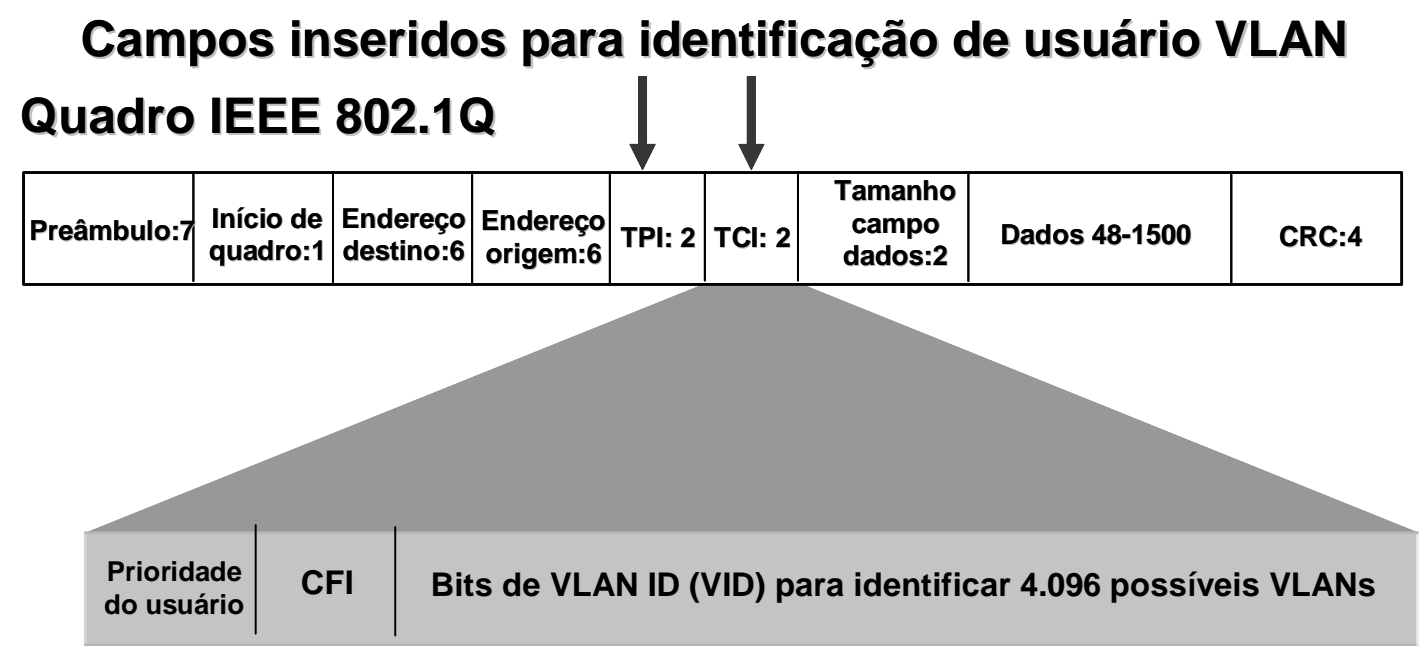

3 bits 1 bit

12 bits

\author{
CFI: Canonical Format Indicator \\ CRC: Código de Redundância Cíclica \\ QoS: Quality of Service \\ TCI: Tag Control Information \\ TPI: Tag Protocol Identifier \\ VLAN ID: Virtual Local Area Network Identifier
}

Figura 18 - Esquemático comparativo entre o quadro Ethernet e o padrão 802.1Q

Por outro lado, existe também o método de designação dinâmica de time slots, onde as ONUs decidem em que momento devem enviar seus dados. Neste método, antes do envio dos dados, cada ONU encaminha uma mensagem específica às outras ONUs, informando quantos bytes serão enviados, o que requer uma comunicação prévia entre as ONUs, resultando em topologias de PON com um maior grau de complexidade, incluindo a necessidade de mais fibras ópticas. Em contraposição, atribui-se ao OLT a condição de arbitrar o acesso por divisão de tempo, no canal compartilhado com as diversas ONUs. Dessa forma, mensagens de pedido ${ }^{16}$ são enviadas pelas ONUs ao OLT, com o status atual dessas ONUs, em diferentes janelas de tempo de transmissão alocadas para cada ONU pelo OLT. Tais informações são processadas pelo OLT que, desta forma, adquire o conhecimento do estado de toda a rede, e, com base nessa informação, pode decidir por um determinado esquema de alocação, cuja informação é

${ }^{16}$ O OLT ao receber um pedido de acesso de uma ONU, monta uma mensagem contendo a permissão (grant) que é enviada a ONU para a continuidade do diálogo. 
transmitida pelo OLT as ONUs através das mensagens de permissão ${ }^{17}$ (grants). Como resultado dessa simplificação, as ONUs não mais necessitam de comunicação entre si, tornando-se elementos mais simples e, conseqüentemente, a rede adquire um aspecto de maior robustez [17], [21].

Independentemente das condições do meio físico, isto é, do estado das fibras ópticas e dos elementos ópticos passivos (conectores e divisores ópticos), as diferentes distâncias entre o OLT e as ONUs produzem diferentes valores de atenuação do sinal óptico associado a cada ONU, resultando num prejuízo na recepção desses sinais no OLT, principalmente no que se refere às ONUs situadas em pontos mais distantes. A Figura 19 representa qualitativamente os valores do nível de potência do sinal óptico recebidos pelo OLT, com a localização da ONU A numa posição mais distante do OLT do que a ONU C, e esta mais distante do que a ONU B.

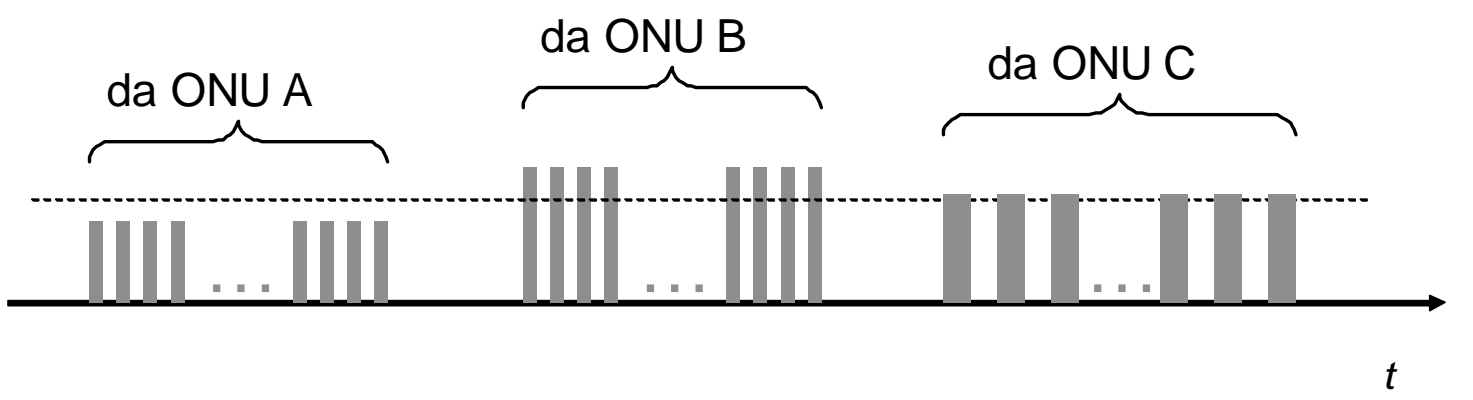

Figura 19 - Situação comparativa dos sinais ópticos recebidos pelo OLT

Uma forma de minimizar este problema é o ajuste do transmissor de cada ONU, de tal modo que o nível de potência dos sinais recebidos pelo OLT seja o mesmo para todas as ONUs. Esse procedimento implica num aumento do investimento no hardware da $\mathrm{ONU}$, agregado à necessidade de um protocolo de sinalização de retorno do OLT para cada ONU. Destaca-se uma possível degradação no desempenho das ONUs, em função desse ajuste dos transmissores tomando-se por base a ONU mais distante do OLT. Uma condição crítica ocorre com a geração do ruído de emissão espontânea dos lasers das ONUs localizadas próximas ao OLT interferindo no sinal da ONU mais distante. Nesse sentido, os estudos apontam para uma outra vertente [17]: uma detecção dos sinais enviados por cada ONU implica que o receptor do OLT deve, no início de cada time slot, adequar rapidamente seu limiar para definição dos valores zero e um, ou seja, o receptor do OLT deve estar capacitado a operar no modo de transmissão em rajada (Burst Mode Transmission ou BM Transmission). Esse tipo de receptor seria obrigatório somente no OLT, pois os receptores das ONUs não necessitariam de adaptação prévia a rápidas mudanças

\footnotetext{
${ }^{17}$ Neste tipo de esquema de controle, somente a interface que possui a permissão em um determinado instante de tempo pode transmitir quadros.
} 
de valor de seus limiares, uma vez que existe apenas um OLT com posicionamento fixo para determinada ONU. Desse modo, os sinais ópticos recebidos pelo OLT estão representados na Figura 20, na condição de operação em modo rajada [17], [21].

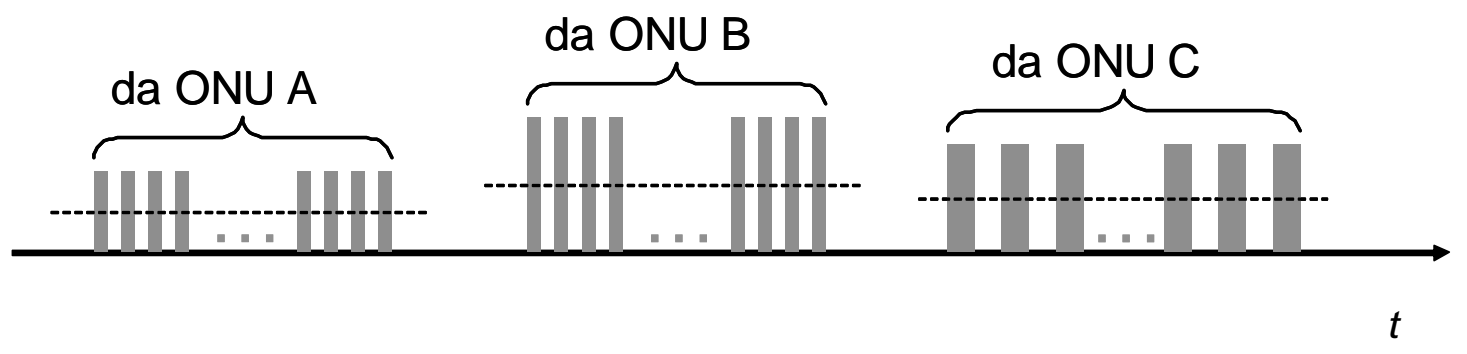

Figura 20 - Sinais ópticos recebidos pelo OLT operando no modo rajada

Numa comunicação ponto-a-ponto full-duplex Ethernet, a segurança não é um item crítico porque existem apenas 2 estações se comunicando através de um canal privativo. No caso da comunicação compartilhada half-duplex Ethernet, a questão da segurança é minimizada, pois os usuários pertencem a um único domínio e estão sujeitos a ele. Por outro lado, para a Ethernet ponto-multiponto a situação se torna mais complexa nos cenários abordados, isto é, um canal downstream do tipo broadcast que atende usuários que não pertencem a um grupo definido, como no caso da EPON. Uma vez que as ONUs, em princípio, não se comunicam entre si, uma ONU qualquer não tem conhecimento da informação das demais ONUs conectadas à mesma rede. Dessa forma, uma ONU modificada para um modo espião poderia obter sucesso na leitura de todos os pacotes enviados no sentido downstream, indicando, então, a necessidade de mecanismos de criptografia para o estabelecimento de mecanismos de segurança associados à transmissão das informações [17].

A Figura 21 ilustra um modelo típico de criptografia, onde a mensagem a ser criptografada está identificada através da expressão Texto simples $P$. Essa mensagem é transformada por uma função parametrizada através de uma Chave de criptografia $k$. Na saída do processo criptográfico temos o Texto cifrado $C$ a ser transmitido. Embora o intruso esteja inserido no cenário, caracterizado como intruso passivo para aquele agente que pode ouvir e até copiar o texto cifrado, ou intruso ativo em que o agente pode modificar uma mensagem legítima, existe a dificuldade do entendimento da mensagem, uma vez que o intruso desconhece a chave de decriptografia para decodificação do texto. Nenhum tipo de técnica afeita à criptografia (cifras de substituição, cifras de transposição, chaves criptográficas secretas e públicas, assinaturas digitais, autenticação dos dados, etc.) será descrita neste trabalho, limitamo-nos apenas e tão somente a compreender o que significa a criptografia e a discutir a posição desse tema na padronização da EPON [26], [38]. 


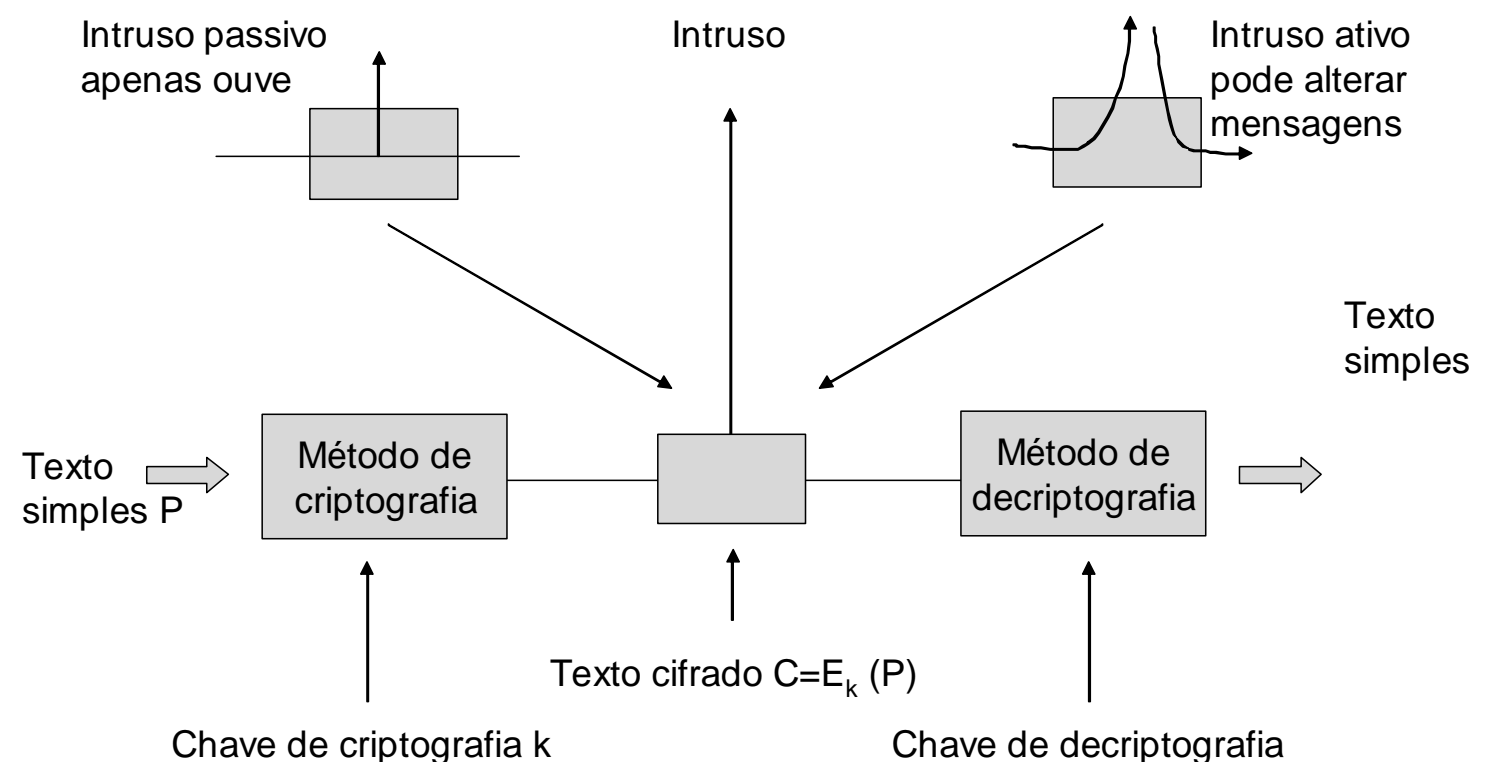

Figura 21 - Modelo típico de criptografia

Criptografia e decriptografia podem ser implementadas na camada física, na camada de dados ou nas camadas de mais alta hierarquia, sendo que as informações obtidas [17] indicam dois métodos propostos:

Criptografia a ser implementada na subcamada MAC codificará apenas a carga útil (payload) do quadro MAC. Desta maneira, a soma de verificação (checksum) será calculada para a carga útil codificada. A adoção desta proposta implica que a subcamada MAC verificará a integridade do quadro recebido antes de passar a carga útil à subcamada superior para decodificação. Esse método impede ONUs, que estejam no modo espião, de lerem a carga útil. Todavia, essas ONUs podem ainda ler endereços das outras ONUs;

Criptografia a ser implementada na camada física PHY, abaixo da subcamada MAC, se constituindo numa alternativa em que a camada PHY codificará toda a mensagem, inclusive o campo do cabeçalho. Desta forma, no final da recepção, a camada PHY decodificará os dados antes de passá-los para a camada MAC para verificação. Como as chaves de criptografia são diferentes para cada $\mathrm{ONU}$, as informações não destinadas à determinada ONU não serão decodificadas dentro do quadro formado e este será rejeitado pela camada MAC. Considera-se então, que nenhuma ONU poderá acessar os dados que não estão endereçados a ela [17].

É importante destacar que, quando se trata de discutir a migração de redes de comutação de circuitos TDM para pacotes IP, embora a rede de próxima geração denominada de NextGeneration Network (NGN) seja uma rede otimizada para o tráfego de dados IP, todos os equipamentos existentes, como por exemplo, STBs, aparelhos de TV analógica e equipamentos 
TDM, bem como os serviços legados, tais como T1, E1 ${ }^{18}$, RDSI, POTS e vídeo analógico, continuarão em uso. Pressupõe-se, então, que a padronização de uma EPON é capaz de prover tanto serviços baseados em IP quanto serviços legados, para o transporte de dados, voz e vídeo, usando técnicas de prioridade em lugar de QoS, emulação de VLAN e provisão de largura de banda.

Neste contexto, a implementação de um esquema de emulação de circuito sobre pacote está principalmente relacionada com a sincronização do relógio ${ }^{19}$. Os usuários fornecem um relógio as suas respectivas ONUs, que por sua vez entregam ao OLT. Como as ONUs não podem transmitir dados simultaneamente, a informação do relógio é enviada ao OLT nos pacotes. É normal, que no cenário da EPON, o OLT seja o relógio de referência para todos as ONUs. Nesse caso, elas recuperarão o relógio do canal receptor, utilizando-o em seu canal de transmissão, e distribuindo-o a todos os dispositivos conectados, como uma referência de relógio secundário [17].

Resumindo, uma rede EPON é projetada para o transporte de quadros no formato Ethernet em taxas do padrão Ethernet e que, sob o ponto de vista de arquitetura, realiza uma combinação de uma rede óptica passiva, constituída de uma infra-estrutura de fibras ópticas na topologia ponto multiponto, com o protocolo Ethernet, para transporte de tráfego IP na rede de acesso e, inclusive, na rede metropolitana [20-21].

\subsection{Avaliação das Tecnologias APON, GPON e EPON}

A tecnologia PON é especificada para conectar diversos usuários, através do acesso múltiplo no domínio do tempo, significando que cada transmissor localizado nos ONTs (lado do usuário) mantém uma comunicação constante com o receptor do OLT, e que por sua vez, controla a programação desse diálogo através do cartão de linha do OLT.

Um caso particular, a APON utiliza protocolos de comutação ATM para otimizar a transmissão de informação. Nessa perspectiva, o ATM é a tecnologia em que uma empresa operadora de telecomunicações encaminha os sinais digitais e garante os serviços de voz e dados, utilizando células de 53 bytes. Células que, devido ao seu tamanho fixo, possibilitam à tecnologia ATM impor garantias de qualidade de serviço em conversações telefônicas. Por outro lado, a garantia de qualidade do sinal de voz geralmente é mencionada como o principal motivo pelo qual uma rede ATM não é otimizada para o controle do tráfego de dados. Se um pacote de dados pudesse ser transmitido em sua forma nativa (Ethernet ou IP), os bytes

\footnotetext{
${ }^{18}$ E1: sinal tributário do SDH com taxa de 2,048 Mbps

19 Relógio é a referência de tempo utilizada em um sistema de transmissão para controle de certas funções, tais como controle da duração dos elementos de sinal e intervalo da amostragem.
} 
adicionais associados com a segmentação de pacotes do ATM não teriam que ser somados na carga total, e os dados seriam transmitidos com mais eficiência [42]. De toda forma, a APON oferece características OAM, incluindo monitoramento de taxas de BER, alarmes e indicações de problemas. A APON pode ser disposta de 2 formas: interligação a cada usuário através de duas fibras ópticas (uma para a direção upstream e a outra para downstream), ou com uma única fibra óptica utilizando a técnica de multiplexação por divisão de comprimento de onda, potencializando a fibra óptica por comprimentos de onda para dois ou mais canais. Desta forma, APON garante o uso de um canal para tráfego upstream, outro para tráfego downstream e um terceiro canal para serviços tipo broadcast. O protocolo APON opera diferentemente nas direções upstream e downstream. No sentido downstream, APON opera com taxas de transmissão de $155 \mathrm{Mbps}$ ou $622 \mathrm{Mbps}$ (as janelas são tipicamente $1490 \mathrm{~nm}$ ou $1550 \mathrm{~nm}$ ), correspondendo para cada taxa, respectivamente, 56 células (54 células ATM e 2 células PLOAM) ou 216 células de dados e 8 quadros PLOAM. Todos os receptores no sentido downstream recebem todas as células, descartando aquelas células que não são direcionadas a eles, baseado na informação de endereçamento ATM (VPI/VCI). Na direção upstream, a APON é padronizada apenas para taxa de $155 \mathrm{Mbps}$, com um comprimento de onda de $1310 \mathrm{~nm}$, e a transmissão é coordenada em sistema TDMA. Os transmissores são conectados para a transmissão através do recebimento de mensagens grant via células PLOAM. A tecnologia APON modifica o ATM na direção upstream e usa células de 56 bytes, com um cabeçalho adicional de 3 bytes para as funções de tempo de guarda, bits de preâmbulo e um delimitador antes do início das células ATM de 53 bytes. A sigla APON foi posteriormente rebatizada, pelo grupo FSAN, para BPON, advindo de Broadband PON, indicando que a tecnologia APON fornecia, aos usuários finais, outros serviços além dos tradicionais.

A GPON representa a evolução da APON, não sendo dependente direto da tecnologia ATM, pois insere um novo protocolo intermediário denominado GFP para encapsulação de células ATM, pacotes de dados e TDM [27]. Atualmente a especificação da GPON prevê alcance físico de até $20 \mathrm{~km}$ com taxas de transmissão $622 \mathrm{Mbps}$ simétrico, 1,25 Gbps simétrico e 2,5 Gbps downstream e 1,25 Gbps upstream assimétricos. Dessa forma, a tecnologia GPON não fragmenta os longos pacotes IP em células fixas de 53 bytes [23].

Em uma outra perspectiva, embora as configurações baseadas em tecnologia ATM ofereçam QoS e SLAs, com um sistema de gerenciamento para provisionar uma largura de banda fim-a-fim, é importante destacar que a maior parte das referências consultadas tende para a escolha de redes de comunicação IP ou redes baseadas no padrão Ethernet [9], [10], [17], [21], [23], [26], [30], [32-33], [37-38], [42].

A EPON é uma rede óptica passiva Ethernet e, por isso, seu protocolo é uma extensão da IEEE 802.3 operando em 1 Gbps com uma distância de até $20 \mathrm{~km}$. A EPON usa o mecanismo MPCP para transformar sua topologia ponto-multiponto numa topologia ponto-a- 
ponto, usando dois bytes do preâmbulo do pacote Ethernet, especificamente o campo LLID. Na direção downstream, cada ONT recebe todos os pacotes, examina o LLID para extrair os quadros Ethernet direcionados aos seus usuários, e descarta os demais quadros. Assim como nas tecnologias anteriores, a transmissão na direção upstream é baseada em TDMA. Periodicamente, o OLT transmite um quadro marcador, na direção downstream, para sincronização, definindo a locação da janela de envio de mensagens. As estações que necessitam transmitir para o OLT, negociam o envio dos dados através de pedidos de reconhecimento durante as janelas de envio de mensagens, e o início da transmissão efetiva se realiza com o envio do quadro GATE.

A Tabela 5 resume as principais características das três tecnologias PON e apresenta um comparativo das principais vantagens e desvantagens entre essas tecnologias. A tecnologia EPON concentra vantagens em todos os itens assinalados. 


\begin{tabular}{|c|c|c|c|}
\hline Itens & APON & GPON & EPON \\
\hline Especificação padronizada & $\begin{array}{l}\operatorname{sim} \\
(\text { ITU-T) }\end{array}$ & $\begin{array}{l}\operatorname{sim} \\
(\mathrm{ITU}-\mathrm{T})\end{array}$ & $\begin{array}{l}\operatorname{sim} \\
\text { (IEEE) }\end{array}$ \\
\hline Data da padronização & 1998 & 2003 & 2004 \\
\hline $\begin{array}{l}\text { Empresas que influenciam na } \\
\text { padronização }\end{array}$ & $\begin{array}{l}\text { provedores } \\
\text { de serviços }\end{array}$ & $\begin{array}{l}\text { provedores } \\
\text { de serviços }\end{array}$ & $\begin{array}{l}\text { fornecedores de } \\
\text { equipamentos }\end{array}$ \\
\hline Taxa de transmissão Gbps & $\begin{array}{l}\text { não } \\
\text { (155 / } 622 \text { Mbps })\end{array}$ & $\begin{array}{l}\operatorname{sim} \\
\text { (até 2,5 Gbps) }\end{array}$ & $\begin{array}{l}\operatorname{sim} \\
(1 \mathrm{Gbps})\end{array}$ \\
\hline Protocolo básico & ATM & ATM & Ethernet \\
\hline $\begin{array}{l}\text { Cabeçalho de protocolo } \\
\text { harmonizado com IP }\end{array}$ & não & não & $\operatorname{sim}$ \\
\hline Tipo de codificação & NRZ & NRZ & $8 \mathrm{~B} / 10 \mathrm{~B}$ \\
\hline Taxa de fracionamento & $1: 32$ & $1: 64$ & $1: 64$ \\
\hline Tecnologia de acesso & TDMA & TDMA & TDMA \\
\hline DBA & $\operatorname{sim}$ & $\operatorname{sim}$ & $\operatorname{sim}$ \\
\hline OAM & $\operatorname{sim}$ & $\operatorname{sim}$ & $\operatorname{sim}$ \\
\hline Segurança & $\operatorname{sim}$ & $\operatorname{sim}$ & $\operatorname{sim}$ \\
\hline Voz & $\operatorname{sim}$ & $\operatorname{sim}$ & $\operatorname{sim}$ \\
\hline QoS & sim & sim & $\operatorname{sim}$ \\
\hline
\end{tabular}

Tabela 5 - Comparativo das tecnologias APON, GPON e EPON

Convém quantificar a principal diferença entre as tecnologias EPON e APON no que se refere ao transporte de tráfego IP, onde os dados são segmentados em pacotes de comprimento variável de até 65.535 bytes. Na EPON, os dados são transmitidos em pacotes de comprimento variável de até 1.518 bytes obedecendo ao protocolo para Ethernet IEEE 802.3, enquanto que na APON os dados são transmitidos em células de comprimento fixo de 53 bytes, sendo 48 bytes de carga útil e 5 bytes de cabeçalho, como especificado pelo protocolo ATM. Em face do exposto, é possível afirmar que a tecnologia ATM estabelece uma taxa fixa de células sobre os pacotes de comprimento variável IP, indicando que para envio de uma mesma quantidade de 
dados em uma rede ATM, devido ao tamanho do cabeçalho, há necessidade de se transmitir mais bytes que numa rede Ethernet, o que se traduz em perda da eficiência [17].

A tecnologia Ethernet tem a vantagem de economia de escala e uma base instalada de equipamentos em usuários residenciais e corporativos, conforme pode ser observado nas Figuras 22 e 23. A Figura 22 mostra que até o ano de 2002 a nível mundial, existiam cerca de 100 milhões de portas Ethernet $10 \mathrm{Mbps}$, acima de 500 milhões de $100 \mathrm{Mbps}$ e acima de 50 milhões de portas 1 Gbps [43].

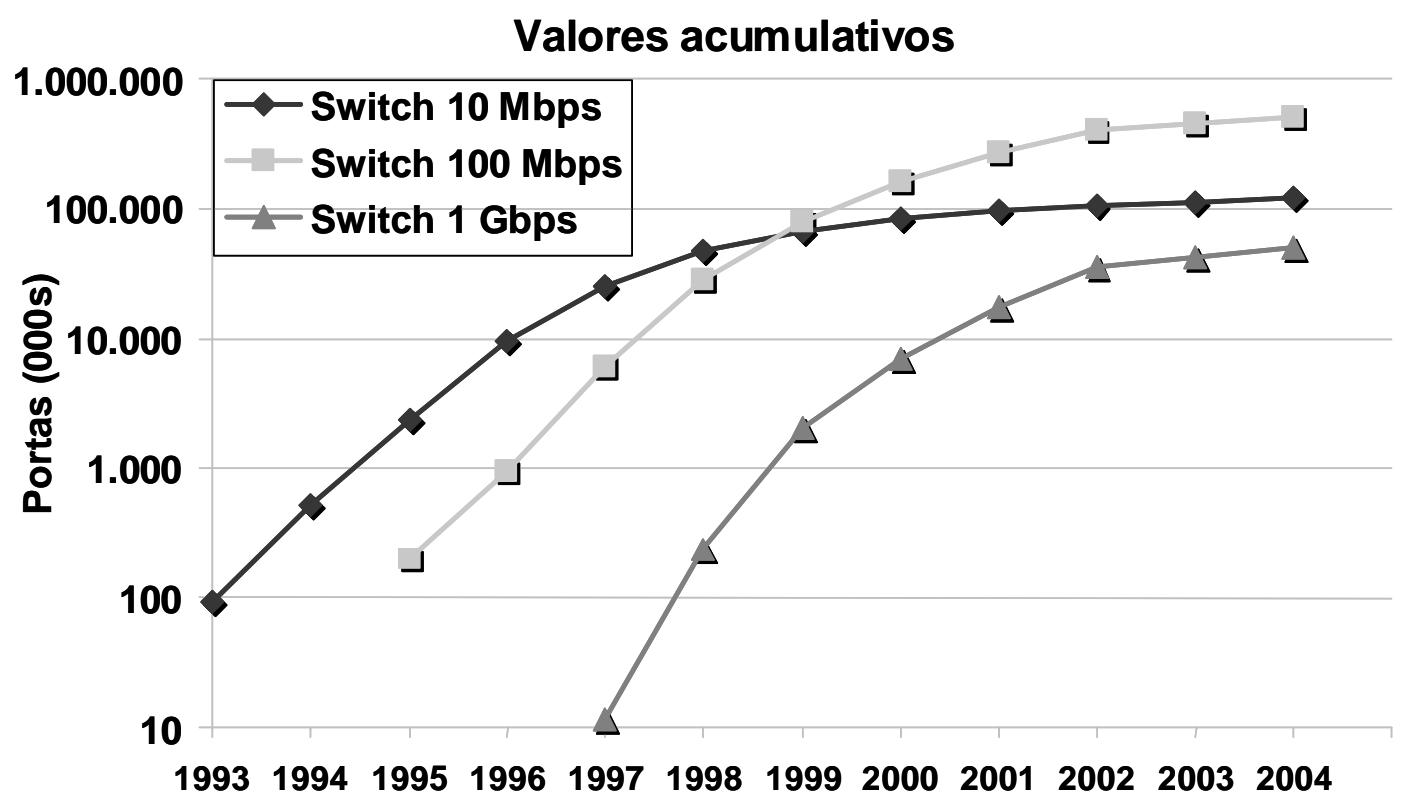

Fontes: Switched 10, Sw 100, Sw 1000: Third Party Analysts - Cisco 2002

Figura 22 - Mercado da tecnologia Ethernet em função do número de portas

A Figura 23 ilustra os custos comparativos entre as tecnologias ATM e Ethernet, por conexão e por taxa de transmissão, em Mbps [44]. Na análise dos custos por conexão, observase que as conexões Ethernet $10 \mathrm{Mbps}$ e $100 \mathrm{Mbps}$ ou Fast Ethernet tem custos muito inferiores em comparação com a conexão ATM 155 Mbps, e a tecnologia Ethernet 1000 Mbps, conhecida como Gigabit Ethernet $(\mathrm{GbE})$ tem custo superior a 6\% em comparação com a conexão ATM 155 Mbps. O comparativo de custo por Mbps aponta que a mais cara tecnologia é a Ethernet 10 Mbps, ao preço de US\$ 32,00, obviamente explicado pelo seu baixo valor de taxa em comparação com as outras tecnologias. No entanto, os custos por Mbps do ATM 155 Mbps e do ATM 622 Mbps, US\$25,00 e US\$ 10,00, representam, em comparação ao Ethernet 100 Mbps, que é US\$ 7,00, valores respectivamente $250 \%$ e $140 \%$ superiores. 


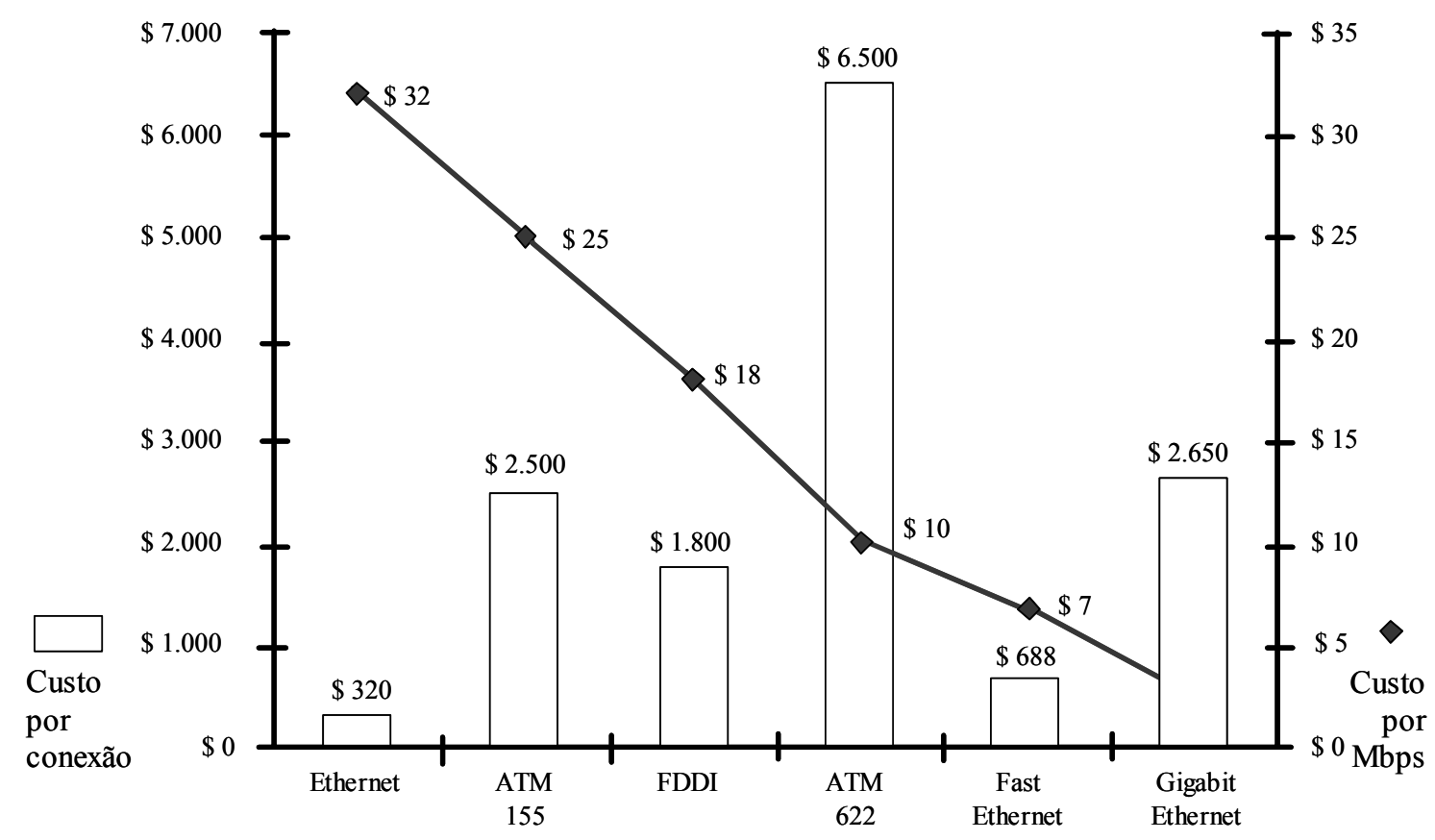

Fonte: 2000 ISEL - DEEC - RCD

Figura 23 - Análise comparativa de custos das tecnologias, por conexão e por Mbps

A GPON se configura como uma versão mais generalizada da APON, e embora não dependa diretamente da tecnologia ATM, requer um novo protocolo para realizar encapsulação adicional nos quadros. Além disso, não existe histórico de avaliação desse tipo de rede em testes de campo.

O comparativo entre as tecnologias APON, GPON e EPON permite considerar que, de modo geral, EPON é ideal para a rede de acesso de um câmpus, por exemplo, onde já existe rede Ethernet, enquanto que APON e GPON são, em princípio, propostas mais adequadas para acesso em redes de maior porte, como por exemplo, em empresas operadoras de telecomunicações que utilizam a tecnologia ATM. Todavia, convém destacar que a tecnologia Gigabit Ethernet começa a ser utilizada em empresas operadoras de telecomunicações, aqui no Brasil do porte da Telefonica e da Telemar. Neste caso, ressalta-se que, entre as redes Wide Area Network (WAN) / Local Area Network (LAN), não haveria mais necessidade de conversão entre os protocolos ATM e IP. Portanto, tornar-se-ia extremamente interessante escalar o padrão Ethernet como um todo, desde as conexões de $10 \mathrm{Mbps}$ dos computadores finais, para 100 Mbps nos concentradores intermediários e para 1000 Mbps no backbone central, associado com a tecnologia EPON na rede de acesso, possibilitando uma composição mais atraente em termos de custo e facilidade de migração, satisfazendo as exigências de banda passante, estabelecendo em breve prioridade de tráfego, através da utilização do padrão $802.1 \mathrm{Q}$, e oferecendo qualidade de serviço necessária às aplicações multimídia. 


\section{PROJETO E DIMENSIONAMENTO DA REDE}

\subsection{Considerações iniciais}

A Universidade de São Paulo (USP), na cidade de São Carlos, ocupa uma área territorial de $575.060 \mathrm{~m}^{2}$, ao longo do qual se erguem $84.597 \mathrm{~m}^{2}$ de instalações. Integram-no a Escola de Engenharia de São Carlos (EESC), o Instituto de Ciências Matemáticas e de Computação (ICMC), o Instituto de Física de São Carlos (IFSC) e o Instituto de Química de São Carlos (IQSC), além do Centro de Informática de São Carlos (CISC) e da Prefeitura do Campus Administrativo de São Carlos (PCASC) [45].

O projeto aqui apresentado, denominado EPON I, utiliza um anel óptico instalado no campus universitário, constituído por um cabo de fibras ópticas monomodo, com extensão aproximada de $1,5 \mathrm{~km}$, que interliga os principais prédios acadêmicos. Todo projeto está baseado em informações obtidas da Seção de Redes do CISC. Considera-se que 240 terminais poderão ser atendidos pela rede EPON proposta na configuração FTTB.

\subsection{Cálculo da largura de banda}

A largura de banda disponível, em cada ponto de terminação da rede, foi determinada com base nas seguintes premissas:

- Largura de banda de 1 Gbps para o OLT;

- Fracionamento 1:4 dos divisores ópticos inseridos no caminho óptico;

- 24 pontos de terminação para cada ONU.

A largura de banda assegurada, na saída de cada divisor óptico passivo, é de 250 Mbps:

$$
\frac{1000 \text { Mbps }}{4 \text { canais }}=250 \text { Mbps }
$$

Partindo do pressuposto que todos os 24 pontos de terminação da rede estão em operação, temos uma largura de banda mínima por terminal de 10 Mbps:

$$
\frac{250 \mathrm{Mbps}}{24 \text { termínais }}=10,42 \mathrm{Mbps}
$$


Uma largura de banda de $10 \mathrm{Mbps,} \mathrm{por} \mathrm{ponto} \mathrm{de} \mathrm{terminação} \mathrm{de} \mathrm{rede,} \mathrm{satisfaz} \mathrm{a} \mathrm{todas}$ aplicações indicadas na Figura 2, considerando inclusive serviços de vídeo e TV digital que necessitam de taxas de transmissão adequadas de 1 Mbps até 8 Mbps.

\subsection{Cálculo de balanço de potência}

O cálculo total de atenuação máxima óptica, que deve atender às exigências de potência média disponível no transmissor e da sensitividade do receptor, mantendo a transmissão dentro da taxa de erro admissível, requer conhecimento dos seguintes parâmetros do sistema:

- Coeficiente de atenuação do cabo óptico $(\mathrm{dB} / \mathrm{km})$ no comprimento de onda de operação;

- Atenuação máxima das emendas por fusão;

- Atenuação máxima dos conectores;

- Atenuação máxima dos divisores ópticos passivos;

- Potência de saída de transmissão;

- Sensitividade do receptor.

Os valores adequados para a fibra óptica monomodo e para os componentes passivos ópticos, apresentados na Tabela 6, estão baseados no estudo da IEEE EFM Study Group, da reunião plenária ocorrida na cidade de Portland, estado de Oregon, nos Estados Unidos, no período de 10 a 12 de julho de 2001, e na especificação de divisores ópticos passivos da empresa Tyco [46-47]. 


\begin{tabular}{|l||l|}
\hline \multicolumn{1}{|c||}{ Item } & \multicolumn{1}{c|}{ Tipo ou Valor } \\
\hline \hline Tipo de fibra óptica & Monomodo \\
\hline Coeficiente de atenuação para o comprimento de onda $1310 \mathrm{~nm}$ & $0,5 \mathrm{~dB} / \mathrm{km}$ \\
\hline Coeficiente de atenuação para o comprimento de onda $1550 \mathrm{~nm}$ & $0,3 \mathrm{~dB} / \mathrm{km}$ \\
\hline Tipo de fonte laser & DFB \\
\hline Tipo de detector & PIN \\
\hline Atenuação máxima no divisor óptico passivo 1:4 & $7,0 \mathrm{~dB}$ \\
\hline Atenuação máxima no divisor óptico passivo $1: 8$ & $10,0 \mathrm{~dB}$ \\
\hline Atenuação máxima no divisor óptico passivo $1: 16$ & $14,3 \mathrm{~dB}$ \\
\hline Atenuação máxima no divisor óptico passivo $1: 32$ & $17,0 \mathrm{~dB}$ \\
\hline Atenuação máxima no conector & $0,5 \mathrm{~dB}$ \\
\hline Atenuação máxima no ponto de emenda por fusão & $0,1 \mathrm{~dB}$ \\
\hline
\end{tabular}

Tabela 6 - Características admissíveis para componentes passivos da rede EPON

O padrão EFM 802.3ah normatizou o uso de transceptores, incluindo 1000BASE-PX10 (versão $10 \mathrm{~km}$ ) para balanço de potência óptica de $21 \mathrm{~dB}$, e 1000BASE-PX20 (versão $20 \mathrm{~km}$ ) para balanço de potência óptica de $26 \mathrm{~dB}$ [35]. Consideramos, no cálculo aqui apresentado, a utilização de transceptores 1000BASE-PX20. Desta forma, garantimos o funcionamento do sistema proposto no projeto e viabilizamos sua expansão.

A Tabela 7 ilustra o cálculo das perdas do sinal óptico no projeto e a avaliação do desempenho do sistema, desde o OLT até a ONU, para uma configuração de perdas máximas, de acordo com as seguintes premissas [35], [46-47]:

- Taxa de erro de bit $(\mathrm{BER})=10^{-12}$;

- Os cálculos de balanço de potência são os mesmos para downstream e upstream;

- Potência média de transmissão ${ }^{20}=-4 \mathrm{dBm}$;

- Sensitividade do receptor ${ }^{21}$ operando a 1,25 Gbps para um comprimento de onda de $1310 \mathrm{~nm}=-26 \mathrm{dBm}$;

- Comprimentos de onda ${ }^{21}=$ bidirecional $1310 \mathrm{~nm} \mathrm{Rx}$ e $1490 \mathrm{~nm} \mathrm{Tx}$;

- Comprimento máximo estimado do cabo óptico =1,5 km;

- Taxa de fracionamento 1:4, porém este cálculo admite a taxa máxima de fracionamento de 2 divisores ópticos passivos (1:4 e 1:8)=1:32;

${ }^{20}$ Especificação Tx do transceptor ONU de fabricação Zonu

${ }^{21}$ Especificação Rx do transceptor OLT de fabricação Zonu 
- Número de conectores (um para cada cordão óptico distribuídos da seguinte forma: saída do OLT e entrada da ONU) = 2 unidades;

- Número de emendas por fusão na fibra óptica (uma para cada emenda do cordão óptico; na entrada e saída de 2 divisores ópticos passivos) $=6$ unidades.

Como pode ser observado na Tabela 7, as perdas que os equipamentos da rede EPON suportam, determinadas pela potência média do transmissor e pela sensitividade do receptor, estão estimadas em $22,00 \mathrm{~dB}$. O cálculo da atenuação máxima referente à fração passiva do sistema (somatória da perda estimada em 1,5 km de fibra óptica, 2 conectores, 6 emendas por fusão e dois divisores ópticos passivos) está totalizado em 19,35 dB.

O valor de 2,65 $\mathrm{dB}$ para a margem de desempenho do sistema, obtido através da diferença entre o total das perdas suportadas pelos equipamentos e o total da atenuação do sistema, indica que o sistema irá operar corretamente na taxa de fracionamento máxima de 1:32, pois o valor das perdas suportadas pelos equipamentos é superior ao valor da atenuação máxima do sistema passivo. Essa margem de desempenho do sistema pode ser utilizada para superar outras perdas eventuais, assegurando à conexão manter a taxa de erro de bit requerida de $10^{-12}$.

\begin{tabular}{|c|c|c|c|}
\hline \multirow{2}{*}{$\begin{array}{l}\text { Cálculo das perdas que } \\
\text { os equipamentos } \\
\text { suportam }\end{array}$} & $\begin{array}{l}\text { Potência média do transmissor } \\
\text { Sensitividade do receptor }\end{array}$ & - & $\begin{array}{r}-4,00 \mathrm{dBm} \\
-26,00 \mathrm{dBm}\end{array}$ \\
\hline & Perdas suportadas pelos equipamentos & & $22,00 \mathrm{~dB}$ \\
\hline \multirow{5}{*}{$\begin{array}{l}\text { Cálculo da atenuação } \\
\text { do sistema }\end{array}$} & Fibra óptica $(1,5 \mathrm{~km} \times 0,5 \mathrm{~dB} / \mathrm{km})$ & \multirow{4}{*}{+} & $0,75 \mathrm{~dB}$ \\
\hline & Conector (2 un x 0,5 dB/un) & & $1,00 \mathrm{~dB}$ \\
\hline & Emenda por fusão ( 6 un x $0,1 \mathrm{~dB} / \mathrm{un}$ ) & & $0,60 \mathrm{~dB}$ \\
\hline & Divisores ópticos $(7,0 \mathrm{~dB}+10,0 \mathrm{~dB})$ & & $17,00 \mathrm{~dB}$ \\
\hline & Total da atenuação do sistema & & $19,35 \mathrm{~dB}$ \\
\hline \multirow{3}{*}{$\begin{array}{l}\text { Cálculo da margem de } \\
\text { desempenho do sistema }\end{array}$} & Perdas suportadas pelos equipamentos & & $22,00 \mathrm{~dB}$ \\
\hline & Total da atenuação do sistema & & $19,35 \mathrm{~dB}$ \\
\hline & Margem de desempenho do sistema & \multicolumn{2}{|r|}{$2,65 \mathrm{~dB}$} \\
\hline
\end{tabular}

Tabela 7 - Cálculo da margem de desempenho do sistema 


\subsection{Representações esquemáticas}

A rede primária deste projeto aproveita três fibras ópticas do anel existente de 12 fibras ópticas monomodo, enquanto a rede secundária é constituída de novos cabos de fibras ópticas. Três OLTs e dez ONUs interligadas por fibras ópticas na topologia estrela simples e na configuração ponto-multiponto, através de componentes passivos, para ramificação da rede, completam o projeto, para atendimento a 240 pontos de terminação da rede.

Para cada fibra óptica está prevista uma divisão do sinal óptico, através de um divisor óptico passivo simétrico a ser instalado em um ponto de intersecção do anel de fibra óptica existente. O projeto não prevê redundância pelas fibras ópticas não utilizadas do anel existente.

Os pontos previstos para instalação de divisores ópticos passivos devem ser localizados nas caixas de distribuição do câmpus, próximos das dependências do Departamento de Engenharia Mecânica (SEM), Centro de Informática de São Carlos (CISC) e IQSC. Cada divisor óptico passivo deve estar acomodado e protegido no interior de uma caixa de emenda óptica principal (CEP). Cada uma das ramificações secundárias prevê uma interligação com uma ONU.

A rota do projeto EPON I indica a localização dos divisores ópticos passivos, nas caixas de distribuição do câmpus e das ONUs nos edifícios acadêmicos e administrativos.

O projeto EPON I considera a instalação de ONUs nos seguintes pontos:

- Primeiro divisor óptico passivo: ONU 1 no Departamento de Física e Informática (FFI), ONU 2 no Departamento de Física e Ciência dos Materiais (FCM), ONU 3 no Departamento de Engenharia Mecânica (SEM) e ONU 4 no Departamento de Engenharia Elétrica (SEL);

- Segundo divisor óptico passivo: ONU 5 no CISC, ONU 6 no Edifício Informática do ICMC, ONU 7 na Biblioteca Central e ONU 8 no Centro Acadêmico Armando Salles Oliveira (CAASO);

- Terceiro divisor óptico passivo: ONU 9 no Departamento de Físico-Química (DFQ) e ONU 10 no Departamento de Química e Física Molecular (DQFM).

Os pontos de terminação da EPON I, para acesso dos usuários, estão relacionados na Tabela 8. 


\begin{tabular}{|c|c|c|}
\hline Divisor & $\overline{\mathrm{ONU}}$ & 24 pontos de terminação da rede por ONU \\
\hline \multirow{4}{*}{ \# 1: SPL 1} & \#\# 1: FFI & $\begin{array}{l}1 \text { edifício, } 19 \text { laboratórios, } 1 \text { secretaria, } 2 \text { salas de apoio, } 1 \text { núcleo } \\
\text { estudantil }\end{array}$ \\
\hline & \#2: FCM & $\begin{array}{l}1 \text { edifício, } 16 \text { laboratórios, } 1 \text { biblioteca, } 1 \text { secretaria, } 4 \text { salas de } \\
\text { apoio, } 1 \text { núcleo estudantil }\end{array}$ \\
\hline & \# 3: SEM & $\begin{array}{l}1 \text { edifício, } 16 \text { laboratórios, } 2 \text { secretarias, } 4 \text { salas de apoio, } 1 \text { núcleo } \\
\text { estudantil }\end{array}$ \\
\hline & $\#$ 4: SEL & $\begin{array}{l}1 \text { edifício, } 19 \text { laboratórios, } 2 \text { secretarias, } 1 \text { sala de apoio, } 1 \text { núcleo } \\
\text { estudantil }\end{array}$ \\
\hline \multirow{4}{*}{ \# 2: SPL 2} & $\#$ \#: CISC & 1 edifício, 23 servidores \\
\hline & \# 6: ICMC & $\begin{array}{l}\text { 1edifício, } 16 \text { laboratórios, } 1 \text { biblioteca, } 1 \text { secretaria, } 4 \text { salas de apoio, } \\
1 \text { núcleo estudantil }\end{array}$ \\
\hline & \# 7: BIBL & 1 biblioteca central, 23 servidores \\
\hline & \#8: CAASO & $\begin{array}{l}2 \text { bibliotecas, } 1 \text { restaurante, } 2 \text { lanchonetes, } 1 \text { rádio, } 1 \text { cineclube, } 17 \\
\text { salas de apoio no colégio }\end{array}$ \\
\hline \multirow[t]{2}{*}{ \# 3: SPL 3} & \# 9: DFQ & $\begin{array}{l}1 \text { edifício, } 16 \text { laboratórios, } 1 \text { biblioteca, } 1 \text { secretaria, } 4 \text { salas de } \\
\text { apoio, } 1 \text { núcleo estudantil }\end{array}$ \\
\hline & \#10: DQFM & 3 edifícios, 16 laboratórios, 1 secretaria, 4 salas de apoio \\
\hline 3 divisores & 10 ONUS & total previsto de 240 pontos de terminação \\
\hline
\end{tabular}

Tabela 8 - Pontos de terminação de rede do projeto EPON I

A Figura 24 ilustra a representação esquemática da EPON I e a sua rota no câmpus.

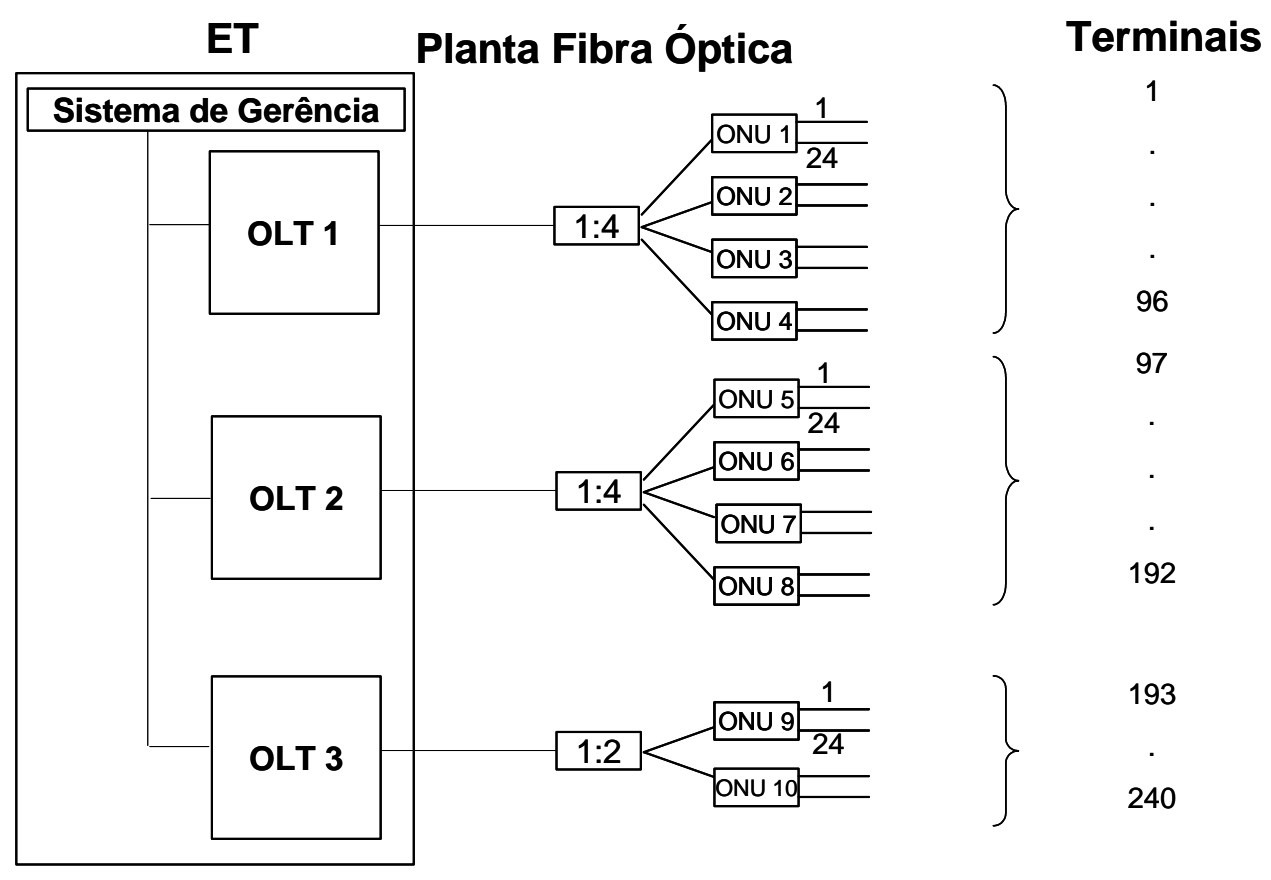

Figura 24 - Representação esquemática do projeto EPON I 


\section{ET}

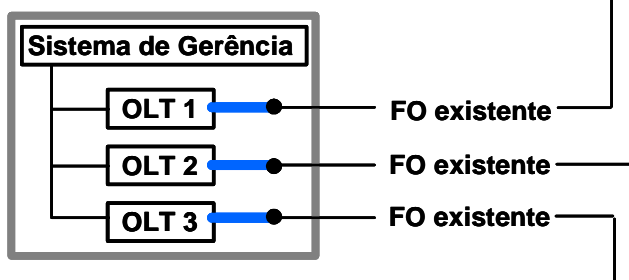

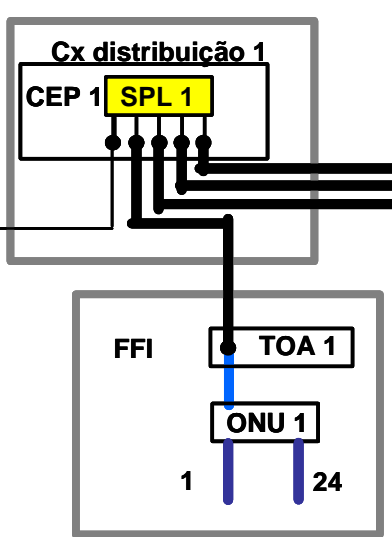

Cx distribuição 2

CEP 2 SPL 2

I

CISC

TOA 5

ONU 5

$9 7 \longdiv { 1 2 0 }$
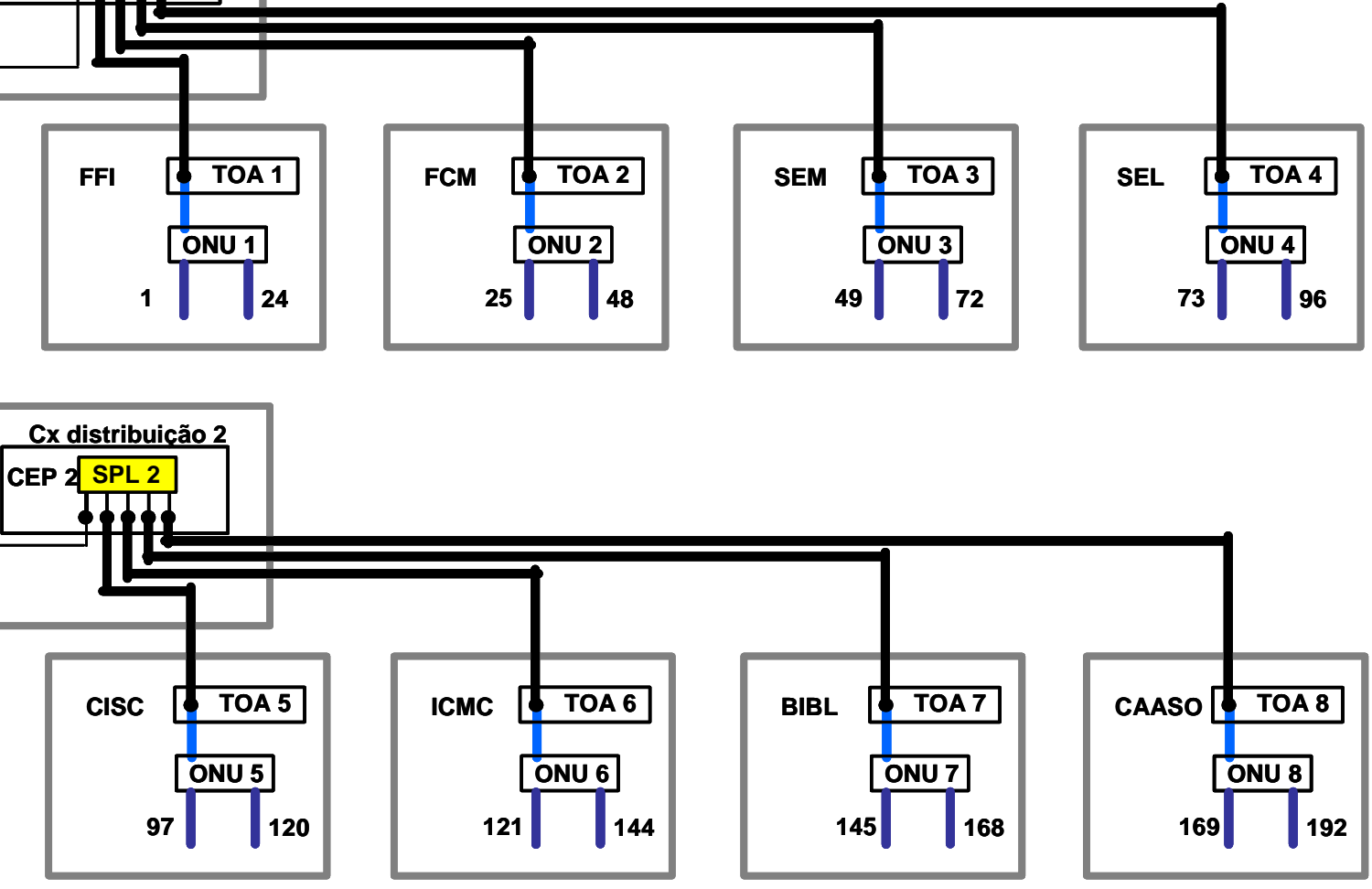
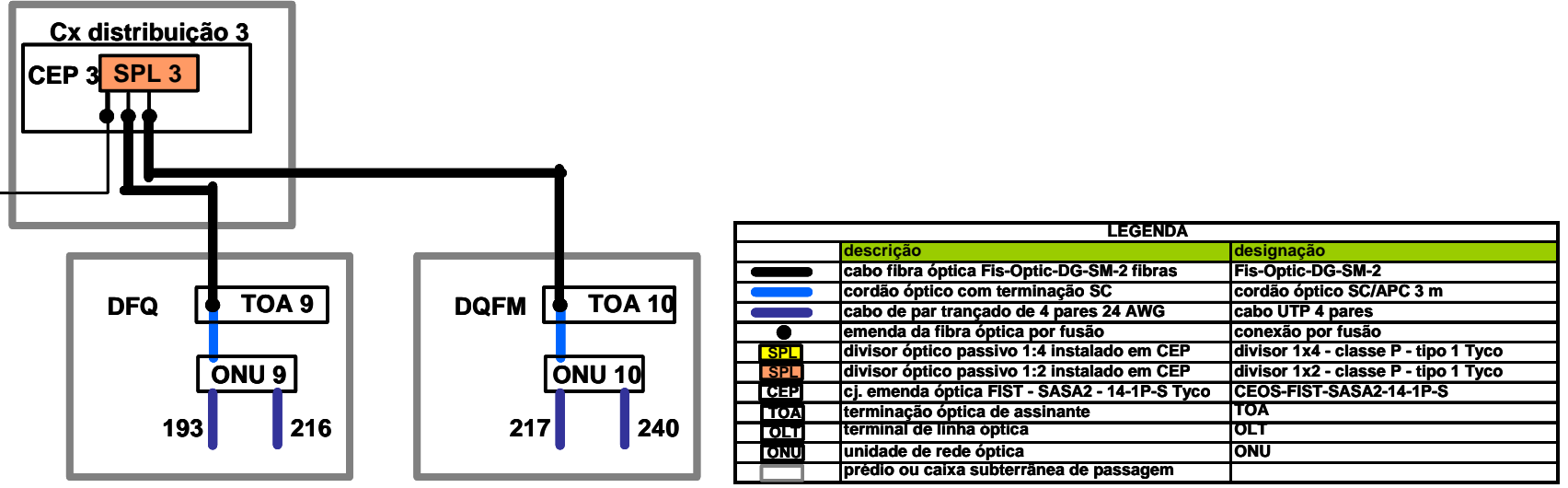


\subsection{Dimensionamento e custos do projeto}

Devido às suas características distintas, o dimensionamento e a estimativa de custos do projeto são realizados em duas partes, Rede e Equipamentos. O segmento de rede deve se caracterizar por uma menor complexidade de hardware e pela utilização de componentes ópticos passivos na planta externa que necessitem de uma menor manutenção em relação à planta metálica. Outras características requeridas são: facilidade de construção, expansão conforme demanda, facilidade de implementação de novos serviços, confiabilidade e privacidade. Com relação aos equipamentos de transmissão e recepção óptica, empregamos neste projeto produtos desenvolvidos pela Alloptic, empresa participante do grupo de estudo IEEE 802.3ah EFM Task Force [33].

\subsection{Requisitos gerais da rede}

\section{Cabos de fibras ópticas}

Deve ser utilizada uma padronização de capacidade e tipos de cabos ópticos e acessórios de fixação, para facilitar a construção e manutenção da rede.

Para este projeto selecionamos o cabo óptico Fis-optic-DG de fabricação Furukawa, ilustrado na Figura 25. Trata-se de um cabo óptico tipo loose, constituído por um tubo termoplástico preenchido com gel para acomodação das fibras ópticas do tipo monomodo. $\mathrm{O}$ elemento de tração dielétrico é disposto em paralelo à unidade básica e deve suportar os esforços de tração na instalação. Este tipo de cabo é apropriado para sistemas de cabeamento com distribuição em câmpus, entre prédios que exijam interligações ópticas externas e em instalações em infra-estrutura de eletrodutos e caixas de passagem subterrâneas [48].

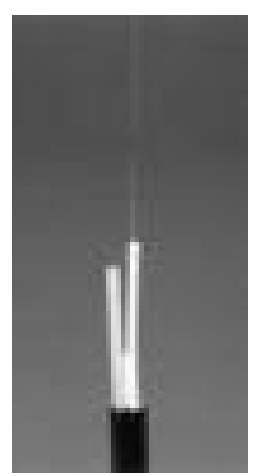

Figura 25 - Cabo Fis-optic-DG 
Sempre que possível deve ser utilizada emenda das fibras ópticas pelo método de fusão, pois as atuais máquinas de emenda por fusão garantem perdas ópticas menores em comparação aos conectores de emenda mecânica.

\section{Cordões ópticos}

As interligações das fibras ópticas com os componentes ativos devem ser realizadas com cordões ópticos. Para este projeto o cordão óptico é constituído de uma fibra óptica do tipo monomodo revestida com conector óptico modelo SC em uma extremidade (vide Figura 26) [49]. O conector SC foi desenvolvido pela NTT e é construído em torno de um ferrolho cilíndrico que retêm a fibra óptica e que se encaixa com um adaptador de interconexão ou receptáculo de acoplamento. Apresenta uma seção de corte quadrada para proporcionar alta densidade de acondicionamento em painéis de ligação.
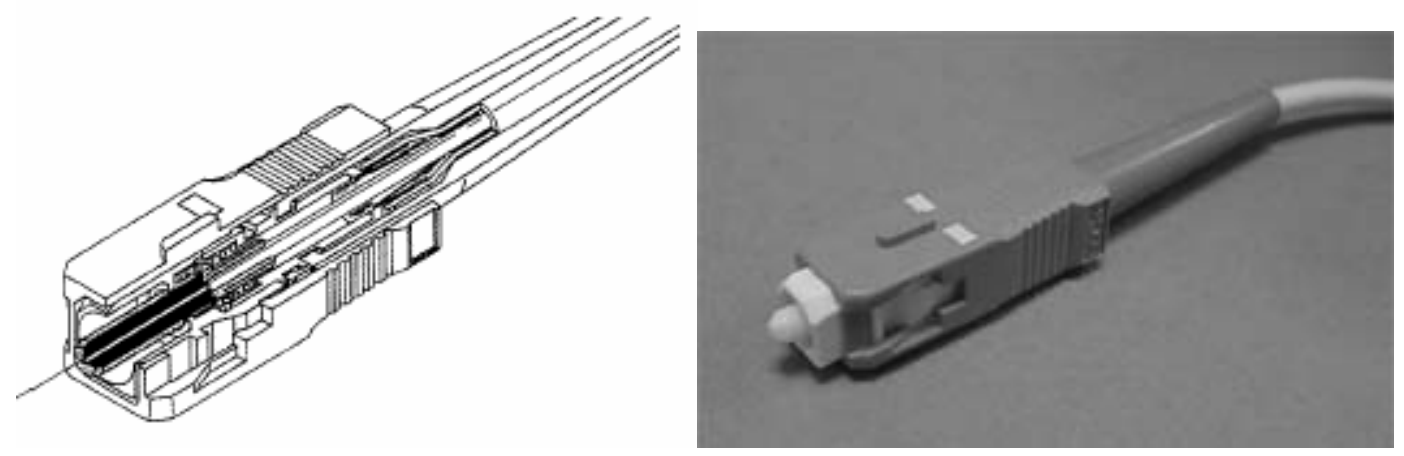

Figura 26 - Detalhes do conector SC em um cordão óptico

\section{Divisores ópticos passivos}

Divisores ópticos passivos são componentes que ramificam a potência incidente em 2 ou mais portas ópticas. Tais divisores distribuem a potência óptica entre fibras ópticas em um sentido pré-determinado. Os divisores são usados em centrais telefônicas, ambientes de usuários ou em aplicações de planta externa, fracionando ou combinando sinais ópticos nas redes ópticas.

Para os divisores ópticos passivos propomos a utilização do tipo simétrico baseado em tecnologia planar, com configuração de portas de entrada e saída do tipo 1:N, desenvolvidos por empresas como Tyco, Corning e Senko, ilustrados na Figura 27 [46], [50]. As conexões do divisor óptico com as fibras ópticas devem ser realizadas pelo método de fusão. 


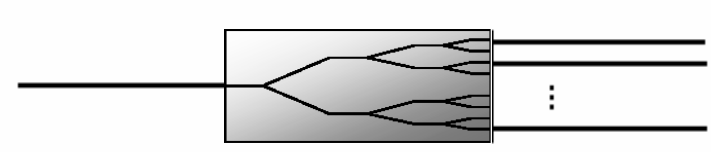

Esquemático do divisor óptico

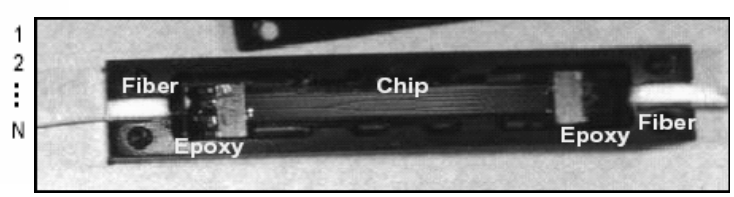

Vista interior do divisor óptico passivo
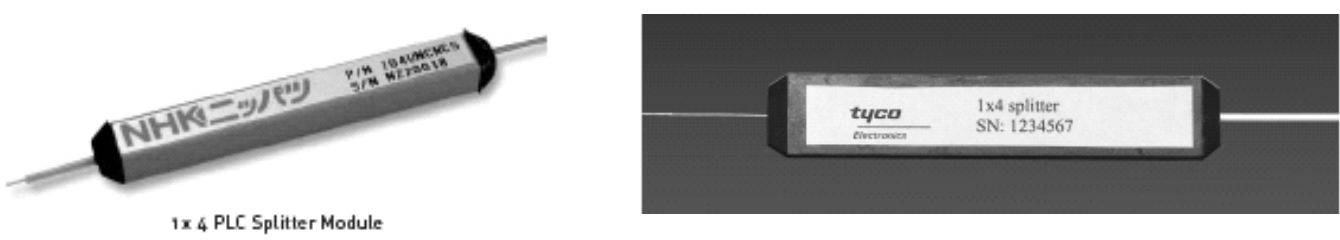

Vista exterior de divisores 1:4

Figura 27 - Divisor óptico passivo 1:N

\section{Caixas de emenda}

A acomodação e abrigo dos divisores ópticos passivos e das conexões de fibras ópticas nas caixas de distribuição do câmpus devem ser realizadas na caixa de emenda óptica primária CEP selada, ou seja, a caixa não deve permitir um acesso fácil, a não ser para fins de manutenção. Identificamos para esta função a caixa FIST - SASA2 - 14-1P-S, de fornecimento da Tyco, ilustrada na Figura 28. Essa caixa possibilita sua instalação em cordoalha, poste ou subterrânea; acondicionamento de comprimento da fibra óptica a ser deixada como reserva técnica; facilidade de instalação da caixa; possibilidade de instalação de divisores ópticos na caixa; instalação de derivações de cabos conforme demanda; e possibilidade de execução de fusões de fibras ópticas sem mudança no posicionamento da caixa de emenda [50]. 


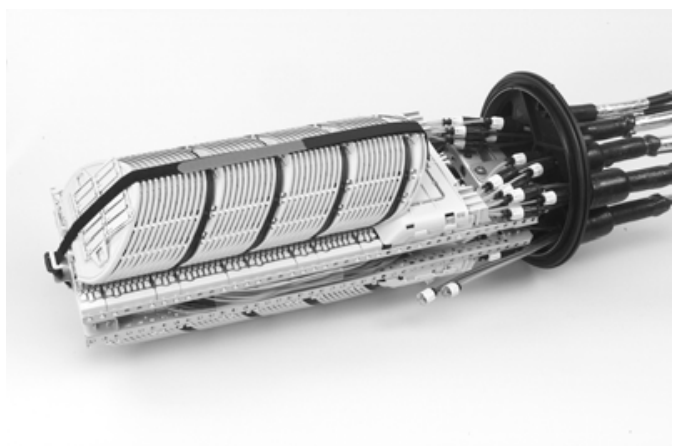

Vista lateral da caixa de emenda
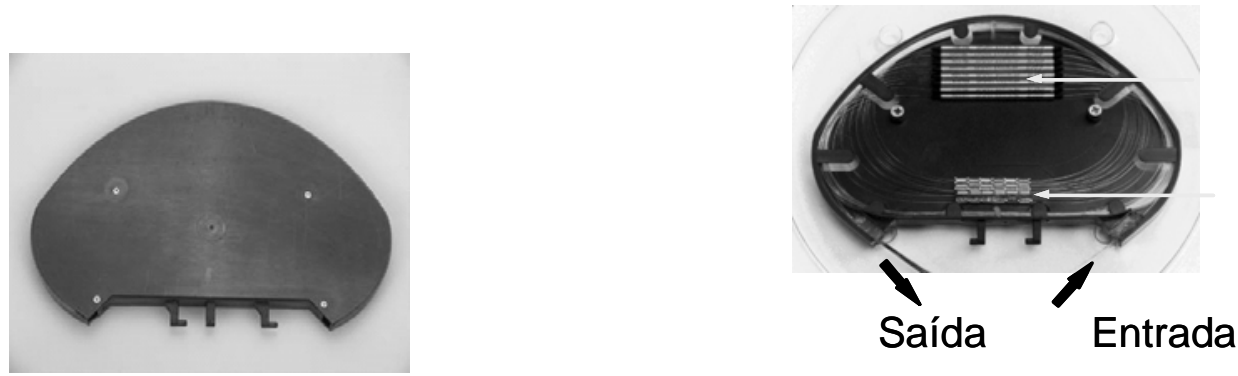

Divisores ópticos

\section{Emendas}

Vista exterior e interior da bandeja adequada à acomodação dos divisores e emendas

Figura 28 - Detalhes da caixa de emenda óptica primária

\section{Terminal óptico do usuário}

O abrigo das emendas de fusão entre a fibra óptica e o cordão óptico no ambiente do usuário devem ser realizadas em Terminal Óptico de Assinante (TOA) instalado em parede. Para essas terminações de rede óptica nos prédios do campus indicamos o TOA fabricado pela Furukawa, ilustrado na Figura 29, com dimensões $168 \mathrm{~mm}$ x $97 \mathrm{~mm}$ x $55 \mathrm{~mm}$ (LxAxP), com dois acessos de entrada e dois para saída de cabos ou de cordões ópticos.

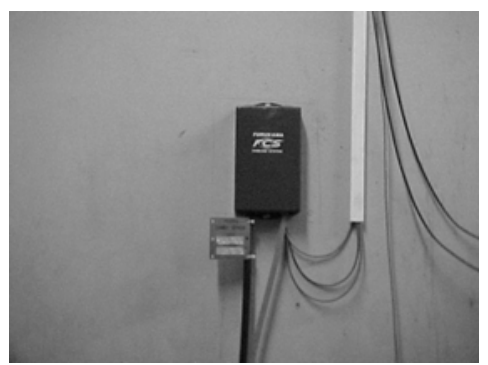

TOA fechada

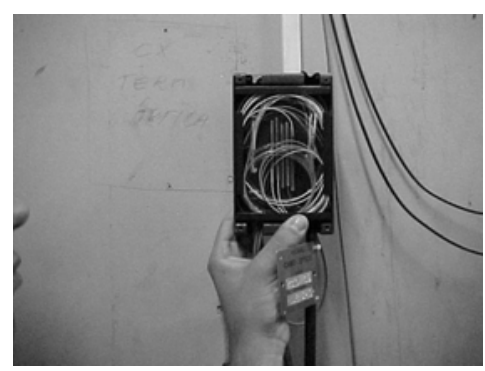

TOA aberta

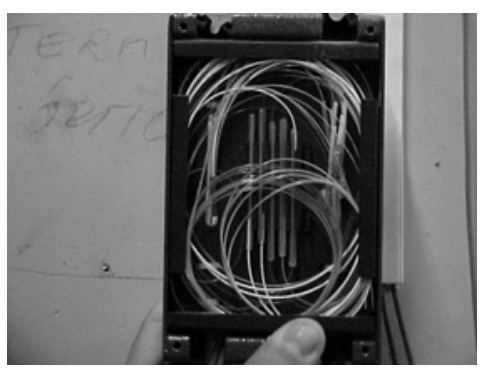

Acomodação das fibras ópticas

Figura 29 - Vista frontal da terminação óptica de assinante 


\subsection{Quantificação e estimativa de custos para a rede}

Todos os custos estimados neste documento são calculados em dólares americanos com impostos inclusos, salvo exposição em contrário. A estimativa de custos no segmento de rede foi elaborada com a composição de preços de produtos das empresas Furukawa e Tyco, dos produtos adquiridos pela Telemar e da quantificação dos custos de mão-de-obra da operadora Telemar [51-52].

A Tabela 9 apresenta os custos dos produtos da rede para a EPON I.

Foram realizadas as seguintes estimativas:

- Três cordões ópticos, cada qual com uma terminação SC, 3 metros de comprimento sem capa de proteção, instalados em ambiente interno da estação telefonica, protegido das intempéries, na interligação da fibra óptica existente com cada um dos três OLTs;

- Três divisores ópticos passivos 1:4 - classe P - tipo 1 da Tyco, cada um instalado na caixa de emenda principal - CEP;

- Três conjuntos de emenda óptica CEOS-FIST-SASA2-14-1P-S da Tyco para acomodar e proteger os três divisores ópticos passivos, instalados nas caixas de distribuição do câmpus;

- Comprimento de 200 metros de cabo óptico Fis-optic-DG-SM-2 fibras da Furukawa, entre o divisor óptico instalado no anel existente até o TOA. Dessa forma, 10 lances de 200 metros cada totalizam 2.000 metros;

- Dez TOAs, estojos para abrigo das emendas de fusão entre a fibra óptica e o cordão óptico no ambiente do usuário;

- Dez cordões ópticos, cada qual com uma terminação SC, 2,5 metros de comprimento com capa de proteção, instalados no TOA, na interligação da fibra óptica com cada uma das dez ONUs;

- Comprimento de 50 metros de cabo de par trançado UTP de 4 pares 24 AWG, entre a ONU até o usuário. Portanto, 10 ONUs com 24 usuários conectados a cada ONU perfazem um total de 12.000 metros;

- Quatrocentos e oitenta conectores RJ-45, instalados em cada extremidade dos lances do cabo UTP no ambiente do usuário, na interligação da ONU com cada uma das duzentos e quarenta terminações da rede. 
Como pode ser observado nos valores indicados, os cabos de fibra óptica e UTP são os componentes de maior peso no custo total do segmento rede do projeto EPON I.

\begin{tabular}{|c|c|c|c|c|c|}
\hline Descrição & Designação & Quantidade / local & $\begin{array}{l}\text { Custo } \\
\text { unitário } \\
\text { (US\$) }\end{array}$ & Total (US\$) & $\%$ \\
\hline $\begin{array}{l}\text { cabo fibra óptica Fis-Optic-DG-SM-2 } \\
\text { fibras }\end{array}$ & $\begin{array}{l}\text { FIS-OPTIC-DG- } \\
\text { SM-2 }\end{array}$ & $2.000 \mathrm{~m} /$ divisor-TOA & $0,45 / \mathrm{m}$ & 9000,00 & 19,48 \\
\hline cabo UTP de 4 pares 24 AWG & Cabo UTP 4 pares & $12.000 \mathrm{~m}$ / ONU-usuário & $0,19 / \mathrm{m}$ & $2.280,00$ & 49,36 \\
\hline divisor 1:4 - classe $\mathrm{P}$ - tipo 1 Tyco & Divisor 1:4 & $3 \mathrm{u} / \mathrm{CEP}$ & $260,00 / \mathrm{u}$ & 780,00 & 16,89 \\
\hline $\begin{array}{l}\text { conjunto de emenda óptica FIST - } \\
\text { SASA2 - 14-1P-S Tyco }\end{array}$ & $\begin{array}{l}\text { CEOS-FIST- } \\
\text { SASA2-14-1P-S }\end{array}$ & $3 \mathrm{u} / \mathrm{CEP}$ & $111,25 / \mathrm{u}$ & 333,75 & $\overline{7,25}$ \\
\hline conector RJ-45 & Conector RJ-45 & 480 / ONU-usuário & $0,28 / \mathrm{u}$ & 134,40 & 2,90 \\
\hline terminação óptica de assinante & TOA & $10 \mathrm{u} /$ edifício & $10,02 / \mathrm{u}$ & 100,20 & 2,16 \\
\hline $\begin{array}{l}\text { cordão óptico SC/APC } 2,5 \mathrm{~m} \\
\text { constituído de } 1 \text { terminação com capa } \\
\text { de proteção azul }\end{array}$ & $\begin{array}{l}\text { cordão óptico com } \\
\text { terminação SC e } \\
\text { capa de proteção }\end{array}$ & $10 \mathrm{u} / \mathrm{TOA}-\mathrm{ONU}$ & $7,20 / \mathrm{u}$ & 72,00 & 1,56 \\
\hline $\begin{array}{l}\text { cordão óptico SC/APC } 3 \text { m constituído } \\
\text { de } 1 \text { terminação sem capa de proteção } \\
\text { azul }\end{array}$ & $\begin{array}{l}\text { cordão óptico com } \\
\text { terminação SC sem } \\
\text { capa de proteção }\end{array}$ & $3 \mathrm{u} /$ OLT-fibra óptica & $6,35 / \mathrm{u}$ & 19,05 & 0,40 \\
\hline \multicolumn{4}{|l|}{ Total } & $4.619,40$ & 100,00 \\
\hline
\end{tabular}

Tabela 9 - Custos dos produtos da rede EPON I

A Tabela 10 apresenta os custos relativos à mão-de-obra para instalação da rede EPON I, com destaque para a instalação dos cabos de fibra óptica e UTP, que tem maior peso no custo. O total de 26 conexões por fusão está assim distribuído:

- Três emendas que totalizam a conexão da fibra óptica que deve ser seccionada do anel existente com o cordão óptico que interligará cada OLT;

- Três emendas que totalizam a conexão da fibra óptica que vem do OLT com o rabicho de entrada do divisor óptico passivo;

- Dez emendas que totalizam as conexões entre os rabichos de saída dos divisores ópticos passivos com a fibra óptica que segue para as ONUs;

- Dez emendas necessárias entre a fibra óptica e o cordão óptico de cada ONU. 


\begin{tabular}{|c|c|c|c|c|c|c|}
\hline Descrição & $\begin{array}{l}\text { Quantidade de } \\
\text { mão-de-obra }\end{array}$ & $\begin{array}{c}\text { Quantidade } \\
\text { material }\end{array}$ & $\begin{array}{l}\mathrm{ur}^{22} \\
\mathrm{R} \$\end{array}$ & $\begin{array}{c}\text { Total } \\
\mathrm{R} \$\end{array}$ & $\begin{array}{l}\text { Total } \\
\text { US\$ }\end{array}$ & $\%$ \\
\hline $\begin{array}{l}\text { instalação do cabo } \\
\text { de fibra óptica }\end{array}$ & $0,12 \mathrm{ur} / \mathrm{m}$ & $2.000 \mathrm{~m}$ & 13,62 & $3.268,80$ & $1.127,17$ & 21,94 \\
\hline $\begin{array}{l}\text { instalação do cabo } \\
\text { UTP }\end{array}$ & 240 lances & 240 lances & 35,00 & $8.400,00$ & $2.896,55$ & 56,37 \\
\hline conexão por fusão & 1,87 ur/conexão & 26 conexões & 40,00 & $1.944,80$ & 670,62 & 13,06 \\
\hline $\begin{array}{l}\text { instalação de } \\
\text { conjunto de emenda }\end{array}$ & $16,00 \mathrm{ur} / \mathrm{conjunto}$ & 3 conjuntos & 16,50 & 792,00 & 273,10 & 5,32 \\
\hline $\begin{array}{l}\text { instalação de } \\
\text { terminal }\end{array}$ & 3,00 ur/terminal & 10 terminais & 16,50 & 495,00 & 170,69 & 3,32 \\
\hline \multicolumn{4}{|c|}{ Total } & $14.900,60$ & $5.138,14$ & 100,00 \\
\hline
\end{tabular}

Tabela 10 - Custos de mão-de-obra para rede EPON I

A Tabela 11 resume os custos da rede EPON I. As maiores porcentagens dos componentes das redes estão relacionadas com a própria instalação, isto é, com os custos de mão-de-obra. Destacam-se, nos custos da rede EPON I, os seguintes fatores:

- Configuração subterrânea visando uma maior segurança para os componentes passivos posicionados no campus. Uma rede em configuração aérea exporia cabos, emendas e divisores ópticos às interferências externas;

- Limitação do número de divisores ópticos passivos para se obter uma menor quantidade de equipamentos, cujos custos são mais significativos que os custos do segmento rede, ao invés de prestigiar uma maior quantidade de OLTs e ONUs;

- Inclusão das terminações dos equipamentos no ambiente do usuário.

\begin{tabular}{|l|r||r|}
\hline \multicolumn{1}{|c||}{ Item } & \multicolumn{1}{c|}{ (US\$) } & \multicolumn{1}{c|}{ (\%) } \\
\hline \hline Cabo óptico & 900,00 & 9,22 \\
\hline Cabo UTP & $2.280,00$ & 23,37 \\
\hline Caixa de emenda & 333,75 & 3,42 \\
\hline Divisores ópticos & 780,00 & 7,99 \\
\hline Outros & 325,65 & 3,34 \\
\hline Instalação & $5.138,14$ & 52,66 \\
\hline \hline Total (US\$) & $9.757,54$ & 100,00 \\
\hline
\end{tabular}

Tabela 11 - Comparativo dos custos da rede

${ }^{22}$ ur (unidade de rede) representa a quantidade de mão-de-obra necessária para execução de serviços na área de telecomunicações. 


\subsection{Requisitos gerais dos equipamentos}

\section{Equipamento da Alloptic}

$\mathrm{Na}$ concepção da Alloptic, a rede EPON pode ser atendida com os equipamentos edgeGEAR 2000 e mduGEAR indicados nas Figuras 30 e 31 [35].

O edgeGEAR 2000 da Alloptic se conecta com provedores de serviços de telefonia e dados através de quatro cartões de interface de rede. O equipamento possibilita inserção de até 8 cartões OLT, para conexão de um máximo de 16 redes EPON. Na sua configuração máxima, o equipamento suporta até 512 ONUs, mais de 4.000 VLANs e 2.500 serviços POTS. Possibilita tráfego de voz, PPPoE Clients, VPNs e acesso Internet, através de uma largura da banda com escalonamento em incrementos de 64 kbps até 1 Gbps.

O edgeGEAR 2000 possui gerenciamentos de rede e de tráfego, e um sistema de testes, tais como funcionalidades de OTDR, analisador de dados e analisador de TDM.

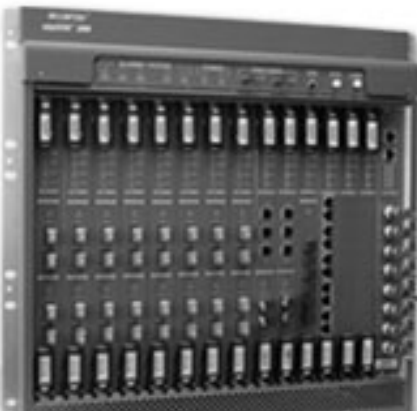

Figura 30 - Vista frontal do equipamento edgeGear 2000 da Alloptic

O equipamento mduGEAR da Alloptic é uma ONU que possui 24 interfaces 10/100BaseT, para fornecer dados de alta velocidade, vídeo IP ou serviços de voz sobre IP, a conjuntos de apartamentos, centros comerciais e edifícios. Cada roteador de acesso Ethernet mduGEAR possibilita até 24 conexões POTS suportadas em duas portas T1/E1, além de uma porta de vídeo opcional para serviços de TV a cabo através de um terceiro comprimento de onda.

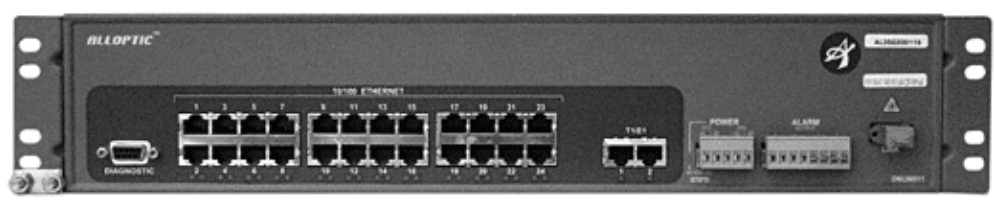

Figura 31 - Vista traseira do equipamento mduGear da Alloptic 


\subsection{Estimativa de custo para os equipamentos}

Para a estimativa de custo dos equipamentos, este estudo considera dois trabalhos conduzidos pelo autor na operadora Telefonica, elaborados em 2002 e 2003. Adicionalmente, utilizamos a composição dos dados fornecidos pela NEC em 2003 para esta rede óptica passiva, projetada para o câmpus da USP de São Carlos.

A Tabela 12 mostra os custos por usuário de um estudo da Telefonica de 2002, entre diversos fornecedores e diversas configurações para serviços focados na rede APON, sem considerar custos de instalação e testes, e impostos não inclusos. Foi previsto atendimento a aproximadamente 120 assinantes por ONU na configuração FTT Building (ou Business), 30 assinantes por ONU na configuração FTTC e 1 assinante por ONT na configuração FTTH. Para todos os casos, foi considerada uma capacidade final de 64 ONUs / ONTs por OLT, ou seja, para cada rede PON.

Os custos obtidos pela Telefonica por usuário da APON são bem diversificados, sendo o valor médio de US\$1.852,36, cuja somatória inclui preços desde US\$ 382,67 indicado pela empresa Trópico na configuração FTTB até US\$ 5.082,76 na proposta FTTC da Furukawa. Foi observado pela Telefonica que o valor de US\$382,67 proposto pela empresa Trópico para a opção FTTB, era equivalente aos custos de implantação de uma rede metálica convencional para atendimento de serviços de voz.

Este projeto considera o valor de US\$ 5.000 ofertado pela Furukawa como valor de referência de uma rede APON para um comparativo de preços.

\begin{tabular}{|l||l||l||r|}
\hline Fornecedor & Configuração & \multicolumn{1}{c||}{ Acesso } & $\begin{array}{c}\text { Custo por } \\
\text { usuário (US } \$ \text { ) }\end{array}$ \\
\hline \multirow{2}{*}{ Nec } & FTTB & E1 & $1.005,16$ \\
\cline { 2 - 4 } & FTTB & 10/100baseT & $1.484,74$ \\
\hline \multirow{3}{*}{ Trópico } & FTTB & POTS/ADSL & 382,67 \\
\cline { 2 - 4 } & FTTC & POTS/ADSL & 631,40 \\
\cline { 2 - 4 } & FTTH & E1/10/100BaseT & $3.771,55$ \\
\hline \multirow{3}{*}{ Furukawa } & FTTB & E1 & $1.451,03$ \\
\cline { 2 - 4 } & FTTB & 10/100BaseT & $3.242,07$ \\
\cline { 2 - 4 } & FTTC & E1 & $3.218,28$ \\
\cline { 2 - 4 } & FTTC & 10/100BaseT & 624,83 \\
\hline \multirow{2}{*}{ Siemens } & FTTB & E1 & $1.200,00$ \\
\cline { 2 - 4 } & FTTC & E1 & $1.502,07$ \\
\hline Alcatel & FTTH & POTS/10/100BaseT/vídeo & 484,08 \\
\hline Marconi & FTTB & VDalógico & \\
\hline
\end{tabular}

Tabela 12 - Custos por usuário na rede APON 
Em 2003 a empresa fornecedora de equipamentos NEC realizou uma estimativa de custos de uma arquitetura da rede óptica passiva GPON para a USP de São Carlos, considerando 3 OLTs e 10 ONUs para um total de 80 acessos. A Tabela 13 apresenta os custos de cada item da proposta da NEC, para um valor total estimado de US\$701.300.

O custo aproximado por acesso para esta rede GPON é US\$ 8.800, o que reflete uma tecnologia de altos custos, imprópria para o mercado consumidor. Uma observação a ser feita é que os custos apresentados incluem todos os equipamentos, materiais utilizados e a instalação dos mesmos, não estando incluídas despesas com projeto. O equipamento PON é considerado o componente com a parcela mais significativa, ultrapassando os $50 \%$ do custo total [53].

\begin{tabular}{|l||r||r|}
\hline \multicolumn{1}{|c||}{ Item } & \multicolumn{1}{c|}{ US\$ } & \multicolumn{1}{c|}{$\%$} \\
\hline \hline Equipamento PON & $374.979,50$ & 53,47 \\
\hline Sobressalentes & $99.549,98$ & 14,20 \\
\hline Gerenciamento software & $93.696,01$ & 13,36 \\
\hline Instalação & $37.497,95$ & 5,35 \\
\hline Material de Instalação & $18.748,98$ & 2,67 \\
\hline Gerenciamento hardware & $6.896,55$ & 0,98 \\
\hline Treinamento & $15.310,34$ & 2,18 \\
\hline Suporte & $54.620,69$ & 7,79 \\
\hline Total (US\$) & $701.300,01$ & 100,00 \\
\hline
\end{tabular}

Tabela 13 - Custos de equipamentos na rede GPON

Ainda em 2003, a Telefonica realizou um novo estudo de rede óptica passiva, e considerou para um atendimento a 5.000 assinantes, a composição de custos da rede EPON por residência, demonstrada na Tabela 14. Essa tabela mostra que o custo por usuário de uma rede EPON é de US\$2.000, cuja parcela referente ao equipamento equivale a 47,50\% do custo total.

\begin{tabular}{|c||c||c|}
\hline Item & US\$ & $\%$ \\
\hline \hline Custo / Home passed & 650,00 & 32,50 \\
\hline Equipamento & 950,00 & 47,50 \\
\hline Serviço de instalação & 200,00 & 10,00 \\
\hline STB & 200,00 & 10,00 \\
\hline \hline Total (US\$) & $2.000,00$ & 100,00 \\
\hline
\end{tabular}

Tabela 14 - Custos de uma rede EPON 
A Tabela 15 apresenta um comparativo dos custos por usuário, obtido dos estudos das empresas Telefonica e NEC. Os custos da tecnologia PON estão em um patamar elevado para as operadoras de telecomunicações, em comparação ao valor da rede metálica, situado atualmente em torno de US\$ 400 por usuário. Os custos das tecnologias APON e GPON retratam os altos custos dos equipamentos ATM, enquanto o custo da tecnologia EPON, de menor valor dentre as três tecnologias observadas, reflete a predominância no mercado dos equipamentos baseados na tecnologia Ethernet. Cabe destacar que estes valores também estão condizentes com a análise comparativa realizada no Capítulo 2 sobre a avaliação das tecnologias APON, GPON e EPON, nos custos por conexão entre as tecnologias ATM e Ethernet, apresentadas na Figura 23.

\begin{tabular}{|l||r||r||r|}
\hline \multicolumn{1}{|c||}{ Custo } & \multicolumn{1}{c||}{ APON Telefonica } & \multicolumn{1}{c|}{ GPON NEC } & EPON Telefonica \\
\hline \hline Período do estudo & $\mathrm{I}^{\mathrm{o}}$ semestre de 2002 & $\mathrm{I}^{\mathrm{o}}$ semestre de 2003 & $\mathrm{I}^{\mathrm{o}}$ semestre de 2003 \\
\hline Número de usuários & 150 & 80 & 5.000 \\
\hline $\begin{array}{l}\text { Custo aproximado por } \\
\text { usuário }\end{array}$ & US\$ 5.000 & US\$ 8.800 & US\$ 2.000 \\
\hline
\end{tabular}

Tabela 15 - Comparativo de custos dos equipamentos por usuário

Portanto, consideramos para este projeto, o valor de US\$ 2.000 por ponto de terminação de rede, obtido pela Telefonica no estudo dos equipamentos EPON.

\subsection{Custo total do projeto}

A Tabela 16 associa os custos da rede e do equipamento para a totalização dos valores deste projeto. Como pode ser observado, o custo de equipamento corresponde a $98 \%$ do custo total do projeto.

O projeto EPON I, com 3 OLTs, 10 ONUs e 240 pontos de terminação de rede, na configuração FTTB, custa aproximadamente US\$ 500.000 .

\begin{tabular}{|l||r||r||}
\hline \multicolumn{1}{|c||}{ Item } & \multicolumn{1}{c||}{ US\$ } & \multicolumn{1}{c|}{$\%$} \\
\hline Rede & $9.757,54$ & 2,00 \\
\hline Equipamento & $2.000 \times 240=480.000$ & 98,00 \\
\hline Total (US\$) & $489.757,54$ & 100,00 \\
\hline
\end{tabular}

Tabela 16 - Custos totais da rede EPON na USP 


\section{CONSIDERAÇÕES FINAIS}

O presente trabalho teve como objetivo analisar a tecnologia PON, identificar os principais tipos de rede e os requisitos para um projeto de rede óptica de acesso no câmpus da universidade.

Para cumprir tal objetivo, foram realizados estudos com três tipos de rede PON, e um comparativo entre as tecnologias APON, GPON e EPON; além da coleta e análise das informações de fornecedores e operadoras para os cálculos e dimensionamento da rede.

O projeto foi baseado nos estudos do grupo da IEEE 802.3 CSMA/CD, pois suas recomendações estão em consonância com os fabricantes dos equipamentos na definição de uma rede de acesso com uso da Ethernet, tornando-se mais atrativa para uma aplicação PON, devido ao grande volume de tráfego já gerado no formato Ethernet.

Com relação ao processo de projeto, destaca-se:

- A escassa quantidade de informações dos equipamentos, devido a fase de estudos e discussão da tecnologia EPON;

- A atualização das especificações que podem causar problemas de compatibilidade entre os componentes previstos neste projeto.

Os estudos para o projeto de uma rede óptica passiva EPON possibilitaram a avaliação de uma configuração FTTB, para atender o câmpus da USP de São Carlos. A rede tem fibras ópticas individuais a partir dos divisores ópticos passivos até as ONUs instaladas nos edifícios. Cada edifício possui até 24 pontos de terminação de rede, atendendo a uma largura de banda de 10 Mbps em cada acesso da EPON. 


\section{REFERÊNCIAS BIBLIOGRÁFICAS}

[1] RITCHIE, W.K.; STERN, J.R. (1993). BT telecommunications series: telecommunications local networks. London: Chapman \& Hall.

[2] HORROCKS, R.J.; SCARR, R.W. (1996). Future trends in telecommunications. 4th ed. Baffins Lane, Chichester: John Wiley \& Sons.

[3] VOORDE, I.V.; PLAS, G.V. (1997). Full service optical access networks: ATM transport on passive optical networks. IEEE Communications Magazine, p.70-75, Apr.

[4] FAULKNER, D.; MISTRY, R.; ROWBOTHAM, T.; OKADA, K.; WARZANSKYJ, W.; ZYLBERSZTEJN, A.; PICAULT, Y. (1997). The full services access networks initiative. IEEE Communications Magazine, p.58-68, Apr.

[5] UEDA, H. et al. (2001). Deployment status and common technical specifications for a B-PON system. IEEE Communications Magazine, p.134-141, Dec.

[6] IDG Now! (2003). Banda larga mundial cresceu 72\% em 2002. World TELECOM. São Paulo, 16 set. Disponível em: <http://world.idg.com.br/AdPortalV3/adCms DocumentoShow.aspx?documento=29141\&Area=599>. Acesso em: 17 set. 2003.

[7] SANTOS, C. (2003). Usuários de banda larga crescem 112\% no Brasil. World TELECOM. São Paulo, 28 jan. Disponível em: <http://idgnow.terra.com.br/idgnow/ internet/2003/01/0060>. Acesso em: 17 set. 2003.

[8] DINIZ, T. (2003). Pequeno se aproxima da tecnologia. Folha de São Paulo. São Paulo, 31 ago. Caderno Folha Negócios, p.5.

[9] GARMS, M.A. et al. (1999). Relatório sobre caracterização da rede telefônica metálica para sistemas ADSL/DMT. São Paulo: Telecomunicações de São Paulo. Relatório de Avaliação DTC02 - 080/99 - emissão: nov.

[10] MYNBAEV, D.K. (2002). From core to metro to access networks: The need for passive optical networks. Business briefing: Global Optical Communications. Disponível em: $<$ http://www.wmrc.com/businessbriefing/pdf/optical2002/reference/10.pdf $>$. Acesso em: 11 nov. 2002.

[11] INTERNATIONAL ENGINEERING CONSORTIUM - IEC (2003). Asymmetric Digital Subscriber Line (ADSL). AG Communication Systems, Web Proforum Tutorials. Disponível em: <http://www.iec.org>. Acesso em: 27 out. 2003.

[12] LAMB, L.D. (2002). Passive optical networks: Broadband services come home. Terawave Communications, Inc. Disponível em: $<$ http://www.ofconference.org/attendee/ presentations2002/Lowell_Lamb.ppt>. Acesso em: 11 nov. 2002. 
[13] PON FORUM (2002). Disponível em: <http://www.ponforum.org>. Acesso em: 11 nov. 2002.

[14] RAY, L.; FARMER, J. (2003). Fiber-to-the-Home FTTH: Overview \& technical tutorial. Disponível em: <http://www.fcc.gov/oet/tutorial/FTTH_Tutorial-8-7-03.ppt>. Acesso em: 26 ago. 2003.

[15] INTERNATIONAL ENGINEERING CONSORTIUM - IEC (2002). Asynchronous transfer mode (ATM): Passive Optical Networks (PONs). Eluminant, Web Proforum Tutorials. Disponível em: <http://www.iec.org>. Acesso em: 11 nov. 2002.

[16] MIAH, B.; CUTHBERT, L. (1997). An economic ATM passive optical network. IEEE Communications Magazine, p.62-68, Mar.

[17] KRAMER G.; PESAVENTO G. (2002). Ethernet passive optical network (EPON): Building a next-generation optical access network. IEEE Communications Magazine, p.66-73, Feb.

[18] MAEDA, Y. (2002). NTT's Broadband access services and deployment experiences in Japan. NTT Access Service Systems Laboratories. Disponível em: $<$ http://www.fsanweb.org/contactus.asp>.Acesso em: 11 jun. 2002.

[19] INTERNATIONAL TELECOMMUNICATION UNION - ITU (2003). Disponível em: $<$ http://www.itu.int>. Acesso em: 02 nov. 2003.

[20] INTERNATIONAL TELECOMMUNICATION UNION - ITU-T (1998). G.983.1: Broadband optical access systems based on Passive Optical Networks (PON). Geneva.

[21] SONG, J. (2003). P2MP Ethernet standardization trends. Samsung. Disponível em: $<$ http://www.tta.or.kr/ITForum/itforum2003/down_docu/Track\%204/s19/3.ppt>. Acesso em: 11 jun. 2003.

[22] BOER, R.T.; ROOD, H. (2001). Connecting homes with fibre-optics: GigaSURF. Disponível em: <http.www.gigaport.n1/ne/network/access/doc/ftthc.pdf>. Acesso em: 23 nov. 2003.

[23] INTERNATIONAL TELECOMMUNICATION UNION - ITU-T (2003). G.984.1: General characteristics for Gigabit-capable Passive Optical Networks (GPON). Geneva.

[24] GIANT: D4.1Top level specification of the $\mathrm{PTSP}^{23}$, TC and MAC components (2001). Disponível em: <http://www.mit.edu/afs/sipb/user/jhawk/Giant_WP4_AB_D4.1.pdf>. Acesso em: 02 nov. 2003.

[25] GRILO, A. (2002) Redes de alto débito: enunciado dos trabalhos de laboratório. Universidade Técnica de Lisboa. Instituto Superior Técnico. Disponível em: $<$ http://www.mafalda.inesc.pt/ amg/Textos/Enunciado_RAD.doc $>$. Acesso em: 02 nov. 2002.

\footnotetext{
${ }^{23}$ PTSP: Packet Transport System Protocol.
} 
[26] RODRIGUES, F.L.S. (2002). Conceituando Redes de Comunicação. Apostila. São Paulo.

[27] ANRITSU (2003). The must-have reference for IP and next generation networking ANRITSU. Disponível em: <http://www.anritsu.co.kr/ musthave.pdf $>$. Acesso em: 02 nov. 2003.

[28] ETHERNET óptica à conquista das MAN. (2003): Redes. Lisboa, n. 97, jul./ago., p.4851. Disponível em: < http://www.zdnet.pt/redes/0803/a03-01-00.shtml>. Acesso em: 25 ago. 2003.

[29] FORD, B. (2002). Operator's requirements for G-PON: Summary of work in ITU-T SG15/Q - GSR. BellSouth. Disponível em: <http://www.fsanweb.org/contactus.asp>. Acesso em: 11 jun. 2003.

[30] EFM ALLIANCE (2003). Disponível em: <http://www.efmalliance.org>. Acesso em: 11 jun. 2003.

[31] PESAVENTO, G. (2003). P2MP Sub task force report: study group in Seoul. Disponível em: <http://www.ieee802.org/3/efm/public/may03/p2mp/>. Acesso em: 11 jun. 2003.

[32] PESAVENTO, G. (2003). Ethernet Passive Optical Network (EPON): architecture for broadband access. Optical Networks Magazine. Jan./Feb. Disponível em: $<$ http://www.ponforum.org/presentations/page115.html>. Acesso em: 11 jun. 2003.

[33] IEEE 802.3ah: Ethernet in the first mile task force (2002). Disponível em: $<$ http:/grouper.ieee.org/groups/802/3/efm/public/index.html>. Acesso em: 28 nov. 2003.

[34] INSTITUTE OF ELECTRICAL AND ELECTRONICS ENGINEERS - IEEE (2004). 802.3ah. IEEE standard for local and metropolitan area networks - amendment: media access control parameters, physical layers, and management parameters for subscriber access networks. New York.

[35] EPON FORUM - IEEE Ethernet Passive Optical Networks Forum (2004). [EFM] Approval of IEEE Std 802.3ah-2004. Disponível em $<$ https://www.ieeecommunities.org/epon>. Acesso em 05 dez. 2004.

[36] INTERNATIONAL ENGINEERING CONSORTIUM - IEC (2002). Ethernet Passive Optical Networks (EPON). Alloptic, Web Proforum Tutorials. Disponível em: $<$ http://www.iec.org >.Acesso em: 11 nov. 2002.

[37] KRAMER, G. (2003). How efficient is EPON? Teknovus. Disponível em: $<$ http://www.ieee802.org/3/efm/public/p2mp_email/pdf00001.pdf $>$. Acesso em: 31 out. 2003.

[38] TANENBAUM, A.S. (1997). Redes de Computadores. Rio de Janeiro: Editora Campus. 
[39] MANFRIN, S.K. (2003). Proposta e implementação de um receptor optoeletrônico integrado para redes ópticas passivas (PONs) empregando multiplexação por divisão de comprimento de onda (WDM). 114p. Tese (Doutorado) - Escola de Engenharia de São Carlos, Universidade de São Paulo, São Carlos.

[40] BEMMEL, V. (2002). LLIDs (PHY IDs) in EPONs. Disponível em: $<$ http://www.grouper.ieee.org/groups/802/3/efm/public/may02/bemmel_1_0502.pdf $>$. Acesso em: 09 nov. 2003.

[41] INSTITUTE OF ELECTRICAL AND ELECTRONICS ENGINEERS - IEEE (1998). 802.1Q. IEEE standards for local and metropolitan area networks: virtual bridged local area networks. New York.

[42] LEE, P. (2003). PON Q\&A: what is a passive optical network? APA Optics. Disponível em: <http://www.apaoptics.com/fiberoptics/APA_Optics_PON.pdf $>$. Acesso em: 03 nov. 2003.

[43] TOLLEY, B. (2002). What's next for Ethernet. Cisco. Disponível em: <http://www. telecoms-mag.com/marketing/articles/mar97/anxer.html>. Acesso em: 16 out. 2002.

[44] INSTITUTO SUPERIOR DE ENGENHARIA DE LISBOA - ISEL. Departamento de Engenharia da Electrônica e das Comunicações - DEEC. Redes de Comunicação de Dados - RCD (2000). Gigabit Ethernet. Lisboa.

[45] UNIVERSIDADE DE SÃO PAULO - USP. Relatório da gestão do Reitor Flávio Fava de Moraes - 1993-1997. Disponível em: <http://www.fmrp.usp.br/rfa/Html/USP.htm>. Acesso em 18 jul. 2004.

[46] TYCO ELECTRONICS (2004). Publicação eletrônica. RUD 5330/B. Single-Mode Planar Waveguide Splitters. Technical Specification. [mensagem pessoal]. Mensagem recebida por<paulo.takeuti@telemar.com.br> em 29 mai. 2004.

[47] PESAVENTO, G. (2001). Technical and Economic Feasibility of EPON Transceivers. IEEE EFM Study Group. Disponível em: < http://www.ieee802. org/3 /efm/ public/ jul01/presentations/diab_1_0701.pdf $>$. Acesso em: 27 jun. 2003.

[48] CABO Fis-optic-DG. Disponível em: $<$ http://www.furukawa.com.br/htm_ing/optic dg. htm>. Acesso em: 26 jul. 2004.

[49] FIBER SHOW (2001). São Paulo. Soluções para Infra-Estrutura Óptica. Telecom Outside Plant. Tyco / Electronics. 1 CD-ROM.

[50] VLEUGELS, L. (2003). Publicação eletrônica. Passive Optical Componentes, V 1.2, Telecom Outside Plant, Tyco / Electronics. [mensagem pessoal]. Mensagem recebida por < paulo.takeuti@telemar.com.br>em 01 jun.

[51] TELEMAR (1999). Manual de atividades de rede de acesso - MARA. Vice Presidência de Tecnologia e Rede. Rio de Janeiro. 
[52] FURUKAWA (2003). Publicação eletrônica. Simulações de Projetos de Rede Óptica Passiva - PON. [mensagem pessoal]. Mensagem recebida por <paulo.takeuti@telemar.com.br> em 08 mar.

[53] WeStenBERG, A.T. (2003). Rede Óptica Passiva de Acesso para Serviços de Banda Larga, Estimativas USP/SC. NEC do Brasil S.A. 
ANEXO 
ANEXO - Resumo e palavras-chave - IEEE Std 802.3ah.-2004

IEEE Std 802.3ah.-2004

(Amendment to IEEE Std 802.3.-2002

as amended by

IEEE Stds 802.3ae.-2002, 802.3af.-2002,

802.3aj.-2003 and 802.3ak.-2004)

\section{3ah ${ }^{\mathrm{TM}}$}

IEEE Standard for Information technology-

Telecommunications and information exchange between systemsLocal and metropolitan area networks-

Specific requirements

Part 3: Carrier Sense Multiple Access with Collision Detection (CSMA/CD) Access Method and Physical Layer Specifications

\section{Amendment: Media Access Control Parameters, Physical Layers, and Management Parameters for Subscriber Access Networks}

\section{IEEE Computer Society}

Sponsored by the

LAN/MAN Standards Committee

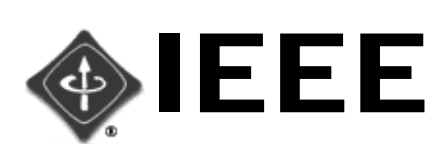


IEEE Std 802.3ah ${ }^{\mathrm{TM}}-2004$

(Amendment to IEEE Std 802.3 $3^{\mathrm{TM}-2002}$

as amended by

IEEE Stds 802.3ae TM-2002, 802.3af TM-2002,

802.3aj ${ }^{\mathrm{TM}}-2003$, and $\left.802.3 \mathrm{ak}^{\mathrm{TM}}-2004\right)$

IEEE Standard for Information technology-

Telecommunications and information exchange between systemsLocal and metropolitan area networks-

Specific requirements-

Part 3: Carrier Sense Multiple Access with Collision Detection (CSMA/CD) Access Method and Physical Layer Specifications

\title{
Amendment: Media Access Control Parameters, Physical Layers, and Management Parameters for Subscriber Access Networks
}

\author{
Sponsor \\ LAN/MAN Standards Committee \\ of the \\ IEEE Computer Society
}

Approved 24 June 2004

IEEE-SA Standards Board 


\begin{abstract}
This amendment to IEEE Std 802.3-2002 as amended by IEEE Std 802.3ae-2002, IEEE Std 802.3af-2003, IEEE Std 802.3aj-2003, and IEEE Std 802.3ak-2004 combines a minimal set of extensions to the IEEE 802.3 Media Access Control (MAC) and MAC Control sublayers with a family of Physical (PHY) Layers. These Physical Layers include optical fiber and voice grade copper cable Physical Medium Dependent sublayers (PMDs) for point-to-point connections in subscriber access networks. This amendment also introduces the concept of Ethernet Passive Optical Networks (EPONs), in which a point to multi-point (P2MP) network topology is implemented with passive optical splitters, along with optical fiber PMDs that support this topology. In addition, a mechanism for network Operations, Administration and Maintenance (OAM) is included to facilitate network operation and troubleshooting. To support these innovations, options for unidirectional transmission of frames are provided for 100BASE$X, 1000 B A S E-X, 10 G B A S E-R, 10 G B A S E-W$, and 10GBASE-X.
\end{abstract}

Keywords: Ethernet in the First Mile, EFM, Ethernet Passive Optical Network, EPON, Ethernet over DSL, Multi-point MAC Control, MPMC, Operations, Administration, Maintenance, OAM, full duplex MAC, P2MP, P2P, 100BASE-LX10, 100BASE-BX10, 1000BASE-LX10, 1000BASEBX10, 1000BASE-PX10, 1000BASE-PX20, 10PASS-TS, 2BASE-TL, last mile

The Institute of Electrical and Electronics Engineers, Inc.

3 Park Avenue, New York, NY 10016-5997, USA

Copyright $(2004$ by the Institute of Electrical and Electronics Engineers, Inc.

All rights reserved. Published 7 September 2004. Printed in the United States of America.

IEEE is a registered trademark in the U.S. Patent \& Trademark Office, owned by the Institute of Electrical and Electronics

Engineers, Incorporated.

Print: ISBN 0-7381-4075-9 SH95249

PDF: ISBN 0-7381-4076-7 SS95249 